\title{
THE PERCEPTIONS OF HUMAN RESOURCE DEVELOPMENT PROFESSIONALS IN TAIWAN REGARDING THEIR WORKING RELATIONSHIPS WITH SUBJECT MATTER EXPERTS (SMES) DURING THE TRAINING DESIGN PROCESS
}

\author{
DISSERTATION \\ Presented in Partial Fulfillment of the Requirements for \\ the Degree Doctor of Philosophy in the Graduate \\ School of The Ohio State University \\ By \\ Yi-chun Lin, Ed.S. \\ $* * * * *$
}

The Ohio State University

2006

Dissertation Committee:

Approved by

Ronald L. Jacobs, Ph.D. Adviser

Joshua D. Hawley, Ed.D.

Joe E. Heimlich, Ph.D.

Adviser

College of Education 



\begin{abstract}
The purpose of this study was to identify the perceptions of human resource development professionals in Taiwan regarding their working relationships with subject-matter experts (SMEs) during the training design process. A descriptive correlation survey was used in this study. The respondents of the study were HRD professionals who worked in high-tech companies located in a science park in Taiwan. From the 314 HRD professionals of the target population, 175 were randomly selected. The total number in the sample frame was 173 . One hundred forty-six of 173 respondents completed the online survey, resulting in an overall response rate of $84.39 \%$ in this study.

A seven-point Likert-type scale questionnaire was used to assess the independent variables, the current and desired ability of HRD professionals in the training design process, classified across the four design stages (analysis, design and development, implementation, and evaluation) and the dependent variable, the ability of HRD professionals in working with SMEs. Questions to elicit information about the seven demographic characteristics were included in the questionnaire as well.

The results from a series of paired t-tests showed there was no perceived difference between the HRD professionals' current and desired ability regardless of whether they had worked with SMEs or not. Another result from one-way ANOVA
\end{abstract}


analysis showed that among HRD professionals who had not worked with SMEs, education level, years of work experience in HR related jobs, and experience in designing training programs were significantly related to current ability in the training design process; among HRD professionals who had worked with SMEs, education level was significantly related to ability to work with SMEs. In particular, a higher percentage of HRD professionals who had not worked with SMEs had obtained bachelor's degrees while a higher percentage of HRD professionals who had worked with SMEs had obtained master's degrees. A higher percentage of HRD professionals who had worked with SMEs had experience in designing training programs compared to HRD professionals who had not worked with SMEs. Finally, the results from Pearson product-moment correlation and simple linear regression analysis showed a significant positive relationship between the ability to work with SMEs and current ability in the training design process among HRD professionals who had worked with SMEs; however, their current ability in the stages of the training design process cannot predict or explain the ability of HRD professionals in working with SMEs in more detail.

This study provides implications for the professional development of HRD practitioners and the practice of HRD in Taiwan companies. Cross-cultural issues are discussed to explain inconsistencies between the results and US-based perspectives on the training design process. 
Dedicated to

My parents and my younger brother 


\section{ACKNOWLEDGMENTS}

I would like to express my sincere gratitude to my adviser, Ronald L. Jacobs, for his time, encouragement, and willingness to contribute his unique perspectives and knowledge to my dissertation. He has been an outstanding mentor not only to guide me in the HRD academic field but also to aid me to build more confidence in beginning my scholarly life. Without his patience and understanding, I could not have followed this path alone to make my dream come true. My appreciation to him is beyond words. A sincere expression of gratitude is extended to my research methodology committee as well, especially to Dr. Joe E. Heimlich for providing guidance and support leading up to both my candidacy exam and the dissertation process. I would also like to express my thanks to Dr. Joshua D. Hawley for his support and encouragement throughout the research process.

I appreciate very much all of the questionnaire respondents for their willingness to share their time in my study. Thank you to Dr. Mohammed Rahman for serving as a statistic consultant in my research analysis process, to my friend Wei-cheng Shen for assistance with translation of the questionnaire into Chinese and statistic compiling on the Q\&A responses, to Bryan Wang for translating the questionnaire back into English, and to my boy friend Rong-jeng Tseng for always giving me spiritual and technical support in my doctoral study. Appreciation is extended to Dr. Angela Chen and Dr. 
Dawn Sydner for serving as the experts in the panel to provide feedback on my study and also for cheering me up during the dissertation process.

I would like to dedicate this dissertation to my younger brother, Li-hsin Ken Lin, and to let him know that this dissertation would not have been possible without his keeping my parents company in my hometown. Otherwise, I could not have had the patience to complete this dissertation.

Finally, a very special appreciation goes to my sweet parents, Mr. Wen-lung Lin and Mrs. Li-yun Chen. My parents served as a major source of inspiration in my lonely master's and doctoral study outside of my own country and also have provided never-ending moral support in every aspect and stage of my life stage. My father has generously financed much of my global education and believes that the investment in my education is the best gift he can give me. He has always been proud of whatever I have done in each stage of the doctoral process. My mother always lets me know how much she cares about me and shares my happiness and my tears through our international phone calls every day. She is my best friend and the best mother in the world. Without the support and love of my parents, I might not have been able to finish my doctoral study alone and have the chance to study in the USA for six and a half years. Finally, I want to thank God for giving me such the lovely parents. 


\section{VITA}

July 31, 1976 ............Born-Taichung, Taiwan

1999...................B.B.A. Major in International Business Trade,

Minor in English Language, Literature and Linguistics,

Providence University, Taiwan

2000

M.S. Human Resource Development, College of Technology,

Pittsburg State University

2001................. Ed.S. Industrial Education, College of Technology,

Pittsburg State University

\section{PUBLICATIONS}

Research Publications

1. Lin, Y. C. \& Jacobs, R. L. (2005). The Working Relationships between Human Resource Development Professionals and Subject Matter Experts (SMEs) during the Training Design Process in Taiwan. In Proceedings of the $4^{\text {th }}$ Asian Conference of the Academy of Human Resource Development, Taipei, Taiwan: Academy of Human Resource Development.

2. Lin, Y. C. \& Jacobs, R. L. (2004). A Theoretical Framework of Collaboration between Training Designers and Subject Matter Experts (SMEs): A Review of Literature. In Proceedings of the $3^{\text {rd }}$ Asian Conference of the Academy of Human Resource Development, Seoul, Korea: Academy of Human Resource Development. 
3. Lin, Y. C. \& Jacobs, R. L. (2003). Trainee Interaction and Transfer of Training in Online Learning: A Review of Literature and Future Research. In Proceedings of the $2^{\text {nd }}$ Asian conference of the Academy of Human Resource Development, Bangkok, Thailand: Academy of Human Resource Development.

\section{FIELDS OF STUDY}

Major Field: Education

Human Resource Development

Research Methods and Statistics

Educational Technology

Career Development
Ronald L. Jacobs, Ph.D.

Joe E. Heimlich, Ph.D.

Richard Voithofer, Ph.D.

James L. Moore III, Ph.D. 


\section{TABLE OF CONTENTS}

Abstract.

Dedication iv

Acknowledgements.............................................

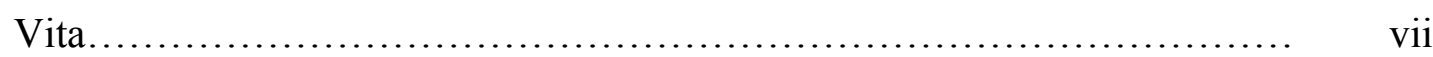

List of Tables............................................................. xii

List of Figures......................................................... $\mathrm{xv}$

Chapters:

1. Introduction.......................................................... 1

Statement of the Problem..................................... 4

Research Questions........................................ 7

Definition of Terms.................................... 8

Limitations of the Study ..................................... 9

Significance of the Study ..................................... 11

2. Review of the Literature......................................... 13

Human Resource Development............................. 13

Human Competence in Human Resource Development

Field.................................................... 13

Roles and Competencies of HRD Professionals...... $\quad 17$

The Role of HRD Professionals in Taiwan........... 33

Training Design............................................... 34

Definition of Training/Instructional Design........... 34

Models of Training Design Process................. 36

Training Designers and Subject Matter Experts (SMEs)......... 41

The Role of Training Designer....................... 41 
The Role of the Training Designer in Taiwan Business and Industry....

Competencies/Expertise Needed for Effective Training

Designers.

The Role of SMEs.................................... 53

Competencies/Expertise Needed for Effective SMEs $\quad 56$

Consultation Relationship................................... 59

Definition........................................ 59

Types of Consulting Relationship Models........... $\quad 60$

Process of Consulting Relationship Model........... 61

Best Ways to Establish Consultation Relationship

Process............................................... 63

Synthesis and Conceptual Framework........................ $\quad 70$

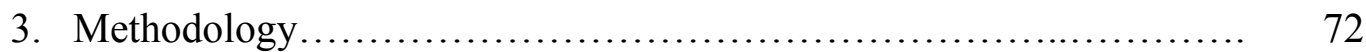

Research Type........................................ 72

Research setting and Participants........................... 73

Sample...................................... 75

Instrumentation......................................... 75

Design of the Instrument........................ 75

Definition of Operationalization Variables ........... $\quad 77$

External Validity................................... 81

Validity and Reliability Instrument ................ 92

Translation of Instrument to Chinese................... $\quad 92$

Research Procedures.................................... 92

Data Collection..................................... 92

Data Analysis..................................... 93

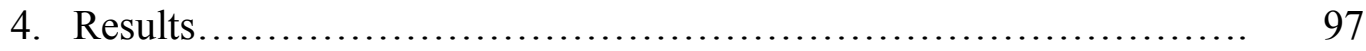

Demographic Characteristics ........................... 97

Descriptive Statistics..................................... 102

Findings on Research Questions............................. 107

Research Question One.............................. 107

Research Question Two.............................. 110

Research Question Three........................... 113

Research Question Four............................. 122

Research Question Five.......................... 125

5. Summary, Discussion, and Implications .......................... 128

Summary of the Findings.................................. 128

Discussion........................................... 130

Implications.......................................... 135

Implications for Future Research..................... 135

Implications for HRD Practitioners.................... 139

Implications for Business Organizations............... 139

Implications for Higher Education.................... $\quad 140$ 


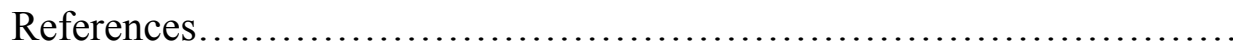

\begin{tabular}{|c|c|c|}
\hline \multicolumn{3}{|c|}{ Appendixes } \\
\hline A & Survey & 15 \\
\hline B & Survey in Chinese... & 16 \\
\hline $\mathrm{C}$ & Recruitment Letter.. & 16 \\
\hline $\mathrm{D}$ & Recruitment Letter in Chinese. & 17 \\
\hline $\mathrm{E}$ & Phone Recruitment Script.... & 17. \\
\hline $\mathrm{F}$ & Phone Recruitment Script in Chinese ........ & 17 \\
\hline $\mathrm{G}$ & 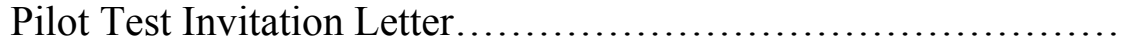 & 17 \\
\hline $\mathrm{H}$ & Pilot Test Invitation Letter in Chinese...... & 17 \\
\hline I & Invitation Letter. & 18 \\
\hline $\mathrm{J}$ & Invitation Letter in Chinese... & 18 \\
\hline $\mathrm{K}$ & Reminder Letter .............. & 18 \\
\hline $\mathrm{L}$ & Reminder Letter in Chinese.. & 18 \\
\hline
\end{tabular}




\section{LIST OF TABLES}

$\underline{\text { Table }}$

2.1 Level of human expertise............................... 15

2.2 Summary of HRD professional's role and competency studies in USA 19

2.3 The roles in training and development functions................. 23

2.4 The six competency groups and seven WLP roles of the WLP competency model................................................... 26

2.5 Summary of multiple U.S.A. competency models and the results of Asia studies..................................................... 32

2.6 Designer consulting roles, actions, and effects for varying task analysis situations................................................... 44

2.7 Summary of designer competency studies.................... 52

3.1 The variables in regard to the parts of the survey, source, and number of items.................................................. 76

3.2 The current/desired ability of HRD professionals in the stages of the training design process ............................................ 79

3.3 The ability of HRD professionals in working with SMEs.......... 80

3.4 Total variance explaining the rotated factors of the current ability of HRD professionals in the stages of the training design process .......... 85

3.5 Total variance explaining the rotated factors of the desired ability of HRD professionals in the stages of the training design process .......... 86

3.6 Factor loading on the twenty-one items of the current/desired ability of HRD professionals............................................. 87 
3.7 Total variance explaining the rotated factors of the ability of HRD professionals in working with SMEs..........................

3.8 Item loading for the dimension of "ability to work with SMEs"...

3.9 Cronbach's alpha coefficient for survey responses................ 91

3.10 Interpretation of correlation coefficient....................... 94

4.1 Frequency and percentage of organization Information............ 100

4.2 Frequency and percentage of demographic characteristics.......... 100

4.3 Frequency, percentage, and cumulative percent of demographic characteristics

4.4 Descriptive statistics for independent variables (current/desired ability) 102

4.5 Descriptive statistics for independent variables (current/desired ability) based on two groups: HRD professionals who had and those who had not worked with SMEs........................................... 105

4.6 Descriptive statistics for independent variable (current ability) and dependent variable (the ability to work with SMEs) among HRD professionals who had worked with SMEs.

4.7 The difference between current and desired ability in each of the stage 107

4.8 Correlation matrix for independent variables................... 108

4.9 Correlation coefficients on the current/desired ability in the stages of the training design process

4.10 The difference between current and desired ability in each of the stages..111

4.11 Correlation coefficients on the current/desired ability in the stages of the training design process between HRD professionals with experience in working with SMEs and those with no experience in working with SMEs.

4.12 ANOVA table-Organization size by current/desired ability in the training design process........................................... 114 
4.13 ANOVA table-Education level by current/desired ability in the training design process............................................ 115

4.14 ANOVA table-Years of work experience by current/desired ability in the training design process........................................ 116

4.15 ANOVA table-Years of work experience in HR related jobs by current/desired ability in the training design process.

4.16 ANOVA table-Experience in designing training programs by current/desired ability in the training design process............................. 118

4.17 The numbers, percentages, and chi-square test results of responses regarding the demographic characteristics and different groupings of the respondents

4.18 ANOVA table-Organization size by the ability to work with SMEs.... 122

4.19 ANOVA table-Education level by the ability to work with SMEs...... 123

4.20 ANOVA table-Years of work experience by the ability to work with SMEs.

4.21 ANOVA table-Years of work experience in HR related jobs by the ability to work with SMEs.

4.22 ANOVA table- Experience in designing training programs by the ability to work with SMEs.

4.23 Correlation coefficients for independent variable (current ability) and dependent variable (ability to work with SMEs).................... 125

4.24 Summary of regression analysis for the ability to work with SMEs as a predictor of current ability through each of the stages of the training design process..................................................... 126 


\section{LIST OF FIGURES}

Figure $\quad$ Page

2.1 Model of the instructional development cycle.................. 37

2.2 Conceptual framework of this study......................... 71

$5.2 \quad$ Revised conceptual framework................................ 138 


\section{CHAPTER 1}

\section{INTRODUCTION}

More and more organizations are investing in training as a means to increase their competitiveness (Jones, 2002). Training programs are used to provide the knowledge and skills required by employees. Since employee requirements undergo constant change, training has become part of the strategic planning of most organizations (DeSimone \& Harris, 1998). Swanson (1990) among others has suggested that, when used appropriately, training programs affect measures of organization performance.

Training programs in organizations are usually developed by specialists that are identified with the human resource development (HRD) field. HRD represents a unique field of study and practice that involves the three major components of employee development, organization development, and career development (Swanson \& Holton, 2001). Training is part of the employee development component of human resource development.

Among all the professional responsibilities of HRD professionals, the design of training represents a foundational activity (Gilley, Eggland, and Gilley, 2002). That is, training design often becomes part of many different professional activities. Because of its prominence, the process of designing training programs has generated much 
interest among practitioners and scholars in the HRD field. In general, the training design process represents an organized systems approach to developing training programs.

The literature reports somewhat varying components of the training design process. However, all the processes share the five basic phases of 1) analyzing, 2) designing, 3) developing, 4) implementing, and 5) evaluating the training programs. Reigeluth (1983) and Dick and Carey (1996) commonly refer to this process as the ADDIE model. The model suggests the steps of the process and the sequence in which they should be followed when engaging in the training design process. Recognition of the training design process as a systems approach suggests that the training program will be more efficient and more effective if the process has been used (Salas and Cannon-Bowers, 2000).

In reality, while the training design process identifies the various stages of the activity, the entire process involves much more than just following the ADDIE model. Of importance here is how the designers of training programs engage in the process with subject matter experts (SMEs). To be effective, training designers must be able to design training programs across many different subject areas, recognizing that they are not knowledgeable in the training content (Keppell, 1997). The training designers and SMEs need to work together on the training project through a distinct consultative process. In general, the training designer contributes knowledge and skills in different aspects of training design. The SME contributes insights and understanding about the content that could not possibly be learned by the training designer alone (Herling, 2001). 
The process used by training designers in working with SMEs differs from the way instruction is developed in most school situations. In this situation, the teacher is presumed to have both knowledge in the subject matter and knowledge of the best ways of developing the lessons and delivering the lessons. This same arrangement is not possible in organizations because of the specialized areas that one might encounter. For instance, it would be impossible for any one individual to possess the knowledge and skills required to operate all the equipment in a manufacturing company.

Designing a training program in an organization is a complex process. It cannot be accomplished by only one person in the organization. Although an SME who works in the organization has in-depth knowledge and skills in the specific aspects of his/her job, he/she cannot independently design training programs without professional knowledge about instructional methods. Moreover, the SME has not mastered other aspects of expertise not specifically related to his/her job (Herling, 2001). Thus, HRD professionals in the organization play an important role not only in synthesizing all specific knowledge from more than one SME to ensure the accuracy and completeness of the training materials content and the right level of difficulty (Davidove, 1993), but also in following the systematic training design process to design the training programs. If the rules are followed, constant collaboration between HRD professionals and SMEs can be the most efficient approach to simplifying the complex training design process. 


\section{Statement of the Problem}

In general, the literature states that the training is most effective when the designers and SMEs perceive themselves as professionals in collaboration in the training design process (Keppell, 1997; Salas \& Cannon-Bowers, 2000). This suggests that the designer has a different role to play in the training design process than the SME. The SME provides a perspective on the content while the designer provides a perspective on the design process. For this reason, training designers and SMEs are the fundamental elements in the design of the training programs. HRD professionals are usually in charge of designing the training programs in the organizations. Thus, the ability of HRD professionals to design a training program and to build the collaborative relationship with SMEs assumes great importance to the success of an effective training program. As Lin and Jacobs (2004) emphasized, training effectiveness is mainly dependent on the training process which, in turn, depends on establishing a relationship between the SME and HRD professionals. Hence, there is a critical need for an effective and efficient method to assist HRD professionals and SMEs in collaborating on the training design process.

While the literature supports the importance of establishing a relationship between the designers and SMEs in the training design process, this approach is not followed in all global practices. In fact, often neither HRD professionals nor SMEs are aware that the process of consideration to design the training programs is an efficient approach in the practice. Dick (1988) highlighted the finding that designers were not sufficiently confident of their skill in instructional design to carry out a project successfully or to establish a successful relationship with an SME. Likewise, the 
SMEs had concerns about the competence of the designer in terms of the training project and whether the training designers were capable of understanding the SMEs' comments (Rodriguez, Stephens, \& Arena, 1991). Another critical challenge for SMEs is the need to assist the designers in conceptualizing the theoretical knowledge that comprises their jobs and in classifying and verifying the training content (Keppell, 1997).

Although the approach of collaboration between training designers and SMEs is not followed in all global practices, it is necessary to understand the perspectives of people from different cultures or countries and to discuss the reasons why this approach has not been applied in practice. Awareness of cultural differences can be a good way to share and understand the perspectives of a wide variety of approaches, worldviews, ways of solving problems, and ways of working, and such differences represent a rich, deep warehouse of knowledge and experience (Deal, 2004). As Lee and Rothwell (1995) noted, "HRD professionals must learn to function crossculturally. It has long been debatable, however, whether the same competencies are equally important for HRD professionals across cultures" (p.5). Investigation of this issue becomes more interesting when the variety of perspectives existing across cultural and national boundaries is considered.

A review of HRD professionals' perceptions showed that the ability of HRD professionals to design training programs and work with SMEs receives less emphasis in HRD departments in Taiwan business and industry compared to the United States. HRD professionals in Taiwan rarely recognize that training design is one of their job tasks. The reality is that outside or inside SMEs and inside trainers play multiple roles 
and one person is often responsible both for providing the training content and designing the training materials, especially in technical skill training programs (Chiu, 2003; Chien, 2003). This is because technical skill training requires professionals who have specific domain expertise rather than novices to accomplish the training projects. For this reason, HRD professionals are not sure whether they have the ability to design this kind of technical skill training. In short, HRD professionals in Taiwan perceive a barrier based on the boundaries of the content differences. This leads HRD professionals to have difficulty in designing training programs across the different content areas in current Taiwan practice.

If designing training programs is an important competency of HRD professionals, and if the collaboration relationship between HRD professionals and SMEs has often been shown to contribute to designing training programs, then more needs to be done to understand the perceptions of HRD professionals about their ability to work with SMEs in the training design process across different cultures and countries.

The purpose of this study is to identify the perceptions of human resource development (HRD) professionals in Taiwan regarding their working relationships with subject matter experts (SMEs) during the training design process. This study describes the role of HRD professionals, their current and desired ability to design training programs and their ability to work with SMEs in the training design process. 


\section{Research Questions}

The following research questions were addressed in order to guide the acquisition of data required to satisfy the statement of the problem:

1. Is there a difference between the current/desired ability in the stages of the training design process among HRD professionals?

2. Is there a difference between the current/desired ability in the stages of the training design process among HRD professionals who have and who have not worked with SMEs?

3. What is the relationship between their demographic characteristics and the current/desired ability in the training design process among HRD professionals who have and who have not worked with SMEs?

4. Among HRD professionals who have worked with SMEs, what is the relationship between their demographic characteristics and the ability to work with SMEs?

5. Among HRD professionals who have worked with SMEs, what is the relationship between the ability to work with SMEs and current ability in the stages of the training design process? 


\section{Definition of Terms}

The key terms for this study are operationally defined as follows:

\section{$\underline{\text { Training }}$}

Training is the planned and systematic learning process to develop an employee's knowledge, skills, and attitudes in order to accomplish the tasks and reach the performance level required by the organization (Swanson, 1995).

\section{$\underline{\text { Designing Training Programs }}$}

Designing training programs refers to the process of synthesizing and operationalizing the inputs from subject matter experts (SMEs) to create the formal training programs which are typically used to enable employees to develop the knowledge and skills required to perform their jobs.

\section{Training Designer}

Training designer refers to the individual who is able not only to synthesize all specific knowledge from more than one SME to ensure the accuracy and appropriateness of training content but also to follow the systematic training design process to design training programs. 


\section{Subject Matter Experts (SMEs)}

Subject matter experts (SMEs) are individuals who have in-depth knowledge and skills in a specific topic or aspect of their jobs, and who work with HRD professionals to assist in the design of training programs related to their knowledge and skills.

\section{$\underline{\text { HRD Professionals }}$}

HRD professionals refers to individuals with job positions at any level in the human resource department and who are in charge of human resource related tasks in an organization.

\section{$\underline{\text { Human Resource Development }}$}

Human resource development is the process of developing and/or unleashing human expertise through organization development, personnel training and development, and career development for the purpose of improving performance (Swanson, 1995).

\section{Limitations of the Study}

The researcher recognizes that there are some factors beyond her control which limit the findings of this study. The limitations for this study are as follows: 
1. A geographic limitation exists. The results of this study are limited to the population of Taiwan HRD professionals. The results cannot be generalized to other countries.

2. There is insufficient information to carefully distinguish the definition of "HRD professionals" in Taiwan. The terms HRM, HRD, WD, WDE, personnel, training, and even industrial relations are often used as synonyms in Taiwan.

3. The data are all self-reported in nature because this study was based on a webbased questionnaire.

4. The research instrument may not have been properly prepared to reflect all the training designer's competencies perceived as important by HRD professionals in Taiwan.

5. The questionnaire was translated into Chinese since English is not the first language for most people in Taiwan. In spite of the great effort the researcher put into validation and translation procedures, the translated version may not have been entirely equivalent to the original English version.

6. The respondents may not have had sufficient knowledge or information to respond accurately to the survey instrument.

7. The perceptions of respondents may have been influenced by the respondents' positions within their organizations as well as personal goals, employment experience, educational background, and ethnicity.

8. The investigation was limited to the perceptions of HRD professionals and did not explore the perceptions of SMEs. 


\section{Significance of the Study}

This study will provide critical information to a wide range of professionals: researchers, HRD practitioners, business organizations, and higher education practice.

This study will contribute to the ability of HRD professionals regarding the training design competencies and the working relationship with SMEs. Numerous studies have emphasized that training design competence is one of the HRD competencies and provided abundant data showing that these competencies are important abilities that HRD professionals need to possess across the boundaries of country and culture (Rothwell, 1999; MaLagan, 1989; Cheng, 1991; Lee \& Rothwell, 1995; Yang, 1994; Peerapornvitoon, 1999; Yoo, 1999; Chen, 2003). In addition, the literature supports the view that the best arrangement for design of training programs is collaboration between the training designer and SMEs (Keppell, 1997; Ingram et al., 1994; Wallington, 1981; Schein, 1978; Davies, 1975). However, few studies have conducted empirical research to examine the relationship between training designers and SMEs. In this study, we go a step further to understand the value of HRD professionals being able to design training programs and to work with SMEs in the training design process as well.

This study provides valid research to allow HRD practitioners to obtain a better understanding on the following two aspects of their job tasks. First, this study will help HRD professionals to reflect what they currently do in the training design projects and to examine whether they meet the basic requirements to fulfill the training design process. Second, this study also contributes to the detailed understanding of 
every aspect of training design knowledge and skills, and the process that should be mastered and followed while interacting with SMEs.

The results of the study reveal the functions of HRD practitioners in the organizations and how the organizations perceive the training design competencies of HRD professionals, which indirectly affect the quality of training and organization goals. Thus, this study will provide management leaders with critical knowledge so that they can evaluate the performance of HRD professionals and be sure of the accuracy of job descriptions about HRD related jobs, which reflect the scope of their work and the underlying work values. In addition, by examining this study, organizations can confirm or contradict the proposition that the collaboration between HRD professionals and SMEs is the most effective method of training program designing.

One of the most common functions of higher education practice is to train and evaluate the ability of current and future students before they enter the career market as well as to increase the effectiveness of the institution's functions of training and education in order to reach the organization's missions. Higher education scholars can utilize these findings to alter the institution's direction to meet the needs of the workforce market in order to eliminate the gap between education and career. 


\section{CHAPTER 2}

\section{REVIEW OF LITERATURE}

This chapter contains five major sections. The first section describes human resource development. The second section introduces training design. The third section explains the training designers and subject matter experts (SMEs). The fourth section explores the consultation relationship.

\section{Human Resource Development}

This section is organized into three parts. The first part reviews human competence as it is viewed in the human resource development field. The second part discusses the roles and competencies of HRD professionals. The third part discusses the role of HRD professionals in Taiwan.

\section{Human Competence in the Human Resource Development Field}

Human resource development (HRD) is a relatively new area of professional practice and academic study (Jacobs, 1990; Swanson \& Holton III, 2001). HRD is defined as the process of developing and/or unleashing human expertise through organization development and personnel training and development for the purpose of 
improving performance (Swanson, 1996). Swanson (2003) emphasized that establishing an expertise is a weight-bearing point in the human resource development field. Expertise focuses on how employees are functioning in the organization in order to change and to improve the organization and its system (Swanson, 1994). As Kuchinke (1996) said, "expertise is of importance to individuals, organizations, and society at large, and its development is at the core of the field of Human Resource Development (HRD)" (p.505). HRD researchers and practitioners realize the importance to employees of developing expertise within organizations. Employees with expertise are able to quickly acquire the updated knowledge and skills necessary for them to perform successfully in their current jobs.

Today, organizations utilize training as a method for achieving superior performance goals that will reduce operational costs and increase organizational productivity (Jacobs, 2001; Rummler \& Brache, 1995). Jacobs (2001\& 2003) demonstrated that HRD professionals are expected to provide training programs in order to develop specific knowledge or expertise for employees. He proposed a useful taxonomy of employee development that demonstrates how effective training and development can improve an employee's competence level from novice to master. As summarized in Table 2.1, the five levels of expertise distinguished by Jacobs and Washington (2003) include novice, specialist, experienced specialist, expert, and master. If employees have an adequate level of competence, the ability of an organization to undertake change is unlimited. This means that the core competencies of an organization are dependent on the expertise development of its workforce. 


\begin{tabular}{ll}
\hline Taxonomy & Description \\
\hline Novice & $\begin{array}{l}\text { Literally, one who is new to a work situation. There is often some but } \\
\text { minimal exposure to the work beforehand. As a result, the individual } \\
\text { lacks the knowledge and skills necessary to meet the requirements set } \\
\text { to adequately perform the work. }\end{array}$
\end{tabular}

Specialist One who can reliably perform specific units of work unsupervised. But the range of work is limited to the most routine ones. Often it is necessary to coach individuals at this level to help them use the most appropriate behaviors.

Experienced One who can perform specific units of work and who has performed Specialist that work repeatedly. As a result, the individual can perform the work with ease and skill. It is possible to remain at this level for an extended period of time.

Expert One who has the knowledge and experience to meet and often exceed the requirements of performing a particular unit of work. The individual is respected by others and highly regarded by peers because of his or her consummate skills, or expertise. The individual can use this utility to deal with routine and non-routine cases, with an economy of effort.

Master One who is regarded as "the" expert among experts or the "real" expert among all employees. He or she is among the elite group whose judgments are looked upon to set the standard and ideals for others.

Table 2.1: Level of human expertise (adapted from Jacobs \& Washington, 2003)

In a review of a number of different articles, the researcher found that the terms competence, competences, competency, and competencies are used and defined differently. In the early era, White (1959) preferred to use 'competence' to describe an employee's personality characteristics related to superior performance and high motivation. Elkin (1990) used the term competences with micro-level job performance 
and competencies with higher management aspects. Mansfield (2004) defined competence differently depending on usage: outcome (vocational standards describing what an employee needs to be able to do in the workplace); tasks that an employee does (describing what currently happens); and personal traits or characteristics (describing what an employee is like). Some authors consistently use 'competency' when referring to the occupational competency that is required for people to succeed at work (Parry, 1998; Spencer and Spencer, 1993; Klemp, 1980). It is really hard to establish a clear boundary to distinguish the difference between the varying references to competence.

In the field of HRD, many HRD researchers use 'competence' to emphasize the cluster of an employee's expertise/knowledge, skill, and ability which directly is related to his/her job performance within the organization (Swanson, 1996; Parry, 1998). Furthermore, competence may describe an employee who has the ability to do something at a minimum level of acceptable performance, not necessarily outstandingly or even well (Swanson, 1994). Jacobs (1997) defined employee competence as the potential to use specific sets of knowledge and skills. In another similar definition, employee competence refers to the individual's potential to use his/her knowledge and skills in a specific situation (Gilbert, 1978).

Competence is viewed not as a component of performance but as a function of worthy performance expressed as "the ratio of value accomplishments to costly behavior" (Gilbert, 1996, p.18). Gilbert believed that worthy performance was a product of both the work environment and an individual's repertoire of behavior, or the specialized responses, knowledge, and understanding of a specific area. Therefore, 
according to Dubois and Rothwell (2004) "knowledge and skills are more obvious competencies employees use to achieve the expected output or results" rather than personal characteristics that support performance in the organization (p. 18).

Spencer and Spencer (1993) argued that competency is "an underlying characteristic of an individual that is causally related to criterion-referenced effective and/or superior performance in a job or situation" (p. 9). Competency defined in this manner includes both visible competencies of knowledge and skills and underlying competencies related to traits, motives, and self-concept (Hartle, 1995, Spencer \& Spencer, 1993). Spencer and Spencer (1993) especially noted that the employee's personal characteristics such as motives, traits and self-concept can predict skill as behavior action which results in the outcome of the effective or superior performance. Therefore, they identified competency simply as the characteristics of an individual that drive superior job performance.

\section{$\underline{\text { Roles and Competencies of HRD Professionals }}$}

In recent years, the roles and competencies of HRD professionals have changed dramatically. The competencies associated with the role are defined as "an area of knowledge or skill that is critical for producing key outputs" (McLagan, 1989, p.77). The literature in HRD has been more concerned with developing highly transferable generic competencies for their overall performance or particular job roles. Many studies have focused on the characteristics and competences which contribute to the effectiveness of HRD professionals because they are responsible for identifying the 
competencies required for each job classification within the organization and establishing performance goals and objectives.

Davis, Naughton, and Rothwell (2004) quoted a statement about competencies from the president of the American Society for Training and Development (ASTD), Tony Bingham: "A defined set of competencies is a hall-mark of a true profession, and the practice of creating and supporting a competency model is a key role of a professional association" (p. 28). Thus, there were three main authors (Pinto \& Walker, 1978; McLagan, 1983, 1989; Rothwell et al., 1996, 1999) who contributed to the development of the HRD competency model, and all were sponsored by ASTD. In three decades, the competencies studies transformed the focus area from training and development (T\&D), through Human Resource Development (HRD), to Workplace Learning and performance (WLP).

In her dissertation, Chen (2003) described the history of the five main competencies model studies in United States since the early 1970's. In the 1970's, Pinto and Walker (1978) were the main authors to focus on T\&D. In the 1980's, McLagan (1983 \& 1989) was the main author who moved the focus from T\&D to the HRD area. In the 1990's, Rothwell with other authors in 1996, in 1999 and in 2004 broadened the research focus from HRD through human performance improvement to WLP because more organizations had become aware of the importance of intellectual capital and performance results in developing training activities. The details are summarized in Table 2.2. 


\begin{tabular}{|c|c|c|c|}
\hline Author/Year/ Title & $\begin{array}{l}\text { Focus } \\
\text { Domain }\end{array}$ & $\begin{array}{l}\text { Result } \\
\text { on Role }\end{array}$ & $\begin{array}{l}\text { Result on } \\
\text { Competencies }\end{array}$ \\
\hline $\begin{array}{l}\text { Pinto \& Walker (1978)-- } \\
\text { Professional training and } \\
\text { development roles and } \\
\text { competencies }\end{array}$ & $\begin{array}{l}\text { Training \& } \\
\text { Development }\end{array}$ & $\begin{array}{l}\text { No } \\
\text { Roles } \\
\text { Defined }\end{array}$ & - 14 Areas of Activities \\
\hline $\begin{array}{l}\text { Ontario Society for Training \& } \\
\text { Development (1979)-- } \\
\text { Competency Analysis for } \\
\text { Trainers: A personal planning } \\
\text { guide }\end{array}$ & $\begin{array}{l}\text { Training \& } \\
\text { Development }\end{array}$ & 4 Roles & - 12 Competencies \\
\hline $\begin{array}{l}\text { McLagan (1983)-- } \\
\text { Models for Excellence }\end{array}$ & $\begin{array}{l}\text { Training \& } \\
\text { Development }\end{array}$ & 15 Roles & $\begin{array}{l}\text { - } 31 \text { Competencies } \\
\text { - } 102 \text { Outputs }\end{array}$ \\
\hline $\begin{array}{l}\text { McLagan (1989)-- } \\
\text { Models for HRD practice }\end{array}$ & $\begin{array}{l}\text { Human } \\
\text { Resource } \\
\text { Development }\end{array}$ & 11 Roles & $\begin{array}{l}-13 \text { Ethical issues } \\
-35 \text { Competencies } \\
-74 \text { Outputs }\end{array}$ \\
\hline $\begin{array}{l}\text { Rothwell (1996)-- } \\
\text { ASTD models for human } \\
\text { performance improvement: } \\
\text { roles, competencies, and outputs }\end{array}$ & $\begin{array}{l}\text { Human } \\
\text { Performance } \\
\text { Improvement }\end{array}$ & 4 Roles & $\begin{array}{l}\text { - } 15 \text { Ethical Issues } \\
\text { - } 38 \text { Competencies } \\
\text { - } 14 \text { Terminal Outputs } \\
\text { - } 144 \text { Enabling Outputs }\end{array}$ \\
\hline $\begin{array}{l}\text { Rothwell et al. (1999)-- } \\
\text { ASTD models for workplace } \\
\text { learning and performance }\end{array}$ & $\begin{array}{l}\text { Workplace } \\
\text { Learning \& } \\
\text { Performance }\end{array}$ & 7 Roles & $\begin{array}{l}\text { - } 52 \text { Competencies } \\
\text { - } 6 \text { Competency Groups }\end{array}$ \\
\hline $\begin{array}{l}\text { Davis, Naughton, \& Rothwell } \\
\text { (2004)-- } \\
\text { Mapping the future: shaping } \\
\text { new workplace learning and } \\
\text { performance competencies }\end{array}$ & $\begin{array}{l}\text { Workplace } \\
\text { Learning \& } \\
\text { Performance }\end{array}$ & 4 Roles & $\begin{array}{l}\text { - } 12 \text { Competencies } \\
\text { - } 9 \text { Areas of Expertise }\end{array}$ \\
\hline
\end{tabular}

Table 2.2: Summary of HRD professional's role and competency studies in the USA (Partly adapted from Chen, 2003) 
Pinto and Walker (1978) conducted a study of the professional roles and competencies of training and development practitioners. Their results represented the first ground-breaking competency model regarding training and development sponsored by ASTD; it was still consistent with previous models, including the noteworthy work of Leanard Nadler, Malcolm Knowles, the U.S. Civil Service Commission report by Neal Chalofsky and others, and the Ontario Society for Training and Development study by John Kenny and others.

For this study, model categories were defined in advance because the researcher planned to collect data on professional activities and use the data to define empirically-relevant roles. This method helps to develop models which characterize with reasonable accuracy the role of structure of training and development practitioners. More importantly, in this study, a list of fourteen activities were produced to describe what training and development practitioners can perform. The activities are as follows:

1. Needs analysis

2. Determining an appropriate training approach

3. Program design and development

4. Develop material resources (make)

5. Managing internal resources (borrow)

6. Managing external resources (buy)

7. Individual development planning and counseling

8. Job/performance-related training

9. Conducting classroom training 
10. Group and organization development

11. Training research

12. Managing work relationships with managers and clients

13. Managing the training for development function

14. Professional self development

The Ontario Society for Training and Development (1979) conducted a competency study for trainers as a personal planning guide. This study created an instrument with four major training and development functions or roles: instructor, designer, manager, and consultant. The study recommended competency analysis which classifies high, medium, and low levels of knowledge or skills appropriate for each of the roles in the related actual situation as much as possible. The model included twelve competency areas for the four role functions: administration, communications, course design, evaluation, group dynamic process, instructional techniques, learning theory, manpower planning, personal and organization interface, research and development, training equipment and materials, and training needs analysis. Each of the competency areas has its own sub-activities.

Models for Excellence, sponsored by the American Society for Training and Development, was McLagan's (1983) first model focusing on the training and development field. The purpose of this study was "to produce a detailed and updatable definition of excellence in the training and development field" as a standard which could be broadly used by organizations, educational institutions, and the ASTD (p. 2). The author emphasized that training and development is one of nine fields in human resource work. ASTD members were reflected in most of the roles specified in this 
study. Thus, McLagan identified fifteen key training and development roles, as shown in Table 2.3. The major functional roles were performed by training and development professionals. The competencies needed by individuals produced the output for each role. There were 31 critical training competencies identified for each role. One hundred and two critical outputs were produced for these roles.

Roles Description

1. Evaluator The role of specifying the extent of a program, services, and/or product's impact

2. Group facilitators

The role of focusing on managing group discussions and group processes that help individuals learn and the group to have positive experience

3. Individual The role of focusing on helping the individual assess personal development counselor competencies, values, goals and planning for future career actions

4. Instructional The role of preparing learning materials writer

5. Instructor The role of presenting information and directing structured learning experiences that help individuals learn

6. Manager

The role of being in charge of planning, organizing, staffing, controlling training and development projects and linking training and development operations with other organization units

7. Marketer

The role of promoting training and development programs including learning packages and services to the target audiences

8. Media specialist The role of producing training and development software by using audio, visual, computer, and other technologies

9. Needs analyst The role of identifying gaps between ideal and actual performance and specifying the cause of the gaps 
10. Program
administrator

\section{Program designer}

12. Strategist
The role of ensuring that the program is running smoothly so that it is necessary to confirm all components that comprise a learning event, such as facilities, equipment, materials, participants and others.

The role of preparing training objectives, defining content, selecting and sequencing program activities

The role of developing long range plans concerning what training and development structure, organization, direction, policies, programs, services, and practices will be in order to accomplish the training and development mission

The role of identifying the activities, tasks, steps, and human resource and support requirements necessary to accomplish specific results in jobs or organizations

The role of developing, researching, and testing theories of learning, training and development

15. Transfer agent The role of helping individuals apply what they have learned after the training programs provided

Table 2.3: The roles in training and development functions (adapted from McLagan, 1983)

In McLagan's (1989) study, the focus shifted from the training and development field to the HRD field because organization development and career development were officially added to form the HRD field. Thus, HRD was defined as "the integrated use of training and development, organization development, and career development to improve individual, group, and organizational effectiveness" (McLagan, 1989, p.7). Therefore, training and development, organization development, and career development become the three main components in the HRD 
field, and this was illustrated by using the human resource wheel. This wheel shows the broad scope of the HR field to describe the relationship between HRD and HRM. Although there is some overlap in and confusion about the concepts of HRD and Human Resource Management (HRM), this model has still had a profound impact on HRD practice. In this model, role categories and new competencies were added to fit the needs of HRD professionals. As a result, this competency model defined eleven roles of HRD professionals, 74 outputs of HRD work, 35 core competencies, and 13 ethical issues. The HRD professional's competence became a focal issue.

Rothwell (1996) established the Human Performance Improvement (HPI) model, which is the basis and center circle for the Workplace Learning and Performance (WLP) model published in 1999. The author believed that training was no longer a sufficient intervention to solve human performance problems. New roles, competencies, and output for HPI were defined to lay the foundation for future work in human performance improvement. The model yielded 14 terminal outputs, 144 enabling outputs, 38 core competencies, four roles, and 15 ethical issues that affect HPI work.

In 1999, Rothwell et al. presented the model of Workplace Learning and Performance (WLP), which was published by ASTD. WLP used the HPI model as the basis to analyze performance, analyze causes, select interventions, implement interventions, manage change, and evaluate employee performance. This model shifted the WLP focus from HRD and combined workplace, learning, and human performance improvement. WLP was defined as: 
"The integrated use of learning and other interventions for the purpose of improving individual and organizational performance. It uses a systematic process of analyzing and responding to individuals, groups, and organizational needs. WLP created a positive, progressive change within organizations by balancing human, ethical, technological, and operational considerations" (Rothwell et al., 1999, p.9).

WLP consisted of two basic models: the disciplines model and the process model. In terms of discipline, the WLP wheel consists of four primary disciplines to improve human performance. The four components are training and development, organizational development, career development and knowledge management. These components have a structure similar to that of the HRD wheel which was developed by McLagan in 1989. The WLP wheel adds knowledge management to create the new discipline model. In terms of process, the WLP model addresses determining the steps in solving performance problems, guiding organizations for learning and performance improvement, and monitoring the external changes that affect learning and performance in the organizations. In short, this model used all kinds of learning interventions to improve human performance in the workplace.

Based on an understanding of the WLP model, WLP defines the competencies necessary for the job performance of WLP professionals just like many competency studies. There are 52 competency items, which are categorized into six competency groups and seven roles, as shown in Table 2.4. 


\begin{tabular}{ll}
\hline & Items \\
\hline Six competency groups & 1. Analytical \\
2. Technical \\
3. Leadership \\
4. Business \\
5. Interpersonal \\
6. Technological \\
Seven WLP roles & 1. Manager \\
& 2. Analyst \\
3. Intervention selector \\
4. Intervention designer and developer \\
5. Intervention implementer \\
6. Change leader \\
7. Evaluator. \\
\end{tabular}

Table 2.4: The six competency groups and seven WLP roles of the WLP competency model (Adapted from Chen, 2005)

Davis, Naughton, and Rothwell (2004) explored the relationship of the WLP wheel to the new learning and performance wheel. The new wheel contains the traditional HR and WLP and includes other organization disciplines which are not related to WLP disciplines. The value of this model is that it helps professionals by giving comprehensive guidance on their "career development at different positions and levels within their organization and across a wide spectrum of areas of expertise (specialization) and roles" (p. 28). This means that the competencies place emphasis on the clusters of skills, knowledge, abilities, and behaviors that employees need and utilize throughout their jobs in the WLP model. The new 2004 ASTD competency addressed three areas: foundational competencies, areas of professional expertise, and roles in the area of responsibility. The practitioners often cross multiple areas in their job, so they need to apply a broad range of skills. The functional competencies were 
classified into three categories: interpersonal, business/management, and personal competencies. The application of the fundamental competencies is the basis for building the individual's areas of expertise. Areas of expertise are regarded more as the individual's specific technical and professional skills and knowledge in the WLP model. The terms used to define roles are not job titles. They describe what an individual is required to do to perform his job effectively with a cluster of competencies and areas of expertise.

Recently, Dubois and Rothwell (2004) presented a new model for managing the talent in employees' work instead of their job tasks. They provided a new perspective that develops a competence-based system by discovering the characteristics of the exemplary performers in the organization. The reason of this new perspective was that a particular job was no longer considered sufficient to define a worker's future development. It was necessary "to explore a new approach as a foundation for their work" (p.10). In terms of HR practitioners, this newly established competence system is a different approach compared to human resource's traditional work-based approach of finding people to fit a job position based on the job description. The advantages of this new method are that it can improve the full use of human talent in the organization and make it possible to develop the various functions of HR, such as recruitment, selection, employee training, performance management, rewards, and future employee development. 
A number of ASTD competency studies have been conducted in Asia, as shown in Table 2.5. Based on McLagan's (1983) model for excellence, the major studies in Taiwan were conducted by Cheng (1988 \& 1991). Cheng identified the roles and competencies of HRD professionals in 500 manufacturing firms in Taiwan. The results showed that many competencies are very important to Taiwan HRD professionals, including management training, technical training, needs assessment, management support and participation, administrative support, cost-benefit analysis, facilities management, and qualifications of the instructors.

Another study regarding HRD professionals' competency, work output and roles in Taiwan was conducted by Lee and Rothwell (1995); this study was based on McLagan's (1989) models for HRD practice. Thirty-five competencies were classified into three groups, 12 roles, 75 kinds of output, and 11 major HR areas. The results concerning competencies, outputs, and roles in Taiwan were similar to those of studies in the United States. Lee (1998) explored the competencies and roles of human resource development practitioners in Taiwan. The Delphi technique was used as the method for collecting data from $35 \mathrm{HRD}$ practitioners, including private enterprise, government officers and educators. The study found that HRD professionals played 11 roles: researcher, marketer, change agent, needs analyzer, program designer, material developer, trainer/facilitator, career counselor, administrator, evaluator, and HRD manager. The 38 competencies were divided into four clusters: technical, intellectual, interpersonal, and business skills, to ensure the competence involved in their jobs. 
In Korea, Yang (1994) examined the competencies of 248 HRD managers in a study also based on McLagan's (1989) models for HRD practice. The results identified 42 competencies, which were divided into eight competency categories: leadership, business, organizational change, technical expertise, theory building, cognitive processing, globalization, and monitoring. The most interesting result was that the three competencies perceived by Korean HRD managers as least important perceived as the most important competencies by United States HRD managers in McLagan's (1989) study. These three competencies are skills in writing, skills in computer use, and understanding of industry. This result suggests the importance of recognizing that cultural differences may create different perspectives regarding competencies.

Other studies conducted in Asia have been conducted based on the WLP model of Rothwell et al. (1999). In Thailand, Peeraponvitoon (1999) identified the competencies and roles of the WLP for present and future job success. The sample was 255 out of $586 \mathrm{HR}$ professionals $(43.5 \%)$ who were responsible for the areas of HRD, HRM, or T\&D. The results showed that professionals at different levels within the organization and across different WLP disciplines agreed that all competencies, competency groups, and roles will be of greater importance in the future than they are at present.

In Korea, Yoo (1999) explored the HRD perceptions of current expertise levels and the current and future importance of WLP competencies. Out of 400 Korean HRD practitioners, $218(54.5 \%)$ responded that the interpersonal competency group was the most important skill at present, but the visioning and technological competency groups 
would be the most important in the future. The role of intervention implementer was perceived as being the most important expertise currently.

In Taiwan, Chen (2003) conducted the most recent research using Rothwell's (1999) competency model as the study framework. The purpose of this study was to report on the current expertise levels and the importance the 52 WLP competencies currently and in the future as perceived by Taiwan WLP practitioners. The responses of 254 questionnaires were used in statistical analysis. The results showed that most practitioners perceived themselves as between the basic and intermediate levels rather than between the advanced and expert levels. Chen (2005) reported a 70\% overlap in the levels of expertise and current importance and also generalized three items with the top ranking for current expertise and current importance in each of the four competency groups in the WLP competency model. First, the ability to see the "big picture" was ranked in the top three in the current expertise and current importance of the business competency group. Second, computer mediated communication and technological literacy were ranked the top one and two in the current expertise and current importance of the technological competency group. Third, both communication and interpersonal relationship building were ranked at the top in the current expertise and current importance of the interpersonal competency group. Fourth, feedback, questioning, and facilitation had the three top rankings in the current expertise and current importance of the technical competency group. Fifth, both goal implementation and leadership were ranked at the top in the current expertise and current importance of the leadership competency group. Lastly, analytical thinking as 
ranked in the top three in the current expertise and current importance of the analytical competency group.

Another finding was that the practitioners perceived communication and interpersonal competency and the role of intervention implementer to be the most important among their current and future competencies. This result was consistent with the workplace culture of Taiwan. The reason is that the business community in Taiwan places more emphasis on harmony and cooperation as a priority for the success of a business and to build relationships. 


\begin{tabular}{|c|c|c|c|}
\hline U.S.A. & Asia & & \\
\hline Model bases & Applied Studies & & \\
\hline \multirow[t]{2}{*}{$\begin{array}{l}\text { McLagan (1983)- Models } \\
\text { for excellence }\end{array}$} & $\begin{array}{l}\text { Taiwan } \\
\text { Cheng (1988) }\end{array}$ & $\begin{array}{l}\text { Taiwan } \\
\text { Cheng (1991) }\end{array}$ & \\
\hline & - HRD professionals & $\begin{array}{l}\text { - HRD professionals in top } 500 \\
\text { manufacturing firms }\end{array}$ & \\
\hline $\begin{array}{l}\text { McLagan (1989)- } \\
\text { Models for HRD practice }\end{array}$ & $\begin{array}{l}\text { Taiwan } \\
\text { Lee \& Rothwell (1995) } \\
\text { - Focus group approach (13 of } 16 \\
\text { experts in HRD Associations) } \\
\text { - } 35 \text { competencies } \\
\text { - } 3 \text { groups } \\
\text { - } 12 \text { roles } \\
\text { - } 75 \text { outputs } \\
\text { - } 11 \text { major HR areas }\end{array}$ & $\begin{array}{l}\text { Taiwan } \\
\text { Lee (1998) } \\
\text { - } 35 \text { HRD practitioners } \\
\text { (enterprise, government officers } \\
\text { and educators) } \\
\text { - Delphi technique } \\
\text { - } 11 \text { roles } \\
\text { - } 38 \text { competencies } \\
\text { - } 4 \text { clusters (technical/ } \\
\text { intellectual/interpersonal/ } \\
\text { business skills) }\end{array}$ & $\begin{array}{l}\text { South Korea } \\
\text { Yang (1994) } \\
\text { - HRD managers } \\
\text { - } 248 \text { respondents } \\
(70.9 \%) \\
\text { - } 42 \text { competencies } \\
\text { - } 8 \text { competency } \\
\text { categories }\end{array}$ \\
\hline $\begin{array}{l}\text { Rothwell et al. (1999)- } \\
\text { ASTD model for WLP }\end{array}$ & $\begin{array}{l}\text { Taiwan } \\
\text { Chen (2003) } \\
\text { HRD practitioners } \\
\text { - Current expertise: is located } \\
\text { between basic and intermediate } \\
\text { - Highest expertise: } \\
\text { communication competency group } \\
\text { - 70\% overlap in the level of } \\
\text { expertise and current importance }\end{array}$ & $\begin{array}{l}\text { Thailand } \\
\text { Peerapornvitoon (1999) } \\
\text { - HRD practitioners from } \\
\text { members of the Personal } \\
\text { Management Association } \\
\text { - } 255 \text { out of } 586 \text { respondents } \\
(43.5 \%)\end{array}$ & $\begin{array}{l}\text { South Korea } \\
\text { Yoo }(1999) \\
\text { - HRD professionals } \\
-218 \text { out of } 400 \\
\text { respondents }(54.5 \%)\end{array}$ \\
\hline
\end{tabular}

Table 2.5: Summary of multiple USA competency models and the results of Asian studies 


\section{The Role of HRD Professionals in Taiwan}

Many studies in the United States have reported on the fundamental HRD roles and the competencies needed for them (McLagan, 1983 \& 1989). Ruona (2000) reported that scholars in the United States have different points of view about HRD as a profession. Unfortunately, in Taiwan, the term HRD has neither a standard definition nor association with such roles as HRD professionals and HRD practitioners. As Chen (2005) stated, the HRD professional in Taiwan has not been perceived as a solid professional and practitioner and is still in pursuit of a legitimate professional identity.

It is a hard to deny that there is a lack of careful distinction among the fields of HRD in Taiwan. An obvious example is that Taiwan Human Resource Management (HRM) textbooks introduce HRD narrowly, focusing on career development and taskrelated development for employees (Chang, 1999). Another phenomenon is that though some of the academic studies in Taiwan realize the meaning of the term of HRD, there is not a specific job position or department for HRD in the organizations. Either HR or HRM is used to cover all generally synonymous terms such as personnel and training. The result is that, although the term HRD is included in most of the studies, the samples for the studies are from the synonymous HR related jobs. This situation still exists. For example, in the most recent study published by Lien and McLean (2004), HR practitioners were used as the subjects for the study because there were no HRD practitioners or managers in Taiwan. Other studies which have been conducted by master's students in Taiwan include the relationship between human resource curricula design and professional core competence by $\mathrm{Su}(2004)$, the competencies and roles of HRD by Chang (2000), professional competencies of HRD managers in high-tech 
industries by Chen (1998), job roles and professional competence of the human resource development specialist by Chang (2001), and the essential competencies for training personnel in business by Jheng (1994).

\section{Training Design}

This section has two parts. The first part presents a definition of training /instructional design. The second part reviews models of the training design process.

\section{Definition of Training/Instructional Design}

Design of training programs is broadly used in the education environment, nonprofit institutes, and organizations in business and industry. The term training/instructional design has been used interchangeably with the terms instructional development, instructional systems design, instructional technology, educational technology, a systems approach, and curriculum development (Briggs, 1997; Streumer \& Tuijnman, 1996; Tuijnman, 1996a; Shrock, 1995).

Training design has been defined in multiple ways. It is widely accepted that training design utilizes a systems theory approach to represent the entire process of a training program. Numerous studies have defined training design based on systems thinking: 
Training design is ........

- A systems approach is an operational concept, referring to a scientific, systematic, and rational procedure for optimizing outcomes of an organization or structure, by implementing a set of related operations to study an existing system, solving problems, and developing new or modifying existing systems. (Ryan, 1975, p.

- The complete process of: (a) analyzing what is to be thought/learned; (b) determining how it is to be thought/learned; (c) conducting a tryout and revision; and (d) assessing whether learners learn (Gustafson, 1996).

- The process of creating a strategy for training a specific training audience, including (1) assessment of cultural considerations, (2) development of an overall training plan, (3) selection of methods that may be used to carry out the plan, (4) sequencing of events, and (5) allowance for modifications to be made dynamically at any point in the training process, from design to completion of delivery (Deal, 2004).

- A system of productions, in which the elements already envolved from memory and the aspects of the design already arrived at up to any given point would serve as the stimuli to envolve the next set of elements. (Nelson, Magliano, \& Sherman, 1988, p. 29) 


\section{Models of the Training Design Process}

Current demands for training are unprecedented. The training design process is expected to accomplish the best quality of training (McLagan, 1983). Instructional System Design (ISD) has been formally adopted by large organizations today (Swanson \& Torraco, 1995), such as the military, industries, and universities. This systematic process of training design helps the training designers make decisions about the nature and scope of the instruction process and develop appropriate solutions to a perceived training problem. Most importantly, the key elements of the process are effective training programs (Ruthwell \& Kazanas, 1992; Rowland, 1992). Gagné et al. (2005) promoted the ISD model, which is referred to as the ADDIE model of instructional design. The ADDIE process flow consists of five common phases: analysis, design, development, implementation, and evaluation, which are abbreviated to ADDIE. Evaluation activities can reveal where revisions are required in each of the other four components. The generic model follows cycles similar to those shown in Figure 2.1. The overall process is based on systematic problem-solving models. The instructional designer must engage in problem-solving activities within a given component of the process in addition to fulfilling the requirements of the overall process. 


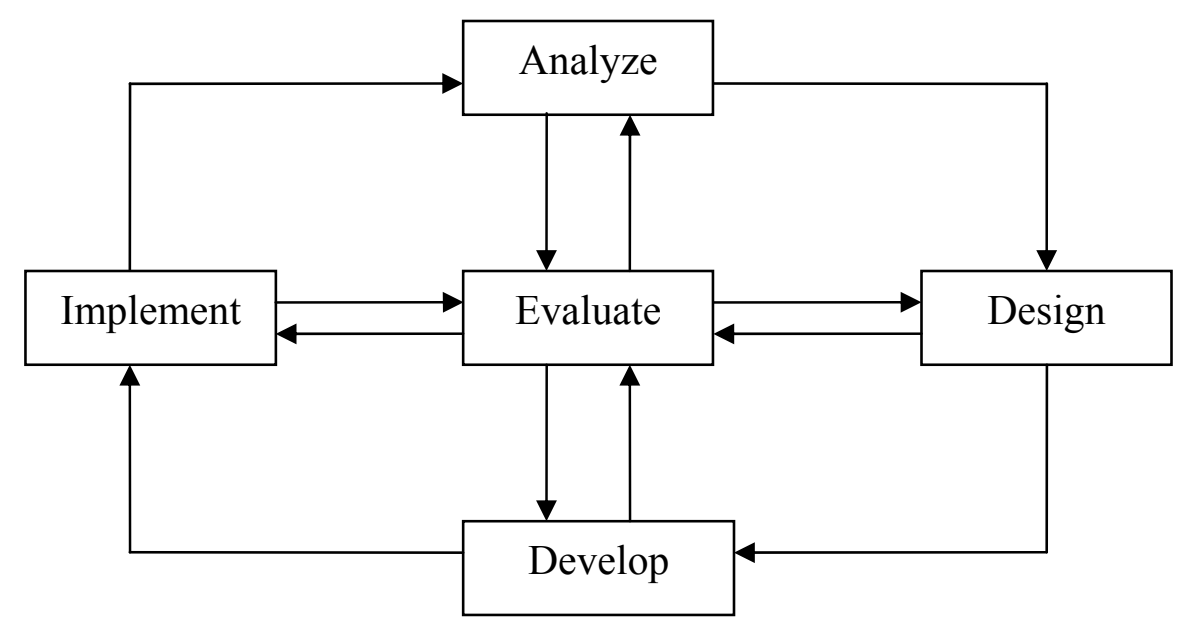

Figure 2.1 Model of the instructional development cycle

There are numerous models of the instructional design process that have been developed for different settings, and each type of model is based on a different theory or philosophy that needs to be considered when a designer selects a model for a particular task. Several models have been identified as variations of instructional design theories and models to meet the needs of different types of organizations.

Gustafson and Branch (2002) provided a collection of models that are classified in a three part taxonomy based on the orientation of the model. The first is the classroomorientation model, which provides guidance for use of the ISD in school settings. The second model is the product-oriented model, which provides guidelines for the production and management of interactive media projects. The third is system-oriented and provides a more precise and more detailed approach. The authors suggested that two well-known systems-oriented approaches also emphasize the importance of the collaboration of skilled team workers such as instructional developers and SMEs. These 
models are Branson's (1977) Interservices Procedures for Instructional Systems Development (IPISD) model and Dick, Carey, and Carey's (2005) Dick and Carey System Approach Model.

The Interservces Procedures for Instructional Systems Development (IPISD) model has been widely used in military training, for example for the Army, Navy, Marines, and Air Force in the United States. According to Gustafson and Branch (2002), Robert Branson is the name most commonly associated with this model. Branson's (1977) IPISD model was developed to provide a common and simple approach to instructional development, including five different phases that are sub-divided in 20 steps. The phases are analysis, design, development, implementation, and control. However, Anderson et al. (1991) argued that this model lacks adaptability and so was unsuccessful in implementation in the U.S. Army.

Dick, Carey, and Carey's (2005) systems approach model is most apparent in the traditional approach to design instruction and is also the most popular model in many business, industry, government, and military training settings, thus becoming the standard for all other ID models. Currently, the book is in the sixth edition and has remained unchanged from the previous editions. This model is a more product-oriented rather than systems-oriented approach and is particularly detailed and useful during the analysis and evaluation phases of a project. This model typically follows a sequential approach of ten phases as follows:

1. Instructional goals are identified: the goal is to determine what the learners should be able to reach after completing the training. This is often the result of a needs assessment. 
2. Instructional goals are analyzed: Analysis of the instructional goals is intended to determine step by step what people are doing when they perform the desired goal. The necessary skills and knowledge to perform the goal will emerge from this process.

3. Learners and contexts are analyzed: Analyzing learners and contexts is intended to gather information about who will be trained, the contexts in which they will learn the skills, and the environment in which they will apply them later on. This step is done at the same time as the analysis of the instructional goals.

4. Performance objectives are written: This is a specific statement of what the learners will be able to do after completion of training.

5. Criterion referenced tests are developed: The assessment instrument will measure the learners' ability to perform the objectives.

6. Instructional strategies are developed: The instructional strategy will be used to allow the learners to achieve the terminal objectives.

7. Instructional materials are developed: This step involves the development of lesson plans, student materials, tests, and an instructor's guide.

8. Formative evaluations are conducted: This involves data collection for the improvement of future instruction. Three different types of assessment are used: one-to-one evaluation, small group evaluation, and field evaluation.

9. Instruction is revised: the entire process begins again with revisions occurring as needed. This step requires that instructional designers go back and revise the instruction as necessary based on the results of the formative evaluation. 
10. Summative evaluation IS conducted: This step is not part of the design process. It is "an evaluation of the absolute and/or relative value or worth of the instruction and occurs only after the instruction has been formatively evaluated and sufficiently revised to meet the standards of the designer" (p.7).

Dick and Carey's systems approach model was particularly influenced by Gagné‘s model, which is considered a seminal model. Gagné's deserves mention that as a very famous pioneer in the principle of instructional design. Two decades ago, Gagné reported the taxonomies of learning outcomes which enable a designer to classify the desired objectives. This approach to instructional design includes nine events of instruction, conditions of learning, and learning outcomes. Gagné proposed that both the events of learning and categories of learning outcome provide a framework for an account of learning conditions.

In addition, Gagné, Briggs, and Wager (1992) developed the Educational Systems Design Model. This model manages the entire process of instructional design for the educational system from the initial stage to the final installation of the program. This model includes three different levels with nine procedures: the system level, the course level, and the lesson level.

The system level describes the initial phase of the development of the system. In the initial phase, there are three primary activities: 1) analysis of the needs, goals and priorities; 2) analysis of the resources, constraints and alternate delivery systems; and 3) determination of the scope and sequence of curriculum and courses and the delivery system design. 
The course level encompasses two activities: 1) the determination of course structure and sequence; and 2) the analysis of course objectives. The objectives are formed based on the desired outcomes of training. The course structure depends upon the constraints identified at the systems level.

The lesson level consists of four phases: 1) defining performance objectives; 2) preparing lesson plans; 3) developing and selecting materials and media; and 4) measuring students' performance. Once this has been completed, the instructional designer must return to the systems level.

\section{Training Designers and Subject Matter Experts (SMEs)}

This section is organized in five parts. The first part reviews the role of the training designer. The second part discusses the role of the training designer in Taiwan business and industry. The third part discusses the competencies/expertise needed by an effective training designer. The fourth part indicates the role of SMEs. The fifth part presents the competencies/expertise needed by effective SMEs.

\section{The Role of Training Designer}

The term training designer refers to the individual who identifies the participant's needs and determines the best method to transfer SME expertise by a way of design during the training design process (Maple, 1994). The designer must be able to work with a variety of resource people such as SMEs, HRD staff, and the facilitator of the program being designed (Nadler, 1984). Another role function of the designer is to "formulate a 
working content structure within which the information and skills to be taught can be formed into a sequence and hierarchy" in the interaction with SMEs (Wallington, 1981, p.30).

According to the definitions of training designers, a training designer would not be knowledgeable in all of the diverse content areas. Thus, a training designer needs to collaborate with SMEs to assist in determining the scope and accuracy of unfamiliar content, to apply instructional design principles to a wide range of unfamiliar content areas, and to begin by analyzing goals, needs, and trainee characteristics in order to understand the instructional problems (Keppell, 1997).

After gaining a comprehensive understanding of the purpose of the collaboration with SMEs, the training designer's role-play in the different situations becomes the next issue. There is no one role that a designer should adopt in every situation. Rather, designers should be flexible enough to adapt their roles to the nature of each project and each client (Tessmer, 1988). Therefore, many authors have proposed a wide range of role models for designers to shift among in certain situations. Rose and Reigert (1976) proposed a role model shift by the designer when meeting different clients, so that he/she is not limited to working with SMEs, including: 1) salesman to convince clients that the project could be implemented and to show the results of other projects as successful examples, 2) facilitator to provide information to enable the clients to make a decision, and 3) counselor to provide immediate feedback and a comfortable physical work environment. Chiu (2003) indicated that the instructional designer might play the role of a missionary, a coordinator or a project-manager, depending on the needs of the SMEs. 
In Tessmer's (1998) study, a designer serves in the consultant role and should adopt different consulting roles while working with SMEs, for example, partner, facilitator, modeler, and counselor, as shown in Table 2.6. In each role, a designer should realize the situation, take action, and know what the effects will be. For example, if the SMEs can successfully understand a detailed knowledge structure during consultation, the training designers should shift more to the counselor role. If the training designer and SMEs are new to the multimedia process, they become a partnership and work together to set goals, times, tasks, and processes in a peer relationship.

Davies (1975) indicated that designers can be successful advisors who suggest options to SMEs. In most cases, it is assumed that SMEs are primary clients and users of the product, and they have the right to reject or accept instructional materials, methods, or planning activities that a designer suggests. Table 2.6 shows details of the role of the designer in dealing with situations involving SMEs. 


\begin{tabular}{|c|c|c|c|}
\hline Role & Situation & Designer Actions & Effects \\
\hline $\begin{array}{l}\text { Partner- } \\
\text { Learning with } \\
\text { the SME }\end{array}$ & $\begin{array}{l}\text { - Designer and SME } \\
\text { are new to the } \\
\text { multimedia process }\end{array}$ & $\begin{array}{l}\text { - Set goals, times, } \\
\text { tasks, processes with } \\
\text { the SME in a peer } \\
\text { relationship }\end{array}$ & $\begin{array}{l}\text { - Designer eliminates } \\
\text { SME frustrations } \\
\text { from consulting } \\
\text { ambiguities and } \\
\text { delays }\end{array}$ \\
\hline $\begin{array}{l}\text { Facilitator- } \\
\text { Assists the SME }\end{array}$ & $\begin{array}{l}\text { - The SME has the } \\
\text { most multimedia } \\
\text { design experience }\end{array}$ & $\begin{array}{l}\text {-Help SME by using } \\
\text { knowledge elicitation } \\
\text { tools. } \\
\text {-Edit and organize } \\
\text { information }\end{array}$ & $\begin{array}{l}\text { - Speeds up design } \\
\text { process. } \\
\text { - Weakens designer } \\
\text { role }\end{array}$ \\
\hline $\begin{array}{l}\text { Modeler- } \\
\text { Role plays the } \\
\text { SME }\end{array}$ & $\begin{array}{l}\text { - Designer has the } \\
\text { most experience. } \\
\text { SME is unclear on } \\
\text { duties }\end{array}$ & $\begin{array}{l}\text { - Role play SME } \\
\text { actions } \\
\text { - Use knowledge- } \\
\text { elicitation tools }\end{array}$ & $\begin{array}{l}\text { - Clarifies SME roles } \\
\text { and activities } \\
\text { - Strengthens ID role }\end{array}$ \\
\hline $\begin{array}{l}\text { Counselor- } \\
\text { Probes and } \\
\text { reflects for the } \\
\text { SME }\end{array}$ & $\begin{array}{l}\text { - SME is successful } \\
\text { in understanding } \\
\text { detailed knowledge } \\
\text { structure during } \\
\text { consultation }\end{array}$ & $\begin{array}{l}\text { - Summarize SME } \\
\text { comments, probe } \\
\text { SME to clarify, } \\
\text { advise }\end{array}$ & $\begin{array}{l}\text { - Sustains SME } \\
\text { output. } \\
\text { - Guides SME } \\
\text { responses }\end{array}$ \\
\hline $\begin{array}{l}\text { Advisor- } \\
\text { Recommend } \\
\text { options }\end{array}$ & $\begin{array}{l}\text { - SMEs are primary } \\
\text { user of the product }\end{array}$ & $\begin{array}{l}\text {--Suggest } \\
\text { instructional } \\
\text { methods, materials } \\
\text { and activities }\end{array}$ & $\begin{array}{l}\text { - SME accepts or } \\
\text { rejects the advice }\end{array}$ \\
\hline
\end{tabular}

Table 2.6: Designer consulting roles, actions, and effects for varying task analysis situations (Adapted from Tessmer, 1998 and Davies, 1975)

Rowland (1994) categorized the role of the designer in two groups: inside and outside. An insider designer understands the design problem immediately and easily because of his/her involvement in a first-hand way with the environment, the people, and the technology. The most important thing is that those factors are mainly affected by a problem within the organization. An outsider designer approaches the problem with 
difficulty from the top down. Often, a model is selected based on second-hand or biased information. From this perspective, it is a disadvantage to be an outside designer. However, there are sometimes advantages to being an outside designer. The main advantage is not having too much environmental baggage. The successful outside designer is able to take a fresh approach to the situation and to be more objective about the information and data surrounding the design problem. Thus, there are limitations and advantages for both inside and outside designers. It is a typical conflict point and source of misunderstanding that designers have inappropriately taken the side of a particular faction in the design process. Sometimes, if they are not allowed access to information or do not want to have data tainted by being too close to the problem, the result may be that designers never really understand what the real problem is.

\section{The Role of the Training Designer in Taiwan Business and Industry}

In practice, the current research on training design in Taiwan has not adequately addressed the importance of the role of HRD professionals as training designers. Most organizations do not have such a position designated as training designer. It is commonly accepted that training design is part the job of the HRD professionals (Chien, 2003; Chiu, 2003). Chen (2003) explained this phenomenon by observing that many organizations either outsource training or have their managers engage in HRD activities such as instructional design, material development and training. Thus, HRD tasks are perceived as part of the manager's job functions.

The topics considered relevant to training design illustrate the scarcity of literature in Taiwan. Even when a reference cited addresses the role of the training designer in the 
business or industry environment, the roles of the training designers indicate that they are experts on work more closely related to technology. This group of training designers in Taiwan is defined as individuals who have capabilities related to the concepts of technology (e.g., the web, media), cost analysis, curriculum planning, communication, and the ability of the organization to integrate training materials into the intranet system. They are in charge of development of E-learning or Web-based training courses which are applied through media and technology (Chien, 2003; Chiu, 2003). That is, they are viewed as experts on technology who are able to develop online courses.

The task difference between training designers and SMEs in the training design process and the importance of the collaborative relationship are not yet established in Taiwan. Chien (2003) found that the SME has low willingness and capability to be involved in and a low rate of completion of training materials. The author concluded that a lack of communication between training designers and SMEs may result in conflict, poor understanding of responsibilities and perhaps even a struggle for dominance. In such a situation, in order to build rapport with people such as SMEs, an easy and often neglected technique is to recognize SMEs' participation and to make them feel they are a vital part of the process.

\section{Competencies/Expertise Needed for Effective Training Designers}

As the role of instructional designers is becoming crucial to the success of training program, it is essential to define the core competencies which should have been acquired by a training designer in the training design project (Parhar \& Mishra, 2000). This is 
especially the case because the competencies that training designers bring to their work affect both the training design process and the design results.

Lee (1994) stated that training designers need to have general knowledge on cognitive learning systems and concepts, instructional strategies, assessment, testing and measurement, methods of instruction, and the writing skills necessary to design effective instruction and specific learning activities, which knowledge is commonly required by many organizations and industries such as insurance, medicine, accounting, and so on. Wallington (1981) suggested other generic and specific skills important to an instructional designer, including the capability to apply principles of the behavioral sciences and systematically search for related information. Other critical skills that a training designer needs to develop in order to complete jobs in training successfully including application of the systems approach concept, analysis, media selection and use, evaluation models, strategies for implementing a training project, strategies for dealing with SMEs, research and theory bases along with budgeting, and learning facilities design (Den-Parker, 1981).

Other skills that enhance the results of the training program are those involved in group process. The group process skills include the knowledge of how to plan and conduct an efficient meeting, how to serve as a leader in completing the agenda in a meeting, and how to develop a team to accomplish the training project (Morrison, 1988a).

Den-Parker (1981) emphasized that skill in instructional design was ranked in the top five of 26 categories in a study based on data from respondents of a training department. The instructional design skill included analysis, planning and development of complex training programs. Dick (1988) highlighted the finding that designers must be 
confident that they have the instructional design skills that will be required to carry out a project successfully and to establish a successful relationship with an SME.

Most importantly, a training designer should possess skill in building and maintaining good consulting relationships with SMEs. Siber (1975) identified 22 people skills that the designers might use during the course of a professional relationship with an SME. These skills are not necessarily used in every instructional design project. The author emphasized that the nature of the interaction, the situational context, and the individuality of the designer will determine how and to what extent the skills will be used.

The Association for Educational Communications and Technology (AECT) (1981) pointed out that interpersonal consulting skill is one of the core competencies for a training designer. Other skills described in similar terms such as interpersonal and communication skills are also viewed as critical in order for a training designer to be well qualified and to handle the relationships with SMEs (Morrison, 1988a; Wallington, 1981). In the results of Den-Parker (1981), interpersonal communication was rated the most critical skill of twenty-six skills for a designer who interacted with clients, SMEs, peers, and other resource people.

In terms of oral interaction with SMEs, Lee (1994) pointed out that another fundamental skill is that of question-asking in order to clarify issues and gain detailed knowledge of a problem from the beginning stages. A designer must be able to listen to multiple levels of response and to hear messages or ideas through such verbal behaviors of the SME as tone, inflection, and volume as well as non-verbal behavior such as body language for the purpose of reflecting on the SME's responses and providing feedback appropriately (Bratton, 1983; 1981). 
The researcher has reviewed the results of current research regarding the competencies of training designers. The Association for Educational Communications and Technology (AECT) appointed a task force to develop a set of core competencies for instructional development professionals which could be used as standards for certification. The task force spent three years revising and perfecting the list (AECT Task Force, 1981). The competencies identified by the task force represented what they believed were core competencies that should be possessed by instructional developers in both business and education. The list has been updated and slightly expanded by the IBSTPI (1988), which has become an independent certifying agency.

In 1986, the International Board of Standards for Training, Performance, and Instruction (IBSTPI) developed and published an instructional design competencies model, which includes the sixteen instructor competencies originally identified. The purpose of the model was to promote high standards of professional practice in the area of training, performance, and instruction for the benefit of individuals and organizational consumers through research and definition and measurement of competencies. IBSTPI analyzed the professional foundations of the design, planning and analysis, design and development, and implementation and management skills necessary to be a master instructional designer (IBSTPI, 1988). Furthermore, Richey et al. (2001) published a third version of the IBSTPI model, in which 23 core competencies were identified and which not only retains the essential elements of the 1986 model, but also addressed the four domains of professional foundations, planning and analysis, design and development, and implementation and management. Each of the competencies was broken down into component performances, and each performance was described in terms of the conditions 
required, the behavior standards, and the criteria to be met. Thus, this study provided the training and development community a set of criteria of core competencies that an instructor should possess in order to complete an instructional assignment successfully.

The IBSTPI model has been used in a number of studies, as shown in Table 2.7. A close look at the resources obtained provides evidence of the literature in other countries, such as India. Parhar and Mishra (2000) pointed out the competencies that are needed for instructional designers to prepare web-based instruction in advance. These authors used the IBSTPI (1988) model in an Internet-based survey which obtained data from 105 respondents, of whom 60 were female and 40 male and whose jobs were in universities or colleges. The results showed that, according to the respondents, instructional designers should be able to demonstrate several important competencies, including organizational, time management, and problem-solving skills and applying fundamental research skills to design projects. Another important competence that 97 respondents strongly agreed on was the establishment of effective communication relationships with individuals or groups by means of visual, oral, and written forms. The article concluded that there was no significant difference between the competencies needed by web-based instructional designers and those needed by traditional instructional designers.

In Taiwan, some studies have placed more emphasis on the designer's competence needs as they are linked with each phase of the whole systematic training process, ranging from needs analysis, training design, training development, and training implementation to training evaluation (Chien, 2003; Chiu, 2003). Chien (2003) concluded that the competencies of instructional designers fall into five main domains of competencies based on the use of a qualitative research method of semi-structured 
interviews with seven professionals who were working in fields related to curriculum design for web-based training including HR, IT departments, trainers, content providers and venders. The competencies were 1) knowledge, which included instructional design theory and principles, technology, and media concepts; 2) attitude, which covered objective perspectives, enthusiasm, and harmony; 3) analysis of learning objectives, environment, cost, and learner needs; 4) communication skills; and 5) organizational ability.

In Taiwan, another author, Chiu (2003), conducted face-to-face investigations regarding the difficulties of the role of instructional designers in the organization based on the responses of five professionals who had instructional design experience in various companies This study demonstrated that the instructional designer competencies consisted of knowledge, attitudes, and skills for executing five phases of web-based training as follows: 1) analysis of the training, environment, cost, learner characteristics, and learning objectives.; 2) formulation of design content based on identification, planning and discussion, media selection, and strategy decisions; 3) development in writing, discussion, and storyboard implementation; 4) implementation of decisions, setting, and WBT course testing; and 5) evaluation of learning effectiveness and user satisfaction. The results showed the difficulty of incorporating creativity in design, technical specification of content design, and getting adequate time for developing a project. 


\begin{tabular}{|c|c|c|c|c|}
\hline & United States & India & Taiwan & Taiwan \\
\hline Year & $1988 \& 2001$ & 2000 & 2003 & 2003 \\
\hline Researcher & IBSTPI & Parhar \& Mishra & Chien & Chiu \\
\hline $\begin{array}{l}\text { Report } \\
\text { Title }\end{array}$ & $\begin{array}{l}\text { Instructional Design } \\
\text { Competencies } \\
\text { (first \& third versions) }\end{array}$ & $\begin{array}{l}\text { Competencies for Web- } \\
\text { based Instructional } \\
\text { Designers }\end{array}$ & $\begin{array}{l}\text { Factors affecting the } \\
\text { curriculum design for } \\
\text { corporate web-based } \\
\text { training }\end{array}$ & $\begin{array}{l}\text { Competencies for } \\
\text { instructional designers } \\
\text { in WBT }\end{array}$ \\
\hline Subject & Instructional designer & Instructional designer & $\begin{array}{l}\text { Curriculum designers for } \\
\text { WBT }\end{array}$ & $\begin{array}{l}\text { Curriculum designers } \\
\text { for WBT }\end{array}$ \\
\hline $\begin{array}{l}\text { Setting } \\
\text { Selected }\end{array}$ & $\begin{array}{l}\text { Applied to diverse settings } \\
\text { (business, health services, } \\
\text { hospitals, and } \\
\text { universities/colleges) }\end{array}$ & School \& college & $\begin{array}{l}\text { HR \& IT departments, } \\
\text { content provider or vender }\end{array}$ & $\begin{array}{l}\text { HRD professionals in } \\
\text { different companies }\end{array}$ \\
\hline $\begin{array}{l}\text { Research } \\
\text { Methods }\end{array}$ & $\begin{array}{l}\text { - Reviewed by } 15 \text { members } \\
\text { of a board of directors from } \\
\text { academic and practice field }\end{array}$ & $\begin{array}{l}\text { - Quantitative: } \\
\text { Web-based survey basis }\end{array}$ & $\begin{array}{l}\text { - Qualitative: } \\
\text { Semi-structured interview } \\
\text { - } 7 \text { designers }\end{array}$ & $\begin{array}{l}\text { - Qualitative: } \\
\text { face-to-face interview } \\
\text { - } 5 \text { designers }\end{array}$ \\
\hline Results & $\begin{array}{l}\text { - } 16 \text { core competencies } \\
\text { (1st version) } \\
-23 \text { core competencies } \\
\left(3^{\text {rd }} \text { version }\right)\end{array}$ & $\begin{array}{l}\text { - Organizational skill, time } \\
\text { management skill, } \\
\text { problem-solving skills, and } \\
\text { applying fundamental } \\
\text { research skills } \\
\text { - } 105 \text { responses ( } 60 \\
\text { female/40 male, } 35-44 \\
\text { years old) }\end{array}$ & $\begin{array}{l}\text { - Five domains: } \\
\text { 1) knowledge, 2) attitude, } \\
\text { 3) analysis of learning } \\
\text { objective, environment, } \\
\text { cost, learner needs, 4) } \\
\text { communication skills; and } \\
\text { 5) organizational ability }\end{array}$ & $\begin{array}{l}\text { - Knowledge, attitudes, } \\
\text { and skills based on the } \\
\text { five phases: analysis, } \\
\text { design, development, } \\
\text { implementation, and } \\
\text { evaluation }\end{array}$ \\
\hline
\end{tabular}

\footnotetext{
Table 2.7: Summary of designer competency studies
} 


\section{The Role of SMEs}

Subject matter experts (SMEs) refer to persons who are "able to be expected to perform within a specialized realm of human activity" (Swanson, 1994, p.94). In particular, SMEs can perform at a superior level and achieve at the high end in a specific domain of expertise. SME is compatible with 'expert' in legal parlance. One general definition of experts is individuals who have the ability to rapidly organize and process small bits of information into meaningful and creative solutions to specific problems (Kuchinke, 1997). This is because experts can immediately link the given information to experiences with similar problems and develop a preliminary concept of what the problem is and how it might be solved (Rowland, 1992; Chi, Glaser, \& Farr, 1988). Nelson, Magliano, and Sherman (1988) explained that "experts tend to chunk or organize information into more highly structured patterns and to complete the task more quickly than novices." Experts also appear to represent problems differently than novices because of their superior ability to recognize patterns, infer relationships, recall desired relevant information, and recall similar problems from past experience (p.33).

Since the SME serves as an expert in the specific expertise, organizations rely on the SMEs as experienced professionals to provide training content. For example, according to Tessmer's (1988) study, SMEs are often involved in multimedia projects with high levels of content-specific knowledge or skills. They are referred to as content specialists in developing the knowledge base that is characteristic of multimedia programs. Thus, it can be seen that SMEs tend to be responsible for the training content in a training project. SMEs are also called content experts or content providers. Training designers elicit knowledge and relevant information from SMEs for the purpose of 
ensuring the accuracy and completeness of training materials content and the appropriate level of difficulty (Davidove, 1993). Keppell (1997) emphasized that there are two similar purposes relevant to explaining the role of SMEs: 1) to provide a clear description and explanation of the content area being examined and 2) to assist the designer's conceptualization by classifying and verifying the content.

Armstrong and Sherman (1988) described the role of the SME in the design of training programs and proposed some principles the SMEs might follow to facilitate and promote good instructional design. However, resistance seems to be a normal phenomenon so that dealing with SMEs often leaves training designers disappointed and upset. They usually cannot expect instant respect and collaboration from the SMEs with whom they work. They are often mystified by this fact (Ingram et al., 1994). SMEs tend to concentrate primarily or entirely on the technical aspects of their subject matter. They are often indifferent or hostile to the intruding training designer (Block, 1981). Thus, Indermill (1986) noted some characteristics of SMEs commonly observed in their attitudes and behaviors. They tend to be "egomaniac, tetchy, prone to self-adulation and extraneous verbiage, ignorant of the existence of the designer's role, and to exhibit inappropriate behaviors such as twitching, finger tapping, smoking, coffee drinking, and knee bouncing" so as to affect the credibility established with other people such as training designers. Therefore, a major challenge that many training designers face today is difficulty in designing training materials on time and within budget when collaborating with SMEs or content experts. Unless these SMEs understand the value of training programs and their importance to employees and organizations or enjoy working with the 
training designers, they may not take the time to do a careful job or convince other experts to engage in the training design process (Davidove, 1993).

Additionally, many studies demonstrate that SMEs do not serve in the role of providing the training contents. SMEs do play other roles such as that of trainer. Lee (1994) explained that an organization usually takes advantage of inside SMEs who are the professionals in the subject field on their own staff to organize the content in a meaningful way to teach it to trainees. This situation occurs especially in manufacturing companies because of the technical skills needed for training programs and the impulse to save money. Thus, SMEs may play the roles of designer, SME, and trainer at the same time. However, organizations are often not sensitive to whether the SMEs are eager to share their knowledge with others or to perform the double jobs within their limited working hours. This commonly leads inside SMEs to have low motivation to be responsible for this training design job (Simpson, 2003).

Many studies have shown the evidence of this kind of situation in the practical world. William's (2001) study was narrowed to the role of technical SMEs as trainers. He proposed as criteria for their being effective trainers that SMEs must possess experience, formal education, and knowledge of adult learning theory or training and development techniques so as not to present problems for the organization and to adequately train others. Furthermore, Williams (1999) conducted an experimental study which examined whether SMEs lacked the appropriate level of proficiency in certain competencies to deliver effective technical training programs and whether technical SMEs were capable of acting as trainers. The study was based on the responses of 165 technical SME respondents who were members of ASTD and who identified their Professional Practice 
Area as technical and skills training. The findings revealed that SMEs with more years of experience and higher levels of professional preparation showed a higher level of proficiency in relation to instructor competencies. On the contrary, their formal education in adult education or training and development technique had no perceived impact on their level of proficiency as related to instructor competencies. Trautman and Klien (1993) conducted a study which showed that SMEs act as the trainers because they can bring a new dimension to the training process. The characteristics SMEs bring to the training process include: 1) instant credibility in the eyes of the classroom participants, 2) a personal understanding of business and related issues, 3) shorter preparation time before training delivery with little or no learning curve for the training content in the technical aspects, 4) real-world practice and experience in using work tools, 5) the most current knowledge on expediting the work process, and 6) immediate updates in accordance with changes in the curriculum and work processes.

\section{Competencies/Expertise Needed for Effective SMEs}

Training designers have to be able to determine which experts have the most or least experience, knowledge, and interest to qualify them to assist in the training design content (Davidove, 1993). Thus, Herling (2000) emphasized that the three most important components of the expertise of SMEs are their knowledge, their experience, and their problem-solving ability. Overall, SMEs have sufficient competency to affect both the core competencies of organizations and the competence development of employees (Swanson, 1996). 
The expertise that SMEs possess is not inherent. It can be developed by training and development. Training and development is the process of systematically developing human expertise in individuals such as SMEs for the purpose of improving performance and providing competence to meet current work expectations (Swanson, 1996). In fact, SMEs' rich knowledge is generally acquired through hundreds and thousands of hours of learning and experience in one area of study (Glaser, 1985). Furthermore, SMEs are considered experts because they can demonstrate their acquired expertise through outstanding performance, and this means that they can consistently do things more effectively and efficiently than novices or non experts can (Herling, 2000).

Chi, Glaser, and Farr (1988) identified seven characteristics of experts which explain how they are different from other people, as follows:

1) Experts are good at their own specific domain knowledge. Experts can propose a more concrete and specific level of knowledge.

2) Experts perceive meaningful patterns in their domain. This means that they use information to organize the knowledge in their own way due to good organization of their knowledge base rather than superior perceptual ability.

3) Experts have good short-term and long-term memory. Experts' recall capabilities exceed the limits of short-term memory because of the automaticity of many portions of their skills.

4) Experts are faster than novices at performing the skills of their domain, and they quickly solve problems with little error.

5) Experts see problems in their domain at a deeper level. Experts see and represent a problem at a more disciplined level whereas novices tend to represent it at a 
superficial level.

6) Experts spend a great deal of time analyzing a problem qualitatively. At the beginning of the problem solving, experts try to understand the problem, whereas novices plunge immediately into attempting to apply equations.

7) Experts have strong self-monitoring skills. Experts are more aware of when they have made an error, why they failed to comprehend an issue, and when they need to check their solution. Their monitoring skills reflect their greater domain knowledge as well as different representation of knowledge.

In one experimental study on expert-novice differences, Elson's (2003) results supported seven research hypotheses about expert and novice performance in an industrial engineering scaled world simulation. The results focused on three aspects of performance. First, experts will generate a better outcome for the primary problem goal, which makes for more correct decisions in solving the problem, and understand the system dynamics of the problem in the test situation more completely than novices. Second, experts will search for data and situation information, recognize and use the data and situation information, and use more domain knowledge in better ways than novices in solving the problem in the test situation. Third, experts will use a forward or top-down problem solving method, and novices will use a backward or bottom-up problem solving method.

Chien (2003) conducted a study of factors affecting the training design for a corporate web-based training program in Taiwan. She concluded that SMEs need to have competencies in professional knowledge, training in media concepts, cost analysis, 
curriculum planning, and understanding of target learners and that effective training design tends to stabilize interfaces, design processes and software.

\section{Consultation Relationship}

\section{Definition}

Consultation is the cooperative, helping relationship established between training designers and SMEs. The word 'consultation' is more clearly defined as assistance in the content, process, and/or structure of a task, or to someone, but not actual responsibility for doing the task (Steele, 1975). The 'consultation relationship' (Steele, 1975) is described as a 'helping relationship' or 'helping profession' (Colton, 1974, Rutt, 1980, Bratton, 1983; Leitzam et al., 1979; Colton, 1974). Furthermore, the working relationship is that of partners who contribute their knowledge, share the responsibilities, and build mutual respect to produce training programs successfully (Armstrong \& Sherman, 1988; Bratton, 1983; Ingram et al., 1994). How much competence the designer possesses about the topic of the training project and how well training designers are capable of understanding the SME's comments are concerns of the SMEs (Rodriguez, Stephens, \& Arena, 1991). Therefore, it is necessary that SMEs understand the competencies of the training designers before the training design process can be fulfilled, and the SMEs should be encouraged to participate in consultation in order to provide more information.

In this regard, working with an SME never occurs in an isolated situation. A training project should go through a series of phases of communication with someone who is usually called a consultant, such as an SME. This process results in a consulting 
project or training project (Ingram et al., 1994). The training designer never approaches an SME in isolation from the rest of a project. Thus, a supportive and disciplined relationship is helpful to motivate SMEs to provide information vital to diagnosing the problem and obtaining a solution (Bratton, 1983).

\section{Types of Consulting Relationship Models}

Several articles have presented similar models in regard to building the consultation between training designers and SMEs when a project requires the contributions of both of them (Davies, 1975; Rutt, 1980; Dormant, 1986). Before beginning the training design, the designer must determine the philosophical assumptions of the SME. Davies (1975), Tilles (1961), and Schien (1969) presented three models based on different assumptions for a training designer.

First, in the product model, the client who views the designer through a product assumption will view the consultant relationship as a customer-seller relationship and only request the solution from the designer. It seems that these clients recognize their problem well enough to request the proper solution from designers. The designers provide knowledge or products and act as experts. Second, in the prescription model, the client who views the designer through a prescriptive assumption will view the consultant relationship as a doctor and patient relationship. The training designers are expected to have a high level of diagnostic ability to identify the true problem and solution and also to maintain a continuous instructional statement for clients. The designers act as an authority to build confidence, trust, and a friendly and warm relationship with clients for the long-term. Third, the product-process model is based on the assumption of a 
collaboration relationship between designers and clients. Both of them have similar concerns about what is expected, what the results to be achieved are, and their roles in exchanging advice so they can work together in order to figure out the problems and accomplish a solution.

Blake and Mouton (1978) added one more consulting model, the affiliative model. This model emphasized good interpersonal relations between the designer and clients for effective consultation. Furthermore, this model was identified as more relationshiporiented and less task-oriented than the other three models. Both parties, designer and client, take the position that they will do whatever is recommended by the other. This model was used by Rutt (1980 \& 1985) because it was felt that it communicated more precisely about the role of the designer. However, this model always results in a high work level, with low productivity

\section{Process of Consulting Relationship Model}

Many authors have proposed different phases of the process model to implement this context. In the 1970's, the authors mentioned earlier proposed dividing the consultation model into three general phases: entry, analysis-diagnosis, and problem solution (Brokes, 1975; Kurpius \& Brubaker, 1976; Davies, 1975; Schein, 1969, 1978; Argyris, 1970; Havelock, 1973; Caplan, 1970).

For example, Davies (1975) illustrated how the training designer and SME become involved in a process-content relationship, dividing their interaction into three phases of relationship activities: entering, in which designers contract with the SMEs on paper; maintaining, in which SMEs' perceived needs are diagnosed and implementation is 
begun, and terminating, in which the process and product are reviewed and evaluated. Block (1981) proposed a similar model as a basis for consulting with an SME. This author divided the work process into five phases: 1) entry and contracting, 2) data collection and diagnosis, 3) feedback and the decision to act, 4) implementation, and 5) extension, recycling, or termination. The author focused most of his attention on discussing the first three phases extensively because he thought the success of the earlier phases could be instrumental in the success of implementation. However, the phase of implementation received little notice because many articles had been written on this aspect in a number of fields and implementation depends on skills drawn from various fields, e.g., skills of accountants and engineers.

In the same year, Wallington (1981) stated that the interaction of designer and SME will involve several procedures until an appropriate instructional module is worked out. These procedures include receiving, classifying, storing information, building and rebuilding structure, requesting new data, and recycling. Indermill (1986) suggested the following guidelines for building credibility with an SME: establishing a relationship, setting the context of the meeting, stating the purpose and expanded outcome of the meeting, identifying the agenda of the interview, defining the roles, explaining your working style as a designer representative, asking questions so that the SME will respond to what the training designer has covered so far and, finally, telling the truth about the problems that have occurred in the organization or department of the organization.

Within a decade, Ingram et al. (1994) outlined Block's (1981) model, in order to facilitate development of most of the necessary skills and guide designers though the process for the purpose of helping more experienced designers and novices who have 
trouble working with SMEs or those who meet with a new type of SME. This model includes preparation, follow-up phases, and the actual meetings with the SME. Moller (1995) also simplified the stages through which designers deal with SMEs, identifying four stages: preparation, initial meeting, process, and choosing. Keppell (1997) developed and tested an approach he named the Instructional Design Knowledge Elicitation Procedure (IDKEP) to assist training designers in conceptualizing unfamiliar content from SMEs. This approach drew on the five key theoretical areas for development identified in the IDKEP: 1) consultation practices, 2) current elicitation procedures in instructional design, 3) knowledge acquisition strategies in constructing the expert's system, 4) interviewing strategies, and 5) knowledge mapping. A knowledge map represents a major focus in the IDKEP.

\section{Best Ways to Establish the Consultation Relationship Process}

Several authors have tried to determine which steps are the most important in the beginning stages of establishing the consultation relationship process. For example, a contract, which can be seen as a way to stimulate negotiation between training designers and SMEs, has been suggested as a mechanism for starting and maintaining a good relationship as well as focusing on the actual values to be obtained. There are two types

of contract: formal and psychological contracts. According to Davies (1975), "the formal contract involves reaching agreement over such things as what is to be done, how much time is to be devoted to the project, what client and consultant resources will be made available." The content of the contract should include seven issues: time constraints, meeting frequency, possible stress situations, proposed techniques, goals, costs, and 
benefits (p. 364). On the contrary, the psychological contract is much shorter but more difficult to negotiate because this contract is concerned with the expectations of the designers and SME for each other, which involves a willingness and commitment to the project.

Of all of the stages of the consultation process, the initial meeting is viewed as the most important stage in the process of working with SMEs (Moller, 1995). The initial meeting with SMEs requires the training designers to conceptualize the content and maintain a professional consultative relationship from the beginning of the consultation process (Bratton, 1981). Another purpose of the initial meeting is to gain the client's confidence and reduce anxiety (Bratton, 1983).

Price (1976) conducted an exploratory study of the verbal behaviors of six practicing instructional developers during their first meetings with new SME clients. The interviews were recorded on audiotape. The system was comprised of four phases-introduction, problem identification, solution discussion, and closing; six content categories--subject matter, objectives, teaching methods, media, evaluation, and others, as well as the twelve process categories--reinforcing, soliciting, promoting, explaining, opining, clarifying, informalizing, structuring, summarizing, declaring, and dispensing. The results of this study showed that the largest percentage of time was spent in the solution discussion, the content discussion most frequently focused on instructional methods, and the process behaviors consisted mostly of explaining, offering opinions, and reinforcing the client.

The need to increase the efficiency of the interviewing process within training design is widely acknowledged. Generally, there are four phases of the interview process: 
1) preparing before the interview; 2) starting the interview; 3) conducting the interview, and 4) interview skills.

All preparation, seen as the first step of preparing for the interview, should contribute to establishing rapport, which goes a long way toward increasing the designer's credibility and expediting the information-gathering process (Yancey, 1995). Bratton (1983) suggested that the training designers must prepare prior to the meeting for the purpose of preventing any misunderstanding from occurring to establish trust and a commitment to the project on the part of the SME.

Thus, a designer's prior knowledge of a topic facilitates their future comprehension. Pre-reading techniques help prepare the designers to organize and associate the new content within a broad and meaningful context as well as to correct the designer's prior knowledge (Wedman, 1987). One such method is text reading of books and other library resources (Bratton, 1981; Wedman, 1987) as well as review of subject-related documents such as accident or sales reports, previous needs assessments, specialized glossaries or dictionaries, existing training materials, procedural manuals, and training and job evaluations (Rodriguez, Stephens, \& Arena, 1991). Yancey (1995) also suggested a basic understanding of information from the organization's financial department or education/training department, the SMEs education and background experience, and subject matter from fields related to the training project content. Based on their reading, designers can make word sketches of content elements. The sketches will not only aid the conceptualization process through active interaction with the material, but may also prove valuable when designing instructional materials (Wedman, 1987). 
Bratton (1981) pointed out that training designers may need to have an understanding of the nature of the training situation being presented, maintain the relationship with the SMEs, and to abstract some basic knowledge of subject matter content which is not familiar in the early phases of the meetings with content experts. Many authors have suggested that training designers should do such pre-planning tasks as preparation of an agenda containing a list of interview questions for the first meeting as an initial point of interaction. The initial meeting agenda stems from all of the preparation work (Davies, 1975; Tessmer, 1988; Rodriguez, Stephens, and Arena, 1991; Cram, 1981, Yancey, 1995).

The second step is the beginning of the interview phase. Many articles have pointed out that the training designer always plays an active and positive role in the interview process. Bratton (1983) suggested that training designers can inform their clients in advance of the first meeting about the types of questions which will be asked and the expected outcomes of the interaction. Davies (1975) and Tessmer (1988) explained the reasons that SMEs always expect training designers to have their questions listed in a statement which includes such items as goals, criteria, and components and tasks of the procedure and which is ready at the beginning of the interview meeting. Rossett (1987) encouraged designers to address such issues such as their role, intent, and competency at the start of the interview. This may be accomplished through a job description, a task list, proposed learning objectives, or other related materials that require clarification. Cram (1981) suggested that it is a good idea to provide something such as a flowchart or sets of objectives for SMEs as the meeting materials. The main purpose is to communicate the expectation that the SME will participate in the training 
design project through the interview. It is a common phenomenon that SMEs may not be prepared for nor expect a focused interview in the first meeting, and questions about the learners and objectives may result in only general impressionistic responses. Even if the SME is knowledgeable about such things, he or she may be initially reluctant or unable to reveal a great deal of information.

The third step is to conduct the interview. The structured interview has many useful purposes in the instructional design process. This interview provides training designers an opportunity to interest SMEs in the project and can affect the quality of the resulting instructional projects (Rodriguez, Stephens, and Arena, 1991). Therefore, designers understand that the chance for an interview is frequently a powerful data-gathering technique for interacting with SMEs in instructional design and development contexts (Bratton, 1981).

Many authors have proposed various interview strategies. Since straightforward answers cannot be easily elicited in a meeting, Bratton (1981) and Wedman (1987) suggested that the best approach to learning new or unfamiliar subject matter from SMEs is to discuss such content in a personal interview, using strategies which are a fundamental factor in gaining the understanding of a new field from the SMEs. Davidove (1993) and Cram (1981) suggested as a way of asking questions in the interview process that the experts should be led to visualize people performing on the job. An example of a question/inquiry that prompts an SME to visualize is, "consider your high-performing sales-person and tell me about the daily tasks that have made him/her a great performer". If the answer is not satisfactory, asking the question in a different way can possibly lead to a more complete answer. Another method is use of a mirror statement, which is a way 
of double checking the accuracy of the information from the SME's contributions, verifying mutual understanding of the materials, and showing the attentiveness of the designer. Another suggestion is that open-ended questions are preferable to encourage conversation and to generate broad responses from the SMEs. The question sentence can begin with such words as what, how, tell me about, or describe instead of question forms that require yes or no answers from the SMEs (Rodriguez, Stephens, \& Arena, 1991; Yancey, 1996).

Three categories of question techniques to be used while interviewing with SMEs have been defined: 1) descriptive questions--open-ended and designed to encourage discussion; 2) structural questions--to confirm the designers' understanding of the subject in detail; 3) contrast questions--designed to discover the meaning of discrete facts and the relationships among them (Spradley, 1979; Bratton, 1979-80; Cram, 1981; Wedman, 1987). Gayeski, Wood, and Ford (1992) pointed out three phases of interview strategies: 1) descriptive elicitation to reveal general concepts of the content or develop a conceptual overview; 2) structural expansion to establish the relationships between the concepts; 3 ) scripting, which relies on the declarative knowledge (know about) obtained in the first two phases to discover procedural knowledge (know how). Keppell (1997) proposed similar interview strategies, identifying three phases: 1) structured questions--on details and in depth; 2) ethnographic--such interviews explore the phenomena and formulate appropriate questions; 3) teach-back--designers clarify the content for SMEs. Keppell (1997) suggested that construction of a knowledge map can be a useful tool to assist training designers in interviewing SMEs and help themselves conceptualize the unfamiliar content abstracted from the interview. Additionally, the author found that 
utilizing the teach-back procedure with the knowledge map can be a powerful means of checking the training designer's understandings of the content against that of the SME. Gayeski, Wood, and Ford (1992) suggested three phases of interview strategies to abstract the information from SMEs. The first two phases are declarative (know about) knowledge, including descriptive elicitation to identify the general concepts of the content and structural expansion to obtain an understanding of the relationships between the concepts. The third phase is scripting expansion to obtain procedural (know-how) knowledge

The last step is to lead to the conclusion of the interview and then to end it. The designer should allow the SME to present additional questions and comments about the subject. Therefore, the designer should summarize the key points of the interview for some additional discussion with the SME (Rodriguez, Stephens, \& Arena, 1991). This step is not one of the most important parts of the interview, but it is an essential step to confirm with the SMEs the whole content of the discussion and to build credibility for continuing the collaboration in other projects. Their relationship can be a long-term consultation relationship. It is sometimes possible that SMEs will become an internal consultant for long-term collaboration with training designers. 


\section{Synthesis and Conceptual Framework}

This section synthesizes the knowledge gleaned from the literature review and develops a conceptual framework as a foundation upon which this study intends to build. The perspectives of HRD professionals regarding their working relationships with SMEs during the training design process are illustrated as the following conceptual framework, in the form of Figure 2.2, to the way that this framework is utilized to guide this study. 


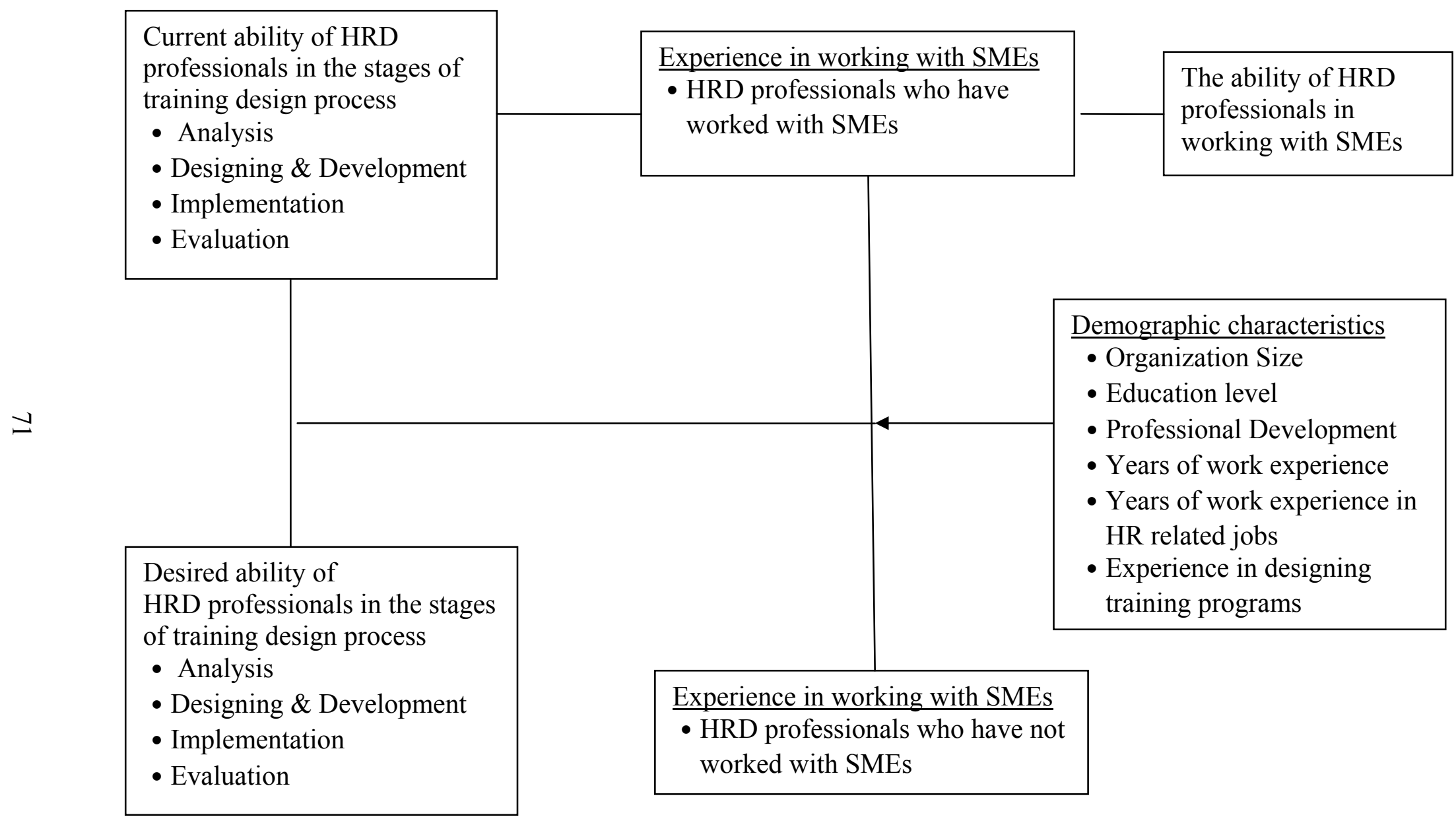

Figure 2.2: conceptual framework of this study 


\section{CHAPTER 3}

\section{METHODOLOGY}

This chapter describes the methodology used to address the proposed research questions. The chapter is divided into four sections. The first section describes the research type. The second section describes the research setting and participants. The third section describes the instrumentation. The final section describes the research procedures.

\section{Research Type}

Descriptive correlational survey research was used to describe and explain the perceptions of HRD professionals in Taiwan regarding their working relationships with subject matter experts (SMEs) during the training design process. The primary purpose of descriptive correlational research is to describe and interpret what exists with respect to the phenomena of interest (Ary, Jacobs, \& Razavieh, 2001).

The research developed a conceptual framework on the perspectives of HRD professionals regarding their working relationships with SMEs in the training design process (See Figure 2.2). The following five research questions were addressed: 
1. Is there a difference between the current/desired ability in the stages of the training design process among HRD professionals?

2. Is there a difference between the current/desired ability in the stages of the training design process among HRD professionals who have and who have not worked with SMEs?

3. What is the relationship between their demographic characteristics and the current/desired ability in the training design process among HRD professionals who have and who have not worked with SMEs?

4. Among HRD professionals who have worked with SMEs, what is the relationship between their demographic characteristics and the ability to work with SMEs?

5. Among HRD professionals who have worked with SMEs, what is the relationship between the ability to work with SMEs and current ability in the stages of the training design process?

\section{Research Setting and Participants}

Four criteria were used to identify a suitable research setting for this study. These criteria included the following: 1) the high-tech organizations that have a human resource or training department as part of the organizational hierarchy; 2) the high-tech organizations that are aware of the importance of training to assist employees in developing their competence; 3) the high-tech organizations that include training as part of the annual financial benefits; and 4) the high-tech organizations in which there is a high likelihood that HRD professionals will work with an SME with technical expertise and experience in the high-tech organizations. 
With regard to the criteria, the research setting in this study was located in Hsinchu Science Park (HSP) in Taiwan. HSP became the first science park in Taiwan in 1980; its mission was to establish a high quality research and development (R\&D) base for the high-tech industry. HSP continuously expanded its infrastructure and facilities, with total government investment to date of 1,121 million US dollars, and reported that as of 2005 , a total of 370 high-tech companies were involved, representing semiconductors, personal computers, telecommunication, and optoelectronics industries. Among the 370 park companies, 321 were domestic companies and 49 were foreign ones. The total revenue of the companies was US\$ 24,973 million, representing a growth of $22 \%$ from 2002. Accumulated paid-in capital was US $\$ 28,829$ million, $92 \%$ of which come from domestic sources, while the remaining $8 \%$ came from overseas. In terms of human resources in Taiwan, there were 93,095 Taiwanese laborers and 4,397 foreign laborers. A total of 4,340 Taiwanese scholars returning from overseas played a critical role in the evolution of the park during the past 23 years. These returnees not only contributed directly by establishing 119 companies in the park, but also brought technology and management skills that improved the general high-tech development of Taiwan (HSBIP, 2005). Thus, the people in this group working in the science park were identified as subject matter experts (SMEs) because most of them had in-depth knowledge and skills in a specific topic or aspect of their jobs. 


\section{$\underline{\text { Sample }}$}

The population to be studied consisted of HRD professionals who worked in the 314 high-tech companies located in Hsin-chu Science Park (HSP). A directory that lists the contact information of the companies was published by the HSP Association in 2005. The total population was about 314 HRD professionals. Based on the size of the population, the sample size, using the table provided by Krejcie and Morgan (1970), was 175 HRD professionals from the total population. Thus, this study was able to meet the minimum sample size.

\section{Instrumentation}

A web-based survey regarding the ability of HRD professionals to design the training programs and their working relationships with SMEs in the training design process was developed by the researcher. The instrument was based on an extensive review of the literature related to the role of HRD professionals, their current and desired ability to design training programs through the stages of the training design process and their ability to work with SMEs.

\section{Design of the Instrument}

For this study, the instrument was composed of three sections with a total of 29 items. In part 1 of the instrument, the respondents were asked for demographic characteristics, including organization size, education level, sources of professional development, years of work experience, years of work experience in human resource (HR) related jobs, experience in designing training programs, and experience in 
working with SMEs. Part 2 of the instrument measured the current and desired ability of HRD professionals in the stages of the training design process by using a comparative seven-point Likert-type scale ranging from 1-7, in which 1 represented "low ability" and 7 represented "high ability." The respondents completed a total of 42 seven-point Likert-type scales based on the selected 21 items. Part 3 of the instrument measured the ability of HRD professionals in working with SMEs by using eight items with a seven-point Likert-type scale. Detailed information regarding the variables is as follows (Table 3.1):

Name of Variable
Source

Number of Items

Part 1 Demographic characteristics Researcher developed

Part 2 Ability of HRD professionals Partly adopted from Instructional in the stages of the training Design Competencies: The design process Standards (IBSTPI, 1988)

- Current

- Desired

Part 3 Ability of HRD professionals Partly adapted from Block's (1981) in working with SMEs model of Flawless Consulting and IBSTPI (1988)

Table 3.1: The variables in regard to the parts of the survey, sources, and number of items 


\section{$\underline{\text { Definition of Operationalization Variables }}$}

As shown in Table 3.1, the researcher designated seven demographic characteristics, two independent variables, and one dependent variable. All variables of those categories are described in the following:

\section{Demographic Characteristics}

The demographic characteristics in this study included seven questions: organization size, education level, sources of professional development, years of work experience, years of work experience in HR related jobs, experience in designing training programs, and experience in working with SMEs.

First, the participants were asked to provide the number of employees in the current company by choosing among six categories: 1) less than 200,2) 200-500, 3) 500-1,000, 4) 1,000-2,000, 5) 2,000-5,000, and 6) over 5,000. Second, education level was classified in six categories ranging from high school diploma to doctoral degree. Third, categories for sources of professional development regarding how HRD professionals learned about designing training programs included: 1) self-directed informal learning, 2) formal professional development programs outside your organization, 3) formal professional development programs inside your organization, 4) learned as part of an academic degree program, 5) other, which it was necessary to specify, and 6) none of the above. All of the items of choice could be applicable to respondents. Fourth, years of work experience was an open-end question to determine how many years the respondents had worked until the present. Fifth, years of work experience in human resource related jobs was an open-end question to determine how 
many years the respondents had worked in human resource related jobs until the present. Sixth, the item to determine experience in designing training programs requested that HRD professionals report whether they had experience or had no experience in designing training programs. If they had the experience, the respondents were asked to respond with the percentage of their job related to designing training programs. The percentage was classified according to four categories: 1) less than $25 \%$, 2) $26 \%-50 \%$, 3) $51 \%-75 \%$, and 4) more than $76 \%$. Lastly, to determine experience in working with SMEs, it was requested that HRD professionals responded as to whether they had experience or had no experience in working with SMEs. If they had the experience, the respondents were to specify the percentage of time they typically spend collaborating with SMEs. The percentage was classified according to four categories: 1) less than $25 \%$, 2) $26 \%-50 \%$, 3) $51 \%-75 \%$, and 4) more than $76 \%$.

\section{Independent Variable}

The following were the independent variables of the study.

The current and desired ability of HRD professionals in the stages of the training design process. These two variables, current and desired ability, served as independent variables. These variables were operationally defined as the perceptions of HRD professionals about their current ability and desired ability in the stages of the training design process. The stages of the training design process were comprised of: 1) analysis, 2) design and development, 3) implementation, and 4) evaluation. The questionnaire items were adapted from IBSTPI (1988). The scale was used a comparative seven-point Likert-type scale ranging from 1-7, in which 1 represented 
"low ability" and 7 represented "high ability." The respondents completed a total of 42 seven-point Likert-type scales based on the selected 21 items as presented in Table 3.2.

\section{ANALYSIS}

1. Assess the needs of trainees to determine what they can currently do and what they should be able to do

2. Analyze the components of jobs, duties, and tasks

3. Identify the characteristics of trainees that influence their ability to achieve the training objectives

4. Analyze the work setting to identify the tools, equipment, and other resources used on the job

5. Analyze the organization to ensure that the goals are consistent with the objectives of the training program

6. Review additional resources related to the content of the training program

\section{DESIGN \& DEVELOPMENT}

7. Specify the target objective that describes what is expected of trainees after the training

8. Specify the enabling objectives that describe what trainees should know or do to achieve the target objectives

9. Develop performance rating scales and cognitive test items to measure the trainees' learning outcomes

10. Develop training materials that are consistent with the training objectives

11. Identify training strategies, methods, and approaches to present the training content

12. Design lessons based on a logical learning sequence

13. Use a structured writing format to prepare trainer and trainee guides

14. Select appropriate technology as a means to deliver training

\section{IMPLEMENTATION}

15. Develop an implementation plan to conduct the training program

16. Ensure the organization to support the training program

17. Record the progress of trainees during the training

\section{EVALUATION}

18. Evaluate the trainees' overall satisfaction with the training program

19. Determine what trainees have learned from the training program

20. Report the results of the training program to management

21. Determine the financial benefits of the training program

Table 3.2: The current/desired ability of HRD professionals in the stages of the training design process 


\section{Dependent Variable}

The following was the dependent variable of the study.

The ability of HRD professionals to work with SMEs. This variable served as the dependent variable of the study. This variable was operationally defined as the perception of HRD professionals to successfully interact with SMEs - using both written and oral means during the training design process. The variable was measured through an eight-item questionnaire. The questionnaire items were adapted from Block (1981) and the IBSTPI (1988). The scale was used a seven-point Likert-type scale ranging from 1-7, in which 1 represented "low ability" and 7 represented "high ability."

The eight items in the questionnaire are presented in Table 3.3.

\section{ITEMS}

1. Clarify the role and tasks expected of the SME during the training project

2. Obtain a commitment from the SME to be involved in the training project

3. Prepare an agenda for each meeting with the SME

4. Provide examples to ensure the SME understands how the training will be carried out

5. Ensure that the SME understands the target objective of the training program

6. Use open-ended questions to prompt the SME to provide more detailed Information

7. Ask the SME to review the training program to identify weaknesses or missing components

8. Renegotiate with the SME regarding the design of the training program

Table 3.3: The ability of HRD professionals in working with SMEs 


\section{External Validity}

In survey research, the term validity refers to the appropriateness, meaningfulness, and usefulness of any inferences a researcher draws based on data obtained through the use of an instrument (Gay \& Airasian, 2003). External validity, also known as reliability, refers to the ability of the results of this study to be generalized to the target population. The four major threats to external validity in a descriptive study are frame error, sampling error, selection error, and non-response error.

First, frame error exists when there is a difference between the listed population and the actual population (Sedlack \& Stanley, 1992). Frame error was minimized for this study by obtaining the most recent directory of high-tech companies in the HSP.

Second, sampling error, in terms of a non-representative sample, could be problematic when the selected sample does not represent the population to be studied. In this study, sampling error was controlled by using random sampling.

Third, selection error occurs when some sampling units have a greater or lesser chance of being selected than others (Alreck \& Settle, 1995). This was controlled by checking the lists of the population for duplication and also by sending recruitment letters via email or making phone calls to HRD professionals in each of the companies. The email addresses and phone numbers were obtained either by website search or the directory of the HSP Association. This ensured that each HRD professional had an equal chance of being selected compared to other HRD professionals.

Finally, non-response error occurs when subjects in a study fail to respond, refuse to return, or do not return the questionnaire from some reason (Sedlack \& 
Stanley, 1992). To control non-response error, several efforts were made to obtain a completed survey from all participating HRD professionals. The researcher made a great effort to increase the response rate by calling or emailing to inform the participants before the deadline. After the deadline, a reminder letter was sent through email for the purpose of re-emphasizing the importance of the potential contribution of the study results to the HRD field in Taiwan and encouraging participation.

A review of the recent research results in Taiwan indicated that the highest level response, 38.9 percent, was in a study of HR practices in high-tech business in Taiwan from the employers' perspectives (Fu et al., 2003). Other recent research reported much lower than 40 percentage response rates. For example, there was only a $15 \%$ response rate in a study regarding ISO 9000 certification in electronics industries in Taiwan (Huang \& Jacobs, 2004). Chen (2003) obtained a $24.2 \%$ response regarding workplace learning and performance (WLP) competence for Taiwan HRD professionals. In light of the response rate in the recent research in Taiwan, it is obvious that if this study can obtain a response rate of $40 \%$, it can be an acceptable contribution to understanding the perceptions of Taiwan HRD professionals on this topic.

\section{$\underline{\text { Validity and Reliability Instrument }}$}

The construct validity, content validity, and face validity of the survey instrument were examined by using the principle component analysis and the confirmatory factor analysis technique and experts reviews. In order to test construct validity, the preliminary investigation of the number of factors included 21 items on 
the training design process and the eight items on working with SMEs, to be used in this study to obtain the empirical data from the Taiwan sample.

The method of principle component analysis (PCA) was employed to extract and interpret the factors for the purpose of reducing the measured variables into a smaller set of combined components that captured as many variations as possible among the measured variables with a small number of components (Yang, 2005). This method was undertaken for the responses for the perceived current/desired ability of HRD professionals in the stages of the training design process. The number of factors to be extracted and rotated was determined using an eigenvalue equal to or greater than 1.0 and factor loading equal to or greater than .50 was set as rigorous criteria for the loadings of a variable to be included in description of a factor (Afifi et al., 2004).

In this study, the result of the extraction of factors, eigenvalues, and the percentage of variance explained in the analysis of the 21 items regarding the current ability of HRD professionals is presented in Table 3.4. The rotated factors of the current ability of HRD professionals can explain $73.230 \%$ of the variance in the analysis stages, $75.967 \%$ of the variance in the design and development stage, $78.473 \%$ of the variance in the implementation stage, and $78.473 \%$ of the variance in the evaluation stage.

Similarly, the result of the extraction of factors, eigenvalues, and the percentage of variance explained in the analysis of the 21 items regarding the desired ability of HRD professionals is presented in Table 3.5. The rotated factors of the desired ability of HRD professionals can explain $76.905 \%$ of the variance in the analysis stages, $76.395 \%$ of the variance in the design and development stage, $81.181 \%$ of the 
variance in the implementation stage, and $81.086 \%$ of the variance in the evaluation stage. Table 3.6 shows the results of factor loadings on the perceived current/desired ability of HRD professionals in the stages of the training design process. 


\begin{tabular}{|c|c|c|c|c|c|c|}
\hline Component & \multicolumn{3}{|c|}{ Initial Eigenvalues } & \multicolumn{3}{|c|}{ Extraction Sums of Squared Loadings } \\
\hline & Total & $\begin{array}{c}\text { \% of } \\
\text { Variance }\end{array}$ & $\begin{array}{c}\text { Cumulative } \\
\%\end{array}$ & Total & $\begin{array}{c}\% \text { of } \\
\text { Variance }\end{array}$ & Cumulative \% \\
\hline 1 & 4.394 & 73.230 & 73.230 & 4.394 & 73.230 & 73.230 \\
\hline 2 & 467 & 7.776 & 81.006 & & & \\
\hline 3 & .369 & 6.144 & 87.150 & & & \\
\hline 4 & 298 & 4.970 & 92.120 & & & \\
\hline 5 & 265 & 4.412 & 96.532 & & & \\
\hline 6 & 208 & 3.468 & 100.000 & & & \\
\hline
\end{tabular}

Total variance explained in the analysis stage

\begin{tabular}{lrrrrrr}
\hline Component & \multicolumn{3}{c}{ Initial Eigenvalues } & \multicolumn{3}{c}{ Extraction Sums of Squared Loadings } \\
\hline & \multicolumn{3}{c}{ \%of of } & Cumulative & \multicolumn{1}{c}{$\%$ of } \\
& Variance & $\%$ & Total & Variance & Cumulative \% \\
\hline 7 & 6.077 & 75.967 & 75.967 & 6.077 & 75.967 & 75.967 \\
8 & .525 & 6.569 & 82.536 & & & \\
9 & .398 & 4.971 & 87.507 & & & \\
10 & .261 & 3.261 & 90.768 & & & \\
11 & .231 & 2.889 & 93.657 & & & \\
12 & .191 & 2.394 & 96.051 & & & \\
13 & .191 & 2.382 & 98.433 & & & \\
14 & .125 & 1.567 & 100.000 & & \\
\hline
\end{tabular}

Total variance explained in the design \& development stage

\begin{tabular}{lrrrrrr}
\hline Component & \multicolumn{3}{c}{ Initial Eigenvalues } & \multicolumn{3}{c}{ Extraction Sums of Squared Loadings } \\
\hline & \multicolumn{3}{c}{$\%$ of } & Cumulative & \multicolumn{3}{c}{$\%$ of } \\
& \multicolumn{1}{c}{ Total } & Variance & \multicolumn{1}{c}{$\%$} & \multicolumn{1}{c}{ Total } & Variance & Cumulative \% \\
\hline 15 & 2.354 & 78.473 & 78.473 & 2.354 & 78.473 & 78.473 \\
16 & .362 & 12.082 & 90.555 & & & \\
17 & .283 & 9.445 & 100.000 & & & \\
\hline
\end{tabular}

Total variance explained in the implementation stage

\begin{tabular}{|c|c|c|c|c|c|c|}
\hline \multirow[t]{2}{*}{ Component } & \multicolumn{3}{|c|}{ Initial Eigenvalues } & \multicolumn{3}{|c|}{ Extraction Sums of Squared Loadings } \\
\hline & Total & $\begin{array}{c}\% \text { of } \\
\text { Variance }\end{array}$ & $\begin{array}{c}\text { Cumulative } \\
\%\end{array}$ & Total & $\begin{array}{c}\% \text { of } \\
\text { Variance }\end{array}$ & Cumulative \% \\
\hline 18 & 2.860 & 71.489 & 71.489 & 2.860 & 71.489 & 71.489 \\
\hline 19 & .593 & 14.826 & 86.315 & & & \\
\hline 20 & .322 & 8.040 & 94.355 & & & \\
\hline 21 & 226 & 5.645 & 100.000 & & & \\
\hline
\end{tabular}

Total Variance explained in the evaluation stage

Table 3.4: Total variance explaining the rotated factors of the current ability of HRD professionals in the stages of the training design process 


\begin{tabular}{lrrrrrr}
\hline Component & \multicolumn{3}{c}{ Initial Eigenvalues } & \multicolumn{3}{c}{ Extraction Sums of Squared Loadings } \\
\hline & \multicolumn{3}{c}{$\begin{array}{c}\text { \% of } \\
\text { Total }\end{array}$} & $\begin{array}{c}\text { Cumulative } \\
\text { Variance }\end{array}$ & \multicolumn{1}{c}{$\%$} & \multicolumn{1}{c}{ Total of } \\
Variance & Cumulative \% \\
\hline 1 & 4.614 & 76.905 & 76.905 & 4.614 & 76.905 & 76.905 \\
2 & .418 & 6.964 & 83.869 & & & \\
3 & .346 & 5.762 & 89.631 & & & \\
4 & .252 & 4.207 & 93.838 & & & \\
5 & .210 & 3.493 & 97.331 & & & \\
6 & .160 & 2.669 & 100.000 & & & \\
\hline
\end{tabular}

Total variance explained in the analysis stage

\begin{tabular}{|c|c|c|c|c|c|c|}
\hline Component & \multicolumn{3}{|c|}{ Initial Eigenvalues } & \multicolumn{3}{|c|}{ Extraction Sums of Squared Loadings } \\
\hline & Total & $\begin{array}{c}\% \text { of } \\
\text { Variance }\end{array}$ & $\begin{array}{c}\text { Cumulative } \\
\%\end{array}$ & Total & $\begin{array}{c}\text { \% of } \\
\text { Variance }\end{array}$ & Cumulative \% \\
\hline 7 & 6.112 & 76.395 & 76.395 & 6.112 & 76.395 & 76.395 \\
\hline 8 & .502 & 6.275 & 82.670 & & & \\
\hline 9 & .341 & 4.269 & 86.939 & & & \\
\hline 10 & .302 & 3.769 & 90.708 & & & \\
\hline 11 & 251 & 3.132 & 93.840 & & & \\
\hline 12 & 204 & 2.550 & 96.390 & & & \\
\hline 13 & 179 & 2.243 & 98.633 & & & \\
\hline 14 & .109 & 1.367 & 100.000 & & & \\
\hline
\end{tabular}

Total variance explained in the design \& development stage

\begin{tabular}{lrrrrrr}
\hline Component & \multicolumn{3}{c}{ Initial Eigenvalues } & \multicolumn{3}{c}{ Extraction Sums of Squared Loadings } \\
\hline & \multicolumn{3}{c}{ \% of } & Cumulative & \multicolumn{1}{c}{$\%$ of } \\
& Total & Variance & $\%$ & Total & Variance & Cumulative \% \\
\hline 15 & 2.435 & 81.181 & 81.181 & 2.435 & 81.181 & 81.181 \\
16 & .327 & 10.911 & 92.092 & & & \\
17 & .237 & 7.908 & 100.000 & & & \\
\hline
\end{tabular}

Total Variance explained in the implementation stage

\begin{tabular}{|c|c|c|c|c|c|c|}
\hline Component & & itial Eigen & alues & Extractio & a Sums of & quared Loadings \\
\hline & Total & $\begin{array}{c}\% \text { of } \\
\text { Variance }\end{array}$ & $\begin{array}{c}\text { Cumulative } \\
\%\end{array}$ & Total & $\begin{array}{c}\% \text { of } \\
\text { Variance }\end{array}$ & Cumulative \% \\
\hline 18 & 3.243 & 81.086 & 81.086 & 3.243 & 81.086 & 81.086 \\
\hline 19 & .411 & 10.280 & 91.366 & & & \\
\hline 20 & .186 & 4.640 & 96.005 & & & \\
\hline 21 & .160 & 3.995 & 100.000 & & & \\
\hline
\end{tabular}

Total variance explained in the evaluation stage

Table 3.5: Total variance explaining the rotated factors of the desired ability of HRD professionals in the stages of the training design process 


\begin{tabular}{|c|c|c|}
\hline & $\begin{array}{l}\text { Current } \\
\text { ability }\end{array}$ & $\begin{array}{l}\text { Desired } \\
\text { ability }\end{array}$ \\
\hline \multicolumn{3}{|l|}{ ANALYSIS } \\
\hline $\begin{array}{l}\text { 1. Assess the needs of trainees to determine what they can } \\
\text { currently do and what they should be able to do }\end{array}$ & .849 & .873 \\
\hline 2. Analyze the components of jobs, duties, and tasks & .841 & .876 \\
\hline $\begin{array}{l}\text { 3. Identify the characteristics of trainees that influence } \\
\text { their ability to achieve the training objectives }\end{array}$ & .856 & .912 \\
\hline $\begin{array}{l}\text { 4. Analyze the work setting to identify the tools, } \\
\text { equipment, and other resources used on the job }\end{array}$ & .867 & .875 \\
\hline $\begin{array}{l}\text { 5. Analyze the organization to ensure that the goals are } \\
\text { consistent with the objectives of the training program }\end{array}$ & .864 & .894 \\
\hline $\begin{array}{l}\text { 6. Review additional resources related to the content of the } \\
\text { training program }\end{array}$ & .858 & .829 \\
\hline \multicolumn{3}{|l|}{ DESIGN \& DEVELOPMENT } \\
\hline $\begin{array}{l}\text { 7. Specify the target objective that describes what is } \\
\text { expected of trainees after the training }\end{array}$ & .862 & .905 \\
\hline $\begin{array}{l}\text { 8. Specify the enabling objectives that describe what } \\
\text { trainees should know or do to achieve the target } \\
\text { objectives }\end{array}$ & .899 & .894 \\
\hline $\begin{array}{l}\text { 9. Develop performance rating scales and cognitive test } \\
\text { items to measure the trainees' learning outcomes }\end{array}$ & .831 & .898 \\
\hline $\begin{array}{l}\text { 10. Develop training materials that are consistent with the } \\
\text { training objectives }\end{array}$ & .858 & .889 \\
\hline $\begin{array}{l}\text { 11. Identify training strategies, methods, and approaches to } \\
\text { present the training content }\end{array}$ & .909 & .847 \\
\hline 12. Design lessons based on a logical learning sequence & .897 & .871 \\
\hline $\begin{array}{l}\text { 13. Use a structured writing format to prepare trainer and } \\
\text { trainee guides }\end{array}$ & .886 & .870 \\
\hline $\begin{array}{l}\text { 14. Select appropriate technology as a means to deliver } \\
\text { training }\end{array}$ & .827 & .815 \\
\hline \multicolumn{3}{|l|}{ IMPLEMENTATION } \\
\hline $\begin{array}{l}\text { 15. Develop an implementation plan to conduct the } \\
\text { training program }\end{array}$ & .879 & .917 \\
\hline 16. Ensure the organization to support the training program & .903 & .885 \\
\hline 17. Record the progress of trainees during the training & .876 & .901 \\
\hline \multicolumn{3}{|l|}{ EVALUATION } \\
\hline $\begin{array}{l}\text { 18. Evaluate the trainees' overall satisfaction with the } \\
\text { training program }\end{array}$ & .841 & .900 \\
\hline $\begin{array}{l}\text { 19. Determine what trainees have learned from the training } \\
\text { program }\end{array}$ & .908 & .934 \\
\hline $\begin{array}{l}\text { 20. Report the results of the training program to } \\
\text { management }\end{array}$ & .873 & .929 \\
\hline 21. Determine the financial benefits of the training program & .753 & .837 \\
\hline
\end{tabular}

Table 3.6: Factor loading on the twenty-one items of the current/desired ability of HRD professionals 
In addition, the main applications of the confirmatory factor analysis techniques were used to confirm a predetermined factor structure based on theory or previous research (Yang, 2005). The result of the extraction of factors, eigenvalues, and the percentage of variance explained in the analysis of the eight items regarding the ability to work with SMEs in this study is presented in Table 3.7. The initial eigenvalue of Factor one (6.260) was loaded onto one factor which had an eigenvalue greater than 1. This factor accounted for $75.219 \%$ of the total variance, and the loading factors were equal to or greater than .50 . Thus, it was confirmed that the eight items represent the dimension called "the ability to work with SMEs", as shown in Table 3.8.

\begin{tabular}{|c|c|c|c|c|c|c|}
\hline Factor & \multicolumn{3}{|c|}{ Initial Eigenvalues } & \multicolumn{3}{|c|}{ Extraction Sums of Squared Loadings } \\
\hline & Total & $\begin{array}{c}\% \text { of } \\
\text { Variance }\end{array}$ & Cumulative & Total & $\begin{array}{c}\% \text { of } \\
\text { Variance }\end{array}$ & Cumulative \\
\hline 1 & 6.260 & 78.254 & 78.254 & 6.018 & 75.219 & 75.219 \\
\hline 2 & .492 & 6.146 & 84.400 & & & \\
\hline 3 & .395 & 4.938 & 89.338 & & & \\
\hline 4 & .232 & 2.894 & 92.232 & & & \\
\hline 5 & .216 & 2.698 & 94.930 & & & \\
\hline 6 & .193 & 2.409 & 97.339 & & & \\
\hline 7 & .146 & 1.823 & 99.162 & & & \\
\hline 8 & .067 & .838 & 100.000 & & & \\
\hline
\end{tabular}

Extraction Method: Maximum Likelihood.

Table 3.7: Total variance explaining the rotated factors of the ability of HRD professionals in working with SMEs 


\begin{tabular}{clc}
\hline $\begin{array}{c}\text { Item } \\
\text { Numbers }\end{array}$ & \multicolumn{1}{c}{ Items for "ability to work with SMEs" (8 items) } & $\begin{array}{c}\text { Factor } \\
\text { Loading }\end{array}$ \\
\hline 1 & $\begin{array}{l}\text { Clarify the role and tasks expected of the SME during the } \\
\text { training project }\end{array}$ & .828 \\
2 & $\begin{array}{l}\text { Obtain a commitment from the SME to be involved in the } \\
\text { training project }\end{array}$ & .905 \\
3 & $\begin{array}{l}\text { Prepare an agenda for each meeting with the SME } \\
4\end{array}$ & $\begin{array}{l}\text { Provide examples to ensure the SME understands how the } \\
\text { training will be carried out }\end{array}$ \\
5 & $\begin{array}{l}\text { Ensure that the SME understands the target objective of the } \\
\text { training program }\end{array}$ & .851 \\
6 & $\begin{array}{l}\text { Use open-ended questions to prompt the SME to provide more } \\
\text { detailed information }\end{array}$ & .808 \\
7 & $\begin{array}{l}\text { Ask the SME to review the training program to identify } \\
\text { weaknesses or missing components }\end{array}$ & .876 \\
8 & $\begin{array}{l}\text { Renegotiate with the SME regarding the design of the training } \\
\text { program }\end{array}$ & .919 \\
\hline
\end{tabular}

Table 3.8: Item loadings for the dimension of "ability to work with SMEs"

Content validity refers to judgment of the degree to which items or questions on a test adequately represent an intended content area (Johnson \& Christensen, 2000). To test the survey instrument for internal content validity, the instrument was adapted partly from Instructional Design Competencies: The Standards (IBSTPI, 1988) for the the current/desired ability in the training design process and partly from Block's (1981) model of Flawless Consulting and IBSTPI (1988) for the part on the ability to work with SMEs. In addition, a panel of five experts examined the instrument. The panel consisted of three professors at The Ohio State University, the president of Dawn Snyder Associates in the U.S.A., and one professor at National Chung-Hsing University in Taiwan. Their comments on content were used to eliminate, add, and modify elements of the survey instrument. 
Face validity refers to the degree to which a test appears to measure what it purports to measure (Gay \& Airasian, 2003). Another panel of experts was asked to judge how well the items represented the intended content area and to scrutinize the clarity of the items' meanings. This panel consisted of eight graduate students at The Ohio State University. Four American graduate students examined the original English version, and four Chinese graduate students examined the Chinese version.

The term reliability, as used in research, refers to the internal consistency of the scores and answers provided by an instrument (Ary, Jacobs, \& Razavieh, 2001). The reliability coefficient is an index that indicates the degree of statistical consistency. The internal-consistency method of estimating reliability involves comparing responses to different sets of items that are part of an instrument (Fraenkel \& Wallen, 2000).

To insure the reliability of the instruments, a pilot study can be implemented. With completion of the translation into the Chinese version, the survey instrument was ready for pilot study distribution. The revised survey in the Chinese version was pilottested by 35 Ohio State University graduate students who could speak and write Chinese. They were all required to fill out the consent form shown on the first page of the web-based survey as the admission to the participation. The hyperlink of the pilot web-based survey was sent to them via email on November 15 and they were asked to return the survey by November 25,2005 . The purpose was to identify confusing items, to provide suggestions for improving the format and wording, and to evaluate the overall appearance of the instrument. The answers from the pilot test participants have not been included in the data. 
To test the instrument for internal consistency, the survey instrument was also assessed by Cronbach's alpha analysis using data from the actual study. The test determines reliability by estimating internal consistency. The internal consistence reliability (Cronbach's alpha) coefficients were calculated for each scale. According to McMillan and Schumacher (1997), a coefficient of .90 indicates a highly reliable instrument, but "coefficients ranging from .70 to .90 are acceptable for most instruments" (p.240). The data were further analyzed using SPSS software (version 13.0) to calculate the Cronbach's alpha coefficient for the Likert-type domains. Table 3.9 shows the Cronbach's alpha coefficient for the survey responses.

\begin{tabular}{|c|c|c|c|}
\hline Variables & & $\begin{array}{c}\text { Numbers of } \\
\text { Items }\end{array}$ & $\begin{array}{l}\text { Cronbach's } \\
\text { alpha }\end{array}$ \\
\hline $\begin{array}{l}\text { The current ability of } \\
\text { HRD professionals in } \\
\text { the stages of the training } \\
\text { design process }\end{array}$ & $\begin{array}{l}\text { Total } \\
\text { Analysis } \\
\text { Design \& Development } \\
\text { Implementation } \\
\text { Evaluation }\end{array}$ & $\begin{array}{c}21 \\
6 \\
8 \\
3 \\
4\end{array}$ & $\begin{array}{l}.976 \\
.927 \\
.954 \\
.863 \\
.865\end{array}$ \\
\hline $\begin{array}{l}\text { The desired ability of } \\
\text { HRD professionals in } \\
\text { the stages of the training } \\
\text { design process }\end{array}$ & $\begin{array}{l}\text { Total } \\
\text { Analysis } \\
\text { Design \& Development } \\
\text { Implementation } \\
\text { Evaluation }\end{array}$ & $\begin{array}{c}21 \\
6 \\
8 \\
3 \\
4\end{array}$ & $\begin{array}{l}.979 \\
.939 \\
.956 \\
.883 \\
.921\end{array}$ \\
\hline $\begin{array}{l}\text { The ability of HRD } \\
\text { professionals in working } \\
\text { with SMEs }\end{array}$ & Total & 8 & .957 \\
\hline
\end{tabular}

Table 3.9: Cronbach's alpha coefficient for survey responses 


\section{Translation of Instrument to Chinese}

The English version of the initial survey was prepared by the author. The study was translated into Chinese by a Ph.D. student from Taiwan. To validate the initial translation, the Chinese version was translated back to English by a Ph.D. student majoring in Workforce Development and Education at The Ohio State University. This was important to ensure that the words matched the meaning with minimal error between the initial English version and the translated-back English version.

\section{Research Procedures}

The data for this study was collected by a web-based survey. The data were analyzed to address the five research questions.

\section{$\underline{\text { Data Collection }}$}

In order to protect participants, this research was approved by the Human Subject Review Committee at The Ohio State University in November 2005. The webbased survey including a consent form for participation was a five-page survey headed by OSU logo. A letter of invitation with the hyperlink of the anonymous web-based survey was sent out by email to participants in the high-tech companies located in Hsin-chu Science Park, Hsin-chu, Taiwan on Dec 1, 2005. Chinese language was used for the survey and the invitation letter. The invitation letter stated the researcher, the topic of the survey, the length of the survey, the confidentiality, and the deadline for response to the survey. The method of recruiting was either to send the recuitment 
letter by email or to make a phone call to HR departments. The email addresses of HR departments were obtained by searching the company websites or the directory published by the HSP Association. In making phone calls, the researcher contacted the operator first and asked to be transferred to the training design representative in the HR department. The purpose of the recruitment via email or phone calls was to explain the purpose of this study, to obtain contact information, to address the confidential and anonymous manner in which this survey would be conducted, and to inform those willing to participate that the survey would be sent out one month later. When the web-based surveys were sent out, the researcher made phone calls and sent emails to encourage the participants to respond. On December 15, 2005, a reminder was sent via e-mail to all of the participants.

\section{$\underline{\text { Data Analysis }}$}

The SPSS program was used as a data analysis tool as it is one of the most commonly used social science analysis computer programs (Gall, Borg, \& Gall, 1996). First, the demographic characteristics of respondents were analyzed by generating descriptive statistics such as frequency and percentage. This study used an alpha level of .05 in data analysis. The statistical method used to analyze the data can be explained according to the proposed research questions as follows: 
Research Question \#1: Is there a difference between the current/desired ability in the stages of the training design process among HRD professionals?

Research Question \#2: Is there a difference between the current/desired ability in the stages of the training design process among HRD professionals who have and who have not worked with SMEs?

In order to answer research questions \#1 and \#2, a paired t-test was used to examine whether there was a statistical difference between the two independent variables, the current ability and desired ability in the stages of the training design process, and Pearson product-moment correlation was used to determine whether a relationship existed between the two independent variables. The four stages of the training design process were analysis, design and development, implementation, and evaluation. $r$ indicated the strength of the linear relationship between two variables. Table 3.10 shows the interpretation of the correlation coefficient reported according to Bartz (1999).

\begin{tabular}{cc}
\hline Range of Pearson's $r$ & Description \\
\hline .80 or higher & Very high \\
.60 to .80 & Strong \\
.40 to .60 & Moderate \\
.20 to .40 & Low \\
.20 or lower & Very low \\
\hline
\end{tabular}

Table 3.10: Interpretation of the correlation coefficient 
Research Question \#3: What is the relationship between their demographic

characteristics and the current/desired ability in the training design process among HRD professionals who have and who have not worked with SMEs?

Research Question \#4: Among HRD professionals who have worked with SMEs, what is the relationship between their demographic characteristics and the ability to work with SMEs?

In order to respond to research question \#3, a one-way ANOVA test was conducted to determine the differences in two independent variables, (a) current ability in the training design process and (b) desired ability in the training design process, in terms of the five demographic characteristics, a) organization size, b) education level, c) years of work experience, d) years of work experience in HR related jobs, and e) experience in designing training programs. The Chi-square test was used to measure the differences between two groups, HRD professionals who had and who had not worked with SMEs, in terms of their demographic characteristics.

In order to respond to research question \#4, one-way ANOVA test was conducted to determine the differences in the dependent variable, the ability of HRD professionals to work with SMEs, in terms of the five demographic characteristics and The $\mathrm{F}$ value was calculated to determine the difference. 
Research Questions \#5: Among HRD professionals who have worked with SMEs, is there a relationship between the ability to work with SMEs and current ability in the stages of the training design process?

The data analysis method in this question was Pearson product-moment correlation and simple linear regression analysis techniques used to examine the relationships among the independent and dependent variables.

$\mathrm{r}$ indicated the strength of the linear relationship between the two variables. If the relationship was sufficiently strong, regression analysis was applied to determine the impact the independent variable (the current ability in the stages of the training design process) had on the corresponding dependent variable (the ability of HRD professionals in working with SMEs) and to estimate how one variable could explain the other variable. The simple linear regression model was as follows:

$$
y=a+b x+e
$$

where $y$ was the variable to be predicted, $a$ was the regression constant, $b$ was the regression coefficient which could determine the sop of the regression line, $x$ was the predictor variable, and $e$ was random error. 


\section{CHAPTER 4}

\section{RESULTS}

This chapter describes the results of the study. The first section presents the demographic characteristics of the respondents. The second section presents the results of the five research questions.

\section{Demographic Characteristics}

The research data was obtained from human resource development (HRD) professionals who were working in high-tech companies located in Hsin-chu Science Park in Taiwan. The original frame included 175 HRD professionals. However, two invitation letters sent via email failed to reach the participants because they had left their jobs. Thus, the total number in the sample frame was 173. One hundred forty-six out of 173 respondents completed the online survey, resulting in an overall response rate of $84.39 \%$ in this study. Prior to determining whether the 146 surveys were usable, the researcher excluded 15 respondents based on two situations: those who did not agree to participate in this online survey and one of those who responded with identical demographic information, indicating response duplication.

All 146 respondents provided complete demographic characteristics, including organization size, education level, sources of professional development, years of 
work experience, years of work experience in human resources (HR) related jobs, and experience in designing training programs. One hundred twenty-six respondents responded by indicating whether or not they had experience in working with SMEs.

Table 4.1 shows descriptive statistics related to the organization information. In terms of the number of employees in the organization, 39 respondents (26.7\%) worked in a company with less than 200 employees, 32 respondents (21.9\%) worked with 5001000 employees, and 25 respondents (17.1\%) worked with over 5,000 employees.

As presented in Table 4.2, the results of the respondent's highest level of formal education were that 60 respondents $(41.1 \%)$ had obtained master's degrees and 67 respondents $(45.9 \%)$ had bachelor's degrees. In terms of the sources of their professional development, although all of the choices included in the item could be applicable to the respondents, the percentage did not add to $100 \%$. Therefore, approximately 60 percent of the respondents usually learned about designing training programs in two ways: self-directed informal learning and formal professional development programs outside their organization. Forty-five percent of the respondents obtained training in formal professional development programs inside their organization. Ten percent responded that they had no learning experience or "others". Those who reported "others" specified involvement in actual cases and education-related courses taken in an undergraduate program.

Table 4.3 shows that 27.4 percent of the respondents had six to ten years of work experience and 26 percent of them had less than five years of work experience. Taken together, 53.4 percent of the respondents had no more than ten years of work experience. That is to say, 46.6 percent of them had more than ten years of work 
experience. Additionally, the number of years of work experience in HR related jobs was also requested. The respondents reported that approximately 44.5 percent of the respondents had less than five years of work experience in HR related jobs and 36.3 percent of the respondents had six to ten years. Taken together, 80.8 percent of the respondents had no more than ten years of work experience in HR related jobs. That is to say, 19.2 percent of them had more than ten years of work experience in HR related jobs.

Forty-eight of the respondents (32.9\%) had no experience in designing training programs, and ninety-eight of the 146 respondents (67.1\%) had experience in designing training programs. Only the 98 respondents who had experience in designing training programs were able to complete the percentage of their job that consisted of designing training programs. According to the responses received, for 47 of the 97 respondents (48\%), less than $25 \%$ of their jobs consisted of designing training programs and, for 27 of them (27.8\%), this responsibility comprised $26-50 \%$ of their jobs.

A total of 126 respondents reported either that they had experience or had no experience in working with SMEs. Sixty-five of the 126 responded that they did not have experience working with SMEs (44.5\%), and 61 of the 126 HRD professionals reported that they did (41.8\%). Only the 61 respondents who had experience in working with SMEs were able to complete the item asking for the percentage of their time typically spent collaborating with SMEs and, in the third part of the survey, the item regarding their ability to work with SMEs. Thirty-five percent of the respondents spent less than $25 \%$ of their time in working with SMEs, 26.7 percent of the 
respondents spent $26-50 \%$ of their time working with SMEs, and twenty-five percent of them spent $51-75 \%$ of their time working with SMEs.

\begin{tabular}{llll}
\hline & & $\mathrm{N}$ & $\%$ \\
\hline $\begin{array}{l}\text { The number of employees } \\
\text { in the organization }(\mathrm{N}=146)\end{array}$ & & & \\
& Less than 200 & 39 & 26.7 \\
& $200-500$ & 16 & 11.0 \\
& $500-1000$ & 32 & 21.9 \\
& $1000-2000$ & 17 & 11.6 \\
& $2000-5000$ & 17 & 11.6 \\
& Over 5000 & 25 & 17.1 \\
\hline
\end{tabular}

Table 4.1: Frequency and percentage of organization information

\begin{tabular}{|c|c|c|c|}
\hline & & $\mathrm{N}$ & $\%$ \\
\hline \multicolumn{4}{|l|}{ Education Level $(\mathrm{N}=146)$} \\
\hline & Doctoral & 3 & 2.1 \\
\hline & Master & 60 & 41.1 \\
\hline & Bachelor & 67 & 45.9 \\
\hline & Associate & 14 & 9.6 \\
\hline & High school & 2 & 1.4 \\
\hline \multirow{4}{*}{$\begin{array}{l}\text { Sources of Professional } \\
\text { Development }(\mathrm{N}=146)\end{array}$} & & & \\
\hline & $\begin{array}{l}\text { - Self-directed informal } \\
\text { learning }\end{array}$ & 89 & 61.0 \\
\hline & $\begin{array}{l}\text { - Formal professional } \\
\text { development program } \\
\text { outside your organization }\end{array}$ & 90 & 61.6 \\
\hline & $\begin{array}{l}\text { - Formal professional } \\
\text { development program } \\
\text { inside your organization }\end{array}$ & 66 & 45.2 \\
\hline \multirow{3}{*}{$\begin{array}{l}\text { - Multiple answers in this } \\
\text { question allowed } \\
\text { - Do not add to } 100 \%\end{array}$} & $\begin{array}{l}\text { - Learned as part of an } \\
\text { academic degree program }\end{array}$ & 35 & 24.0 \\
\hline & - Others & 10 & 6.8 \\
\hline & - None & 10 & 6.8 \\
\hline
\end{tabular}

Table 4.2: Frequency and percentage of demographic characteristics 


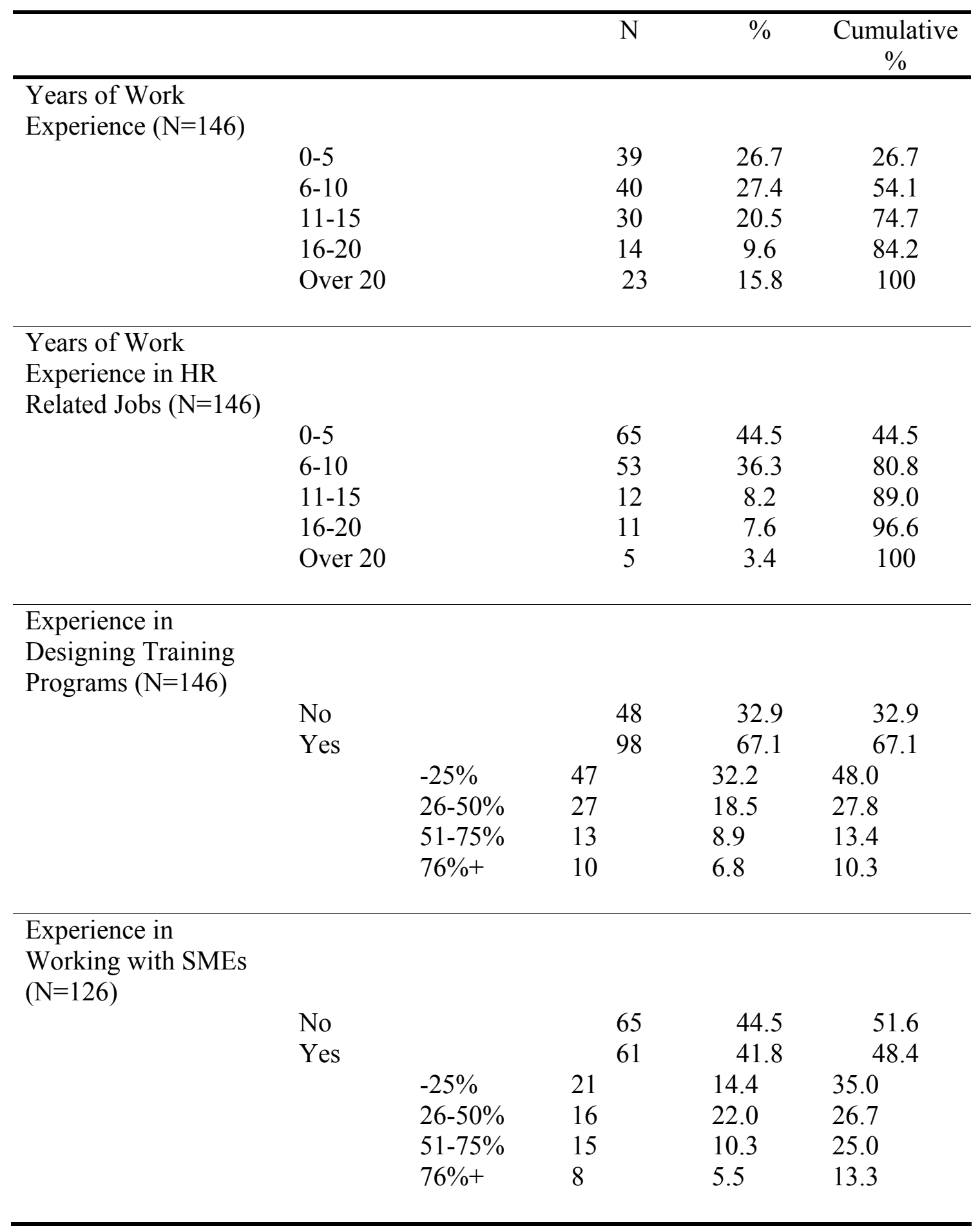

Table 4.3: Frequency, percentage, and cumulative percent of demographic characteristics 


\section{Descriptive Statistics}

This section provides the descriptive statistics for the variables used in this study. Twenty-nine items were used to measure two independent variables and one dependent variable. Each item was scaled on a seven-point Likert-type scale. The descriptive statistics, including the numbers of respondents, means, standard deviation, and mean difference were calculated, as shown in Tables 4.4 and 4.5.

As presented in Table 4.4, the results showed that 129 respondents indicated that, overall, they currently had a slightly positive ability to perform in the training design process (Mean=4.44, $\mathrm{SD}=1.078)$. Moreover, 127 respondents indicated that, overall, they desired to have a slightly stronger ability in the training design process (Mean=5.62, $\mathrm{SD}=1.088$ ). Lastly, the mean of the desired ability of HRD professionals was higher than the mean of their current ability in the training design process (mean difference $=+1.18$ ). In particular, the mean differences between the current and desired ability in both the analysis stage (mean difference $=+1.36)$ and the design and development stage (mean difference $=+1.34$ ) were slightly higher than the mean differences in the other two stages, implementation (mean difference $=+1.16)$ and evaluation (mean difference $=+1.16)$.

\begin{tabular}{lcccccccc}
\hline & \multicolumn{7}{c}{ HRD professionals } \\
Stages & \multicolumn{1}{c}{ Current Ability (C) } & \multicolumn{2}{c}{ Desired Ability (D) } & (D-C) \\
\cline { 2 - 7 } & $\mathrm{N}$ & $\mathrm{M}$ & $\mathrm{SD}$ & $\mathrm{N}$ & $\mathrm{M}$ & $\mathrm{SD}$ & $\begin{array}{c}\text { Mean } \\
\text { Difference }\end{array}$ \\
\hline Total & 129 & 4.44 & 1.078 & 127 & 5.62 & 1.088 & +1.18 \\
Analysis & 126 & 4.41 & 1.054 & 124 & 5.77 & 1.471 & +1.36 \\
Design \& development & 124 & 4.26 & 1.176 & 125 & 5.60 & 1.095 & +1.34 \\
Implementation & 123 & 4.52 & 1.271 & 123 & 5.68 & 1.141 & +1.16 \\
Evaluation & 124 & 4.49 & 1.120 & 124 & 5.65 & 1.106 & +1.16 \\
\hline
\end{tabular}

Table 4.4: Descriptive statistics for independent variables (current/desired ability) 
As presented in Table 4.5, the results showed that the 61 respondents who had worked with SMEs indicated that, overall, they currently had a slightly higher ability to perform in the stages of the training design process (Mean=4.73, $\mathrm{SD}=1.074)$. Additionally, 60 respondents indicated that, overall, they had a relatively stronger desire for an improved ability to perform in the stages of the training design process (Mean=5.80, $\mathrm{SD}=1.079)$. Lastly, the mean of their desired ability was higher than that of their current ability in the stages of the training design process among HRD professionals who had worked with SMEs (mean difference $=+1.07$ ). In particular, the mean differences between the current and desired ability in both the analysis stage (mean difference $=+1.18)$ and the design and development stage (mean difference $=$ $+1.17)$ were slightly higher than the mean differences in the other two stages, implementation $($ mean difference $=+.99)$ and evaluation $($ mean difference $=+1.08)$.

On the other hand, 65 HRD professionals who had not worked with SMEs indicated that, overall, they currently had a slightly higher ability to perform in the stages of the training design process (Mean=4.14, $\mathrm{SD}=.998)$. Moreover, 65 respondents indicated that, overall, they desired to have a somewhat higher ability to perform in the stages of the training design process (Mean=5.46, $\mathrm{SD}=1.062$ ). Lastly, the mean difference showed that their desired ability was higher than their current ability in the stages of the training design process among HRD professionals who had not worked with SMEs (mean difference $=+1.32$ ). In particular, the mean differences between the current and desired ability in both the analysis stage (mean difference= $+1.56)$ and the design and development stage (mean difference $=+1.51$ ) were slightly 
higher than the mean difference in the other two stages, implementation (mean difference $=+1.32$ ) and evaluation (mean difference $=+1.25)$. 


\begin{tabular}{|c|c|c|c|c|c|c|c|c|c|c|c|c|c|c|}
\hline \multirow[b]{3}{*}{ Stages } & \multicolumn{7}{|c|}{$\begin{array}{l}\text { HRD professionals with experience in working with } \\
\text { SMEs }\end{array}$} & \multicolumn{7}{|c|}{$\begin{array}{l}\text { HRD professionals with no experience in working with } \\
\text { SMEs }\end{array}$} \\
\hline & \multicolumn{3}{|c|}{ Current Ability (C) } & \multicolumn{3}{|c|}{ Desired Ability (D) } & \multirow{2}{*}{$\begin{array}{c}\text { (D-C) } \\
\text { Mean } \\
\text { Difference }\end{array}$} & \multicolumn{3}{|c|}{ Current Ability (C) } & \multicolumn{3}{|c|}{$\underline{\text { Desired Ability (D) }}$} & \multirow{2}{*}{$\begin{array}{c}\text { (D-C) } \\
\text { Mean } \\
\text { Difference }\end{array}$} \\
\hline & $\mathrm{n}$ & M & $\mathrm{SD}$ & $\mathrm{n}$ & M & $\mathrm{SD}$ & & $\mathrm{n}$ & $\mathrm{M}$ & SD & $\mathrm{n}$ & $\mathrm{M}$ & $\mathrm{SD}$ & \\
\hline Total & 61 & 4.73 & 1.074 & 60 & 5.80 & 1.079 & +1.07 & 65 & 4.14 & .998 & 65 & 5.46 & 1.062 & +1.32 \\
\hline Analysis & 59 & 4.63 & 1.043 & 60 & 5.81 & 1.082 & +1.18 & 64 & 4.17 & 1.019 & 62 & 5.73 & 1.785 & +1.56 \\
\hline $\begin{array}{l}\text { Design \& } \\
\text { Development }\end{array}$ & 59 & 4.55 & 1.135 & 60 & 5.72 & 1.172 & +1.17 & 63 & 3.95 & 1.136 & 64 & 5.46 & 1.008 & +1.51 \\
\hline Implementation & 59 & 4.84 & 1.299 & 60 & 5.83 & 1.167 & +.99 & 62 & 4.19 & 1.167 & 62 & 5.51 & 1.099 & +1.32 \\
\hline Evaluation & 60 & 4.67 & 1.104 & 60 & 5.75 & 1.223 & +1.08 & 62 & 4.29 & 1.078 & 63 & 5.54 & .981 & +1.25 \\
\hline
\end{tabular}

Table 4.5: Descriptive statistics for independent variables (current/desired ability) based on two groups: HRD professionals who had and those who had not worked with SMEs 
As presented in Table 4.6, the results showed that 56 HRD professionals who had worked with SMEs indicated that they had a somewhat high ability to work with SMEs (Mean=4.90, $\mathrm{SD}=1.433$ ). The mean difference showed that, overall, their ability to work with SMEs was not much higher than their current ability in the training design process (mean difference $=+.17$ ). In particular, there was not a mean difference between their ability to work with SMEs and their current ability in the analysis stage (mean difference $=+.27)$, the design and development stage (mean difference $=+.35$ ), the implementation stage (mean difference $=+.06$ ) and the evaluation stage (mean difference $=+.23)$.

HRD professionals with experience in working with SMEs Current Ability (C) Ability to work $\quad$ (W- C) with SMEs $(\mathrm{W})$

\begin{tabular}{lccccccc} 
Stages & $\mathrm{n}$ & $\mathrm{M}$ & $\mathrm{SD}$ & $\mathrm{n}$ & $\mathrm{M}$ & $\mathrm{SD}$ & $\begin{array}{c}\text { Mean } \\
\text { Difference }\end{array}$ \\
\hline Total & 61 & 4.73 & 1.074 & 56 & 4.90 & 1.433 & +.17 \\
Analysis & 59 & 4.63 & 1.043 & & & & +.27 \\
Design \& Development & 59 & 4.55 & 1.135 & & & & +.35 \\
Implementation & 59 & 4.84 & 1.299 & & & & +.06 \\
Evaluation & 60 & 4.67 & 1.104 & & & & +.23 \\
\hline
\end{tabular}

Table 4.6: Descriptive statistics for independent variable (current ability) and dependent variable (the ability to work with SMEs) among HRD professionals who had worked with SMEs 


\section{Findings on Research Questions}

This section reports the results from each of the research questions of the study.

\section{Research Question \#1}

Is there a difference between the current/desired ability in the stages of the training design process among HRD professionals?

In order to answer this research question, a paired t-test was used to examine whether there was a statistical difference in the current and desired ability in the stages of the training design process, and Pearson product-moment correlation was used to determine whether a relationship existed between the variables, the current ability and the desired ability in the stages of the training design process among HRD professionals.

Table 4.7 shows that there was not a statistically significant difference between the current and desired ability in the analysis stage $(\mathrm{t}=-.557)$, in the design and development stage $(\mathrm{t}=-.893)$, in the implementation stage $(\mathrm{t}=-.569)$, or in the evaluation stage $(\mathrm{t}=-.396)$ at the alpha level of .05 .

\begin{tabular}{llcc}
\hline Stages & $\mathrm{t}$ & $\mathrm{df}$ & $p$ \\
\hline Analysis & -.557 & 116 & .579 \\
Design \& Development & -.893 & 109 & .374 \\
Implementation & -.569 & 115 & .571 \\
Evaluation & -.396 & 113 & .693 \\
Total & -1.065 & 97 & .290 \\
& & & \\
\hline
\end{tabular}

Table 4.7: The difference between current and desired ability in each of the stages 
Table 4.8 reports the correlation matrix among the independent variables. The result shows that the independent variables had a significant strong correlation with each other $(\mathrm{p}<.05)$.

As presented in Table 4.9, there was a significant moderate relationship $(\mathrm{r}=.43)$ between the current and desired ability of HRD professionals in the stages of the training design process at the alpha level of .05. In particular, their current ability and desired ability had a significant moderate correlation in the analysis stage $(\mathrm{r}=.44$, $\mathrm{p}<.05)$ and in the design and development stage $(\mathrm{r}=.43, \mathrm{p}<.05)$, and a significant low correlation in the implementation stage $(\mathrm{r}=.30, \mathrm{p}<.05)$ and the evaluation stage $(\mathrm{r}=.30$, $\mathrm{p}<.05)$.

\begin{tabular}{lllllllll}
\hline & \multicolumn{3}{l}{ Current Ability } & \multicolumn{5}{l}{ Desired Ability } \\
Stages & 1 & 2 & 3 & 4 & 1 & 2 & 3 & 4 \\
\hline 1. Analysis & & & & & & & & \\
2. Design \& Development & $.90^{* *}$ & & & $.89^{* *}$ & & \\
3. Implementation & $.80^{* *}$ & $.83^{* *}$ & & $.72^{* *}$ & $.82^{* *}$ & \\
4. Evaluation & $.79^{* *}$ & $.79^{* *}$ & $.88^{* *}$ & & $.77^{* *}$ & $.82^{* *}$ & $.89^{* *}$ \\
\hline
\end{tabular}

Note: $\mathrm{N}$ ranges from 113 to 123

$* * \mathrm{p}<.01$

Table 4.8: Correlation matrix for independent variables 


\begin{tabular}{lc}
\hline & $\gamma$ \\
\hline Current $\leftrightarrow$ Desired (Analysis) & $.44^{* *}$ \\
Current $\leftrightarrow$ Desired (Design \& Development) & $.43^{* *}$ \\
Current $\leftrightarrow$ Desired (Implementation) & $.30^{* *}$ \\
Current $\leftrightarrow$ Desired (Evaluation) & $.30^{* *}$ \\
Current $\leftrightarrow$ Desired (Total) & $.43^{* *}$ \\
\hline
\end{tabular}

* Correlation is significant at the alpha level of .05 (2-tailed)

** Correlation is significant at the alpha level of .01 (2-tailed)

Table 4.9: Correlation coefficients on the current/desired ability in the stages of the training design process

Thus, the results showed not a significant difference between the current and desired ability in the stages of the training design process among HRD professionals. This means that there was no perceived difference between HRD professionals' current and desired ability. 


\section{Research Question \#2}

Is there a difference between the current/desired ability in the stages of the training design process among HRD professionals who have and who have not worked with SMEs?

In order to answer this research question, the paired t-test was used to examine whether there was a statistical difference in the current and desired ability in the stages of the training design process, and Pearson product-moment correlation was used to determine whether a relationship existed between the variables, the current ability and the desired ability in the stages of the training design process, classified according to HRD professionals who had and who had not worked with SMEs.

Table 4.10 shows that among HRD professionals who had worked with SMEs, there was not a statistically significant difference between the current and desired ability in the analysis stage $(\mathrm{t}=.494)$, the design and development stage $(\mathrm{t}=.037)$, the implementation stage $(t=.535)$, or the evaluation stage $(t=.517)$ at the alpha level of .05 . On the other hand, among HRD professionals who had not worked with SMEs, there was also not a statistically significant difference between the current and desired ability in the analysis stage $(\mathrm{t}=-1.460)$, the design and development stage $(\mathrm{t}=-1.149)$, the implementation stage $(\mathrm{t}=-1.391)$, or the evaluation stage $(\mathrm{t}=-1.108)$ at the alpha level of .05 . 


\begin{tabular}{lccc}
\hline Stages & $\mathrm{t}$ & $\mathrm{df}$ & $p$ \\
\hline HRD professionals with experience in & & & \\
working with SMEs & & & \\
Analysis & .494 & 57 & .623 \\
Design \& Development & .037 & 51 & .971 \\
Implementation & .535 & 57 & .595 \\
Evaluation & .517 & 56 & .607 \\
Total & .269 & 50 & .789 \\
& & & \\
\hline HRD professionals with no & & & \\
experience in working with SMEs & & & \\
Analysis & -1.460 & 57 & .150 \\
Design \& Development & -1.149 & 56 & .255 \\
Implementation & -1.391 & 56 & .170 \\
Evaluation & -1.108 & 55 & .273 \\
Total & -1.840 & 45 & .072 \\
& & & \\
\hline
\end{tabular}

Table 4.10: The difference between current and desired ability in each of the stages

As presented in Table 4.11, among HRD professionals who had worked with SMEs, there was a significant low relationship between the current and desired ability in the stages of the training design process $(r=34, p<.05)$. In particular, for the group of HRD professionals who had worked with SMEs, their current ability and desired ability had a significant low correlation in the analysis stage $(\mathrm{r}=.31, \mathrm{p}<.05)$, and a significant moderate correlation in the design and development stage $(r=.42, p<.05)$, but were not significantly correlated in the implementation stage $(r=.21, \mathrm{p}>.05)$ or the evaluation stage $(\mathrm{r}=.23, \mathrm{p}>.05)$.

On the contrary, among HRD professionals who had not worked with SMEs, there was a significant moderate relationship between the current and desired ability in the stages of the training design process $(r=44, p<.05)$. In particular, for the group of HRD professionals who had not worked with SMEs, their current ability and desired 
ability showed significant moderate correlation in the analysis stage $(\mathrm{r}=.56, \mathrm{p}<.05)$ and significant low correlation in the design and development stage $(r=.36, \mathrm{p}<.05)$, the implementation stage $(\mathrm{r}=.34, \mathrm{p}<.05)$, and the evaluation stage $(\mathrm{r}=.39, \mathrm{p}<.05)$.

\begin{tabular}{lcc}
\hline & $\begin{array}{c}\text { HRD professionals } \\
\text { with experience in } \\
\text { working with SMEs } \\
\gamma\end{array}$ & $\begin{array}{c}\text { HRD professionals } \\
\text { with no experience in } \\
\text { working with SMEs } \\
\gamma\end{array}$ \\
\hline Current $\leftrightarrow$ Desired (Analysis) & $.31^{*}$ & $56^{* *}$ \\
Current $\leftrightarrow$ Desired (Design \& & $.42^{* *}$ & $.36^{* *}$ \\
Development) & .21 & $.34^{* *}$ \\
Current $\leftrightarrow$ Desired (Implementation) & .23 & $.39^{* *}$ \\
Current $\leftrightarrow$ Desired (Evaluation) & $.34^{*}$ & $44^{* *}$ \\
\hline
\end{tabular}

* Correlation is significant at the alpha level of .05 (2-tailed)

** Correlation is significant at the alpha level of .01 (2-tailed)

Table 4.11: Correlation coefficients on the current/desired ability in the stages of the training design process between HRD professionals with experience in working with SMEs and those with no experience in working with SMEs

Thus, the results showed not a significant difference between the current and desired ability in the stages of the training design process among HRD professionals who had and who had not worked with SMEs. This means that there was no perceived difference between the current and desired ability among HRD professionals who had and who had not worked with SMEs. 


\section{Research Question \#3}

What is the relationship between their demographic characteristics and the current/desired ability in the training design process among HRD professionals who have worked with SMEs and HRD professionals who have not worked with SMEs?

In order to answer this research question, a one-way ANOVA test was conducted to determine the differences in two independent variables, (a) current ability in the training design process and (b) desired ability in the training design process, in terms of the five demographic characteristics, a) organization size, b) education level, c) years of work experience, d) years of work experience in HR related jobs, and e) experience in designing training programs, as shown in Tables $4.12,4.13,4.14,4.15$, and 4.16 . The $\mathrm{F}$ value was calculated to determine the difference. The Chi-square test was used to measure the differences between two groups, HRD professionals who had and who had not worked with SMEs, in terms of their demographic characteristics.

Table 4.12 presents the ANOVA test results between groups based on organization size and current and desired ability in the training design process. For the group of HRD professionals who had worked with SMEs, no statistical difference was found between the groups based on organization size as it related to current ability in the training design process $(\mathrm{F}=1.110, \mathrm{p}>.05)$ and desired ability in the training design process $(\mathrm{F}=2.299, \mathrm{p}>.05)$.

For the group of HRD professionals who had not worked in SMEs, the ANOVA test indicated that organization size was not significantly related to current ability in 
the training design process $(\mathrm{F}=1.784, \mathrm{p}>.05)$ or desired ability in the training design process $(\mathrm{F}=1.201, \mathrm{p}>.05)$.

\begin{tabular}{lccccc}
\hline Source & SS & df & MS & F & $p$ \\
\hline HRD professionals with experience in & & & & & \\
working with SMEs & & & & & \\
Current ability & 5.322 & 5 & 1.064 & 1.110 & .368 \\
Error & 46.036 & 48 & .959 & & \\
Total & 51.358 & 53 & & & \\
Desired ability & 10.329 & 5 & 2.066 & 2.299 & .060 \\
Error & 42.238 & 47 & .899 & & \\
Total & 52.567 & 52 & & & \\
& & & & & \\
HRD professionals with no experience & & & & & \\
in working with SMEs & & & & & \\
Current ability & 7.194 & 5 & 1.439 & 1.784 & .134 \\
Error & 37.902 & 47 & .806 & & \\
Total & 45.097 & 52 & & & \\
Desired ability & 5.465 & 5 & 1.093 & 1.201 & .325 \\
Error & 38.224 & 42 & .910 & & \\
Total & 43.689 & 47 & & & \\
& & & & & \\
\hline
\end{tabular}

Table 4.12 ANOVA table-Organization size by current/desired ability in the training design process

Table 4.13 presents the ANOVA test results for the groups based on education level and current and desired ability in the training design process. For the group of HRD professionals who had worked with SMEs, no statistical difference was found between groups based on education level as it related to current ability in the training design process $(\mathrm{F}=1.276, \mathrm{p}>.05)$ and desired ability in the training design process $(\mathrm{F}=2.462, \mathrm{p}>.05)$ 
For the group of HRD professionals who had not worked with SMEs, the ANOVA test indicated that education level was significantly related to current ability in the training design process $(\mathrm{F}=4.573, \mathrm{p}<.05)$, but not significantly related to desired ability in the training design process $(\mathrm{F}=1.134, \mathrm{p}>.05)$.

\begin{tabular}{lccccc}
\hline Source & SS & df & MS & F & $p$ \\
\hline HRD professionals with experience in & & & & & \\
working with SMEs & & & & & \\
Current ability & 3.651 & 3 & 1.217 & 1.276 & .293 \\
Error & 47.706 & 50 & .954 & & \\
Total & 51.358 & 53 & & & \\
Desired ability & 6.886 & 3 & 2.295 & 2.462 & .074 \\
Error & 45.681 & 49 & .932 & & \\
Total & 52.567 & 52 & & & \\
& & & & & \\
HRD professionals with no experience & & & & & \\
in working with SMEs & & & & & \\
Current ability & 9.865 & 3 & 3.288 & $4.573 *$ & .007 \\
Error & 35.232 & 49 & .719 & & \\
Total & 45.097 & 52 & & & \\
Desired ability & 3.136 & 3 & 1.045 & 1.134 & .346 \\
Error & 40.553 & 44 & .922 & & \\
Total & 43.689 & 47 & & & \\
& & & & & \\
\hline
\end{tabular}

$* \mathrm{p}<.05$

Table 4.13: ANOVA table-Education level by current/desired ability in the training design process

Table 4.14 presents the ANOVA test results for the groups based on the years of work experience and current and desired ability in the training design process. For the group of HRD professionals who had worked with SMEs, the years of work experience was not significantly related to current ability in the training design process $(\mathrm{F}=.413, \mathrm{p}>.05)$ and also not significantly related to desired ability in the training design process $(\mathrm{F}=.295, \mathrm{p}>.05)$. 
For the group of HRD professionals who had not worked with SMEs, the ANOVA test indicated that the years of work experience was not significantly related to current ability in the training design process $(\mathrm{F}=.905, \mathrm{p}>.05)$ and also not significantly related to desired ability in the training design process $(F=.379, \mathrm{p}>.05)$.

\begin{tabular}{lccccc}
\hline Source & SS & df & MS & F & $p$ \\
\hline HRD professionals with experience in & & & & & \\
working with SMEs & & & & & \\
Current ability & 1.674 & 4 & .419 & .413 & .799 \\
Error & 49.683 & 49 & 1.014 & & \\
Total & 51.358 & 53 & & & \\
Desired ability & 1.261 & 4 & .315 & .295 & .880 \\
Error & 51.306 & 48 & 1.069 & & \\
Total & 52.567 & 52 & & & \\
& & & & & \\
HRD professionals with no experience & & & & & \\
in working with SMEs & & & & & \\
Current ability & 3.163 & 4 & .791 & .905 & .469 \\
Error & 41.934 & 48 & .874 & & \\
Total & 45.097 & 52 & & & \\
Desired ability & 1.486 & 4 & .372 & .379 & .823 \\
Error & 42.203 & 43 & .981 & & \\
Total & 43.689 & 47 & & & \\
& & & & & \\
\hline
\end{tabular}

Table 4.14: ANOVA table-Years of work experience by current/desired ability in the training design process

Table 4.15 presents the ANOVA test results for the groups based on the years of work experience in HR related jobs and current and desired ability in the training design process. For the group of HRD professionals who had worked with SMEs, the years of work experience in HR related jobs was not significantly related to current ability in the training design process $(\mathrm{F}=1.310, \mathrm{p}>.05)$ and also not significantly related to desired ability in the training design process $(\mathrm{F}=.998, \mathrm{p}>.05)$. 
For the group of HRD professionals who had not worked with SMEs, the ANOVA test indicated that years of work experience in HR related jobs was significantly related to current ability in the training design process $(F=2.963, p<.05)$, but not significantly related to desired ability in the training design process $(\mathrm{F}=1.163$, $\mathrm{p}>.05)$

\begin{tabular}{lrrrrr}
\hline Source & SS & df & MS & F & $p$ \\
\hline HRD professionals with experience in & & & & & \\
working with SMEs & & & & & \\
Current ability & 3.743 & 3 & 1.248 & 1.310 & .282 \\
Error & 47.615 & 50 & .952 & & \\
Total & 51.358 & 53 & & & \\
Desired ability & 3.026 & 3 & 1.009 & .998 & .402 \\
Error & 49.541 & 49 & 1.011 & & \\
Total & 52.567 & 52 & & & \\
& & & & & \\
HRD professionals with no experience & & & & & \\
in working with SMEs & & & & & \\
Current ability & 8.929 & 4 & 2.232 & $2.963 *$ & .029 \\
Error & 36.167 & 48 & .753 & & \\
Total & 45.097 & 52 & & & \\
Desired ability & 4.266 & 4 & 1.067 & 1.163 & .340 \\
Error & 39.422 & 43 & .917 & & \\
Total & 43.689 & 47 & & & \\
& & & & & \\
\hline
\end{tabular}

$* \mathrm{p}<.05$

Table 4.15: ANOVA table-Years of work experience in HR related jobs by current/desired ability in the training design process 
Table 4.16 presents the ANOVA test results for the groups based on experience in designing training programs and current and desired ability in the training design process. For the group of HRD professionals who had worked with SMEs, the experience in designing the training programs was not significantly related to current ability in the training design process $(\mathrm{F}=3.847, \mathrm{p}>.05)$ and also not significantly related to desired ability in the training design process $(\mathrm{F}=.063, \mathrm{p}>.05)$.

For the group of HRD professionals who had not worked with SMEs, the ANOVA test indicated that experience in designing training programs had a significant relationship with current ability in the training design process $(\mathrm{F}=11.685$, $\mathrm{p}<.05$ ), but was not significantly related to desired ability in the training design process $(\mathrm{F}=.295, \mathrm{p}>.05)$.

\begin{tabular}{lccccc}
\hline Source & SS & df & MS & F & $p$ \\
\hline HRD professionals with experience in & & & & & \\
working with SMEs & & & & & \\
$\quad$ Current ability & 3.538 & 1 & 3.538 & 3.847 & .055 \\
$\quad$ Error & 47.820 & 52 & .920 & & \\
Total & 51.358 & 53 & & & \\
Desired ability & .065 & 1 & .065 & .063 & .803 \\
Error & 52.502 & 51 & 1.029 & & \\
Total & 52.567 & 52 & & & \\
& & & & & \\
HRD professionals with no experience & & & & & \\
in working with SMEs & & & & & \\
Current ability & 8.406 & 1 & 8.406 & $11.685^{*}$ & .001 \\
Error & 36.690 & 51 & .719 & & \\
Total & 45.097 & 52 & & & \\
Desired ability & .278 & 1 & .278 & .295 & .590 \\
Error & 43.411 & 46 & .944 & & \\
Total & 43.689 & 47 & & & \\
& & & & & \\
\end{tabular}

$* \mathrm{p}<.05$

Table 4.16: ANOVA table- Experience in designing training programs by current/desired ability in the training design process 
The results of the Pearson Chi-square analysis presented in Table 4.17 showed that there were no significant relationships between the demographic characteristics (organization size, years of work experience, and years of work experience in HR related jobs) of HRD professionals who had worked with SMEs and those who had not worked with SMEs. There was a significant low relationship between the education level of HRD professionals who had and those who had not worked with SMEs (Cramer's V=.305). Also, there was a significant low relationship between experience in designing training programs of HRD professionals who had and those who had not worked with SMEs $(\mathrm{Phi}=.281)$.

This means that a higher percentage of HRD professionals who had worked with SMEs had obtained master's degrees and had experience in designing training programs compared to HRD professionals who had not worked with SMEs. Specifically, 49.2 percent of HRD professionals who had worked with SMEs had obtained master's degrees; in contrast, 50.8 percent of HRD professionals who have not worked with SMEs had obtained bachelor's degrees. Moreover, a higher percentage of HRD professionals who had worked with SMEs had experience in designing training programs compared to HRD professionals who had not worked with SMEs. Specifically, 80.3 percent of HRD professionals who had worked with SMEs and 53.8 percent of HRD professionals who had not worked with SMEs had experience in designing training programs. 


\begin{tabular}{|c|c|c|c|c|c|c|}
\hline & \multicolumn{6}{|c|}{$\begin{array}{l}\text { HRD professionals with experience in working with } \\
\text { SMEs }\end{array}$} \\
\hline & \multicolumn{2}{|c|}{$\underline{\text { Yes }(n=61)}$} & \multicolumn{2}{|c|}{$\underline{\text { No }(n=65)}$} & \multirow[b]{2}{*}{$p$} & \multirow[b]{2}{*}{ Value } \\
\hline & $\mathrm{n}$ & $\%$ & $\mathrm{n}$ & $\%$ & & \\
\hline Organization Size & & & & & .150 & .254 \\
\hline Less than 200 & 11 & 18 & 24 & 36.9 & & \\
\hline $200-500$ & 7 & 11.5 & 6 & 9.2 & & \\
\hline $500-1000$ & 18 & 29.5 & 11 & 16.9 & & \\
\hline $1000-2000$ & 8 & 13.1 & 4 & 6.2 & & \\
\hline $2000-5000$ & 7 & 11.5 & 9 & 13.8 & & \\
\hline Over 5000 & 10 & 16.4 & 11 & 16.9 & & \\
\hline Education Level & & & & & .019 & $.305 *$ \\
\hline Doctoral & 3 & 4.9 & 0 & 0 & & \\
\hline Master & 30 & 49.2 & 21 & 32.3 & & \\
\hline Bachelor & 26 & 42.6 & 33 & 50.8 & & \\
\hline Associate & 2 & 3.3 & 9 & 13.8 & & \\
\hline High school & 0 & 0 & 2 & 3.1 & & \\
\hline Years of Work Experience & & & & & .769 & .120 \\
\hline $0-5$ & 17 & 27.9 & 18 & 27.7 & & \\
\hline $6-10$ & 15 & 24.6 & 17 & 26.2 & & \\
\hline $11-15$ & 15 & 24.6 & 13 & 20.0 & & \\
\hline $16-20$ & 7 & 11.5 & 5 & 7.7 & & \\
\hline Over 20 & 7 & 11.5 & 12 & 18.5 & & \\
\hline $\begin{array}{l}\text { Years of Work Experience in } \\
\text { HR Related Jobs }\end{array}$ & & & & & .675 & .136 \\
\hline $0-5$ & 27 & 44.3 & 31 & 47.7 & & \\
\hline $6-10$ & 21 & 34.4 & 23 & 35.4 & & \\
\hline $11-15$ & 6 & 9.8 & 5 & 7.7 & & \\
\hline $16-20$ & 6 & 9.8 & 3 & 4.6 & & \\
\hline Over 20 & 1 & 1.6 & 3 & 4.6 & & \\
\hline $\begin{array}{l}\text { Experience in Designing } \\
\text { Training Programs }\end{array}$ & & & & & .002 & $.281 *$ \\
\hline No & 12 & 19.7 & 30 & 46.2 & & \\
\hline Yes & 49 & 80.3 & 35 & 53.8 & & \\
\hline$-25 \%$ & 20 & 32.8 & 17 & 26.2 & & \\
\hline $26-50 \%$ & 13 & 21.3 & 13 & 20.0 & & \\
\hline $51-75 \%$ & 8 & 13.1 & 3 & 4.6 & & \\
\hline $76 \%+$ & 8 & 13.1 & 2 & 3.1 & & \\
\hline
\end{tabular}

$* \mathrm{p}<.05$

Table 4.17: The numbers, percentages, and chi-square test results of responses regarding the demographic characteristics and different groupings of the respondents 
Thus, the results showed a significant relationship between the demographic characteristics (education level, years of work experience in HR related jobs, and experience in designing training programs) and current ability in the training design process among HRD professionals who had not worked with SMEs. This result means that the higher the education level, years of work experience in HR related jobs, and experience in designing training programs of the HRD professionals, the higher their perceived current ability in the training design process. In addition, a higher percentage of HRD professionals who had worked with SMEs had obtained master's degrees $(49.2 \%)$ while a higher percentage of HRD professionals who had not worked with SMEs had obtained bachelor's degrees (50.8\%). A higher percentage of HRD professionals who had worked with SMEs had experience in designing training programs compared to HRD professionals who had not worked with SMEs. A lower percentage of HRD professionals who had worked with SMEs had had no experience in designing training programs $(9.5 \%)$. 


\section{Research Question \#4}

Among HRD professionals who have worked with SMEs, what is the relationship between their demographic characteristics and the ability to work with SMEs?

To determine whether differences in demographic characteristics, a) organization size, b) education level, c) years of work experience, d) years of work experience in HR related jobs, and e) experience in designing training programs, influenced the results of the study, a one-way ANOVA test was conducted for the five demographic characteristics and the ability of HRD professionals to work with SMEs, as shown in Tables 4.18, 4.19, 4.20, 4.21, and 4.22. The F value was calculated to determine the difference.

Table 4.18 presents the ANOVA test result that organization size was not significantly related to the ability to work with SMEs ( $F=1.559, \mathrm{p}>.05)$ among HRD professionals who had worked with SMEs.

\begin{tabular}{cccccc}
\hline Source & SS & df & MS & F & $p$ \\
\hline Ability to work with SMEs & 7.117 & 5 & 1.423 & 1.559 & .190 \\
Error & 42.904 & 47 & .913 & & \\
Total & 50.021 & 52 & & & \\
\hline
\end{tabular}

Table 4.18: ANOVA table-Organization size by the ability to work with SMEs

Table 4.19 presents the ANOVA test result that education level was significantly related to the ability to work with SMEs $(\mathrm{F}=2.916, \mathrm{p}<.05)$ among HRD professionals who had worked with SMEs. 


\begin{tabular}{cccccc}
\hline Source & SS & df & MS & F & $p$ \\
\hline Ability to work with SMEs & 7.577 & 3 & 2.526 & $2.916^{*}$ & .043 \\
Error & 42.444 & 49 & .866 & & \\
Total & 50.021 & 52 & & & \\
\hline
\end{tabular}

$* \mathrm{p}<.05$

Table 4.19: ANOVA table-Education level by the ability to work with SMEs

Table 4.20 presents the ANOVA test result that years of work experience was not significantly related to the ability to work with SMEs $(\mathrm{F}=1.103, \mathrm{p}>.05)$ among HRD professionals who had worked with SMEs.

\begin{tabular}{crrrrr}
\hline Source & \multicolumn{1}{c}{ SS } & \multicolumn{1}{c}{ df } & \multicolumn{1}{c}{ MS } & F & $p$ \\
\hline Ability to work with SMEs & 4.210 & 4 & 1.053 & 1.103 & .366 \\
Error & 45.810 & 48 & .954 & & \\
Total & 50.021 & 52 & & & \\
\hline
\end{tabular}

Table 4.20: ANOVA table-Years of work experience by the ability to work with SMEs

Table 4.21 presents the ANOVA test result that years of work experience in HR related jobs was not significantly related to the ability to work with SMEs $(F=1.021$, p>.05) among HRD professionals who had worked with SMEs.

\begin{tabular}{crrrrr}
\hline Source & \multicolumn{1}{c}{ SS } & \multicolumn{1}{c}{ df } & \multicolumn{1}{c}{ MS } & F & \multicolumn{1}{c}{$p$} \\
\hline Ability to work with SMEs & 3.924 & 4 & .981 & 1.021 & .406 \\
Error & 46.097 & 48 & .960 & & \\
Total & 50.021 & 52 & & & \\
\hline
\end{tabular}

Table 4.21: ANOVA table-Years of work experience in HR related jobs by the ability to work with SMEs 
Table 4.22 presents the ANOVA test result that experience in designing training programs was not significantly related to the ability to work with SMEs $(\mathrm{F}=.908$, p >.05) among HRD professionals who had worked with SMEs.

\begin{tabular}{crrrrl}
\hline Source & \multicolumn{1}{c}{ SS } & \multicolumn{1}{c}{ df } & MS & F & $p$ \\
\hline Ability to work with SMEs & .875 & 1 & .875 & .908 & .345 \\
Error & 49.146 & 51 & .964 & & \\
Total & 50.021 & 52 & & & \\
\hline
\end{tabular}

Table 4.22: ANOVA table-Experience in designing training programs by the ability to work with SMEs

Thus, the results showed that there was a statistically significant relationship between education level and the ability to work with SMEs among HRD professionals who had worked with SMEs. This result means that the higher the education level of HRD professionals, the higher the perceived ability of the HRD professionals to work with SMEs. 


\section{Research Question \#5}

Among HRD professionals who have worked with SMEs, is there a relationship between the ability to work with SMEs and current ability in the stages of the training design process?

In order to answer this research question, Pearson product-moment correlation and simple linear regression analysis techniques were used to examine the relationship between current ability and the ability to work with SMEs among HRD professionals who had worked with SMEs.

Table 4.23 presents the correlation among the variables. The results showed that the ability to work with SMEs had a significant strong relationship to the current ability of HRD professionals in the training design process $(\mathrm{r}=65, \mathrm{p}<.05)$. In particular, the ability to work with SMEs and current ability had a significant strong correlation in the analysis stage $(\mathrm{r}=.61, \mathrm{p}<.05)$, the design and development stage $(\mathrm{r}=.60, \mathrm{p}<.05)$, and the evaluation stage $(\mathrm{r}=.62, \mathrm{p}<.05)$ and significant moderate correlation in implementation stage $(\mathrm{r}=.57, \mathrm{p}<.05)$.

\begin{tabular}{lc}
\hline & $\gamma$ \\
\hline Current $\leftrightarrow$ Ability to work with SMEs (Analysis) & $.61^{* *}$ \\
Current $\leftrightarrow$ Ability to work with SMEs (Design \& Development) & $.60^{* *}$ \\
Current $\leftrightarrow$ Ability to work with SMEs (Implementation) & $.57^{* *}$ \\
Current $\leftrightarrow$ Ability to work with SMEs (Evaluation) & $.62^{* *}$ \\
Current $\leftrightarrow$ Ability to work with SMEs (Total) & $.65^{* *}$ \\
\hline
\end{tabular}

Correlation is significant at the alpha level of .01 (2-tailed)

Table 4.23: Correlation coefficients for independent variable (current ability) and dependent variable (ability to work with SMEs) 
This result showed that among HRD professionals who had worked with SMEs, there was a significant positive relationship between the ability to work with SMEs and current ability in the four stages of the training design process. Therefore, simple linear regression analysis was used to determine the impact of the variables, as shown in Table 4.24.

Table 4.24 shows that there was a statistically significant relationship between the ability to work with SMEs and current ability in the stages of the training design process at the alpha level of .05 . This means that the linear combination of current ability in the stages of the training design process can explain $38.9 \%$ of the variance in the ability to work with SMEs (R square =.389). Thus, the result shows that the ability to work with SMEs differed based on current ability in the stages of the training design process. However, the ability to work with SMEs was not significantly related to current ability in the analysis, design and development, implementation, or evaluation stages $(\beta=.309, \beta=.210, \beta=-.360, \beta=.501, p>.05)$. This means that current ability in the stages of the training design process cannot predict or explain the ability of HRD professionals in working with SMEs in more detail.

\begin{tabular}{|c|c|c|c|c|c|}
\hline Stages & B & SE & $\beta$ & $\mathrm{t}$ & $p$ \\
\hline Analysis & .275 & .268 & .309 & 1.027 & .310 \\
\hline Design \& Development & .192 & .261 & .210 & .735 & .466 \\
\hline Implementation & -.299 & .236 & -.360 & -1.265 & .213 \\
\hline Evaluation & .429 & .233 & .501 & 1.843 & .072 \\
\hline R Square & $\begin{array}{l}\text { Adjust R } \\
\text { Square }\end{array}$ & $\begin{array}{l}\text { Std. Error of the } \\
\text { Estimate }\end{array}$ & $\overline{\mathrm{df}}$ & $\bar{F}$ & $p$ \\
\hline .664 & .389 & .678 & 4 & 8.651 & .000 \\
\hline
\end{tabular}

Table 4.24: Summary of regression analysis for the ability to work with SMEs as a predictor of current ability through each of the stages of the training design process 
Thus, the results showed a significant positive relationship between the ability of HRD professionals to work with SMEs and the current ability among HRD professionals who had worked with SMEs. That is, the higher the perceived current ability of HRD professionals in each stage of the training design process, the higher the perceived ability of the HRD professionals to worked with SMEs. 


\section{CHAPTER 5}

\section{SUMMARY, DISCUSSION, AND IMPLICATIONS}

This chapter is divided into four sections. The first section presents a summary of the findings. The second section presents a discussion of the findings, including the conclusions and the rationales for explaining the findings of the study. The final section proposes a revised conceptual framework and discusses implications of the findings for future research and for the practice and policy of HRD practitioners, business organizations, and higher education.

\section{Summary of the Findings}

The following is a summary of the results of the study.

- There was not a significant difference between the perceived current and desired ability in the stages of the training design process among HRD professionals.

- There was not a significant difference between the perceived current and desired ability in the stages of the training design process among HRD professionals who had and who had not worked with SMEs. 
- There was a significant positive relationship between education level and perceived current ability in the training design process among HRD professionals who had not worked with SMEs.

- There was a significant positive relationship between years of work experience in HR related jobs and perceived current ability in the training design process among HRD professionals who had not worked with SMEs.

- There was a significant positive relationship between experience in designing training programs and perceived current ability in the training design process among HRD professionals who had not worked with SMEs.

- There was a significant relationship between education level and perceived ability to work with SMEs among HRD professionals who had worked with SMEs.

- A higher percentage of HRD professionals who had worked with SMEs had obtained master's degrees.

- A higher percentage of HRD professionals who had not worked with SMEs had obtained bachelor's degrees.

- A higher percentage of HRD professionals who had worked with SMEs had experience in designing training programs compared to HRD professionals who had not worked with SMEs.

- There was a significant positive relationship between the perceived ability to work with SMEs and perceived current ability in the training design process among HRD professionals who had worked with SMEs. 
- The majority of HRD professionals usually learned about designing training programs by self-directed informal learning and formal professional development programs outside their organizations.

\section{Discussion}

This section discusses three areas of possible interpretation of the results and presents an explanation of the findings.

No Significant Difference Between Current and Desired Ability of HRD Professionals in the Training Design Process

This study found no significant difference between HRD professionals' perceived current and desired ability in the stages of the training design process. The result that HRD professionals' perceived current ability was not different from their desired ability was surprising. The result can be interpreted in two ways.

First, it can be interpreted that the HRD professionals might not like to admit their weakness or lack of ability in training design, which caused a response bias. They pretended to have sufficient ability to design training programs so that they rarely indicated a desire to improve their training design ability. Such a response might have been caused by the cultural difference between the United States and Asia. Two examples from research in Asian countries supported this explanation. Chen (2005) demonstrated in a study of competencies of Taiwan HRD practitioners that the 
majority of the respondents perceived their competence to be in basic and intermediate levels. Very few of them perceived their competence to be in advanced or expert levels. Chan (2003) demonstrated that Korean frontline employees, middle managers, and senior managers rated their perceived dimensions of work knowledge higher at the time of the study than as performed three years previously.

Second, the result might be interpreted as an indication that the HRD professionals were not sure of what they knew and were not aware of what they did not know. It is likely that this interpretation describes the actual situation. One reason for accepting this interpretation is that at the time of this study HRD professionals in Taiwan were not knowledgeable about the proposition that the design of training programs should be based on the training design process, which is a systematic process comprised of analysis, design, development, implementation, and evaluation. For this reason, the HRD professionals may have experienced difficulty in responding to the items regarding the training design competencies classified by the five steps of the training design process. A second reason is that the HRD professionals in Taiwan at this time rarely recognized training design as part of their job task. The reality was that SMEs or inside trainers were responsible for both providing the training content and designing the training materials, especially in technical skills training programs (Chiu, 2003; Chien, 2003). For these reasons, it is probable that the HRD professionals were not sure of the level of their current ability in the training design process and had difficulty identifying a need or desire to improve their training design ability. 
The Significant Positive Relationship Between Current Ability in the Training Design Process and the Ability to Work with SMEs

This study found that sixty-one of the HRD professionals who participated in this study had experience in working with SMEs (48.41\%). The results showed a significant positive relationship between their current ability in the training design process and their ability to work with SMEs. This suggests that the higher the current ability of HRD professionals in the training design process, the higher their ability to work with SMEs.

Two interpretations may explain this result. First, the results could be the result of an awareness that HRD success in designing training programs is based on building a collaborative relationship with SMEs. This result was consistent with the proposition that training effectiveness is mainly dependent on establishing a helping relationship between SMEs and HRD professionals. Hence, there is a critical need for an effective and efficient method to assist HRD professionals and SMEs in collaborating on the training design process (Lin \& Jacobs, 2004).

Second, HRD professionals perceived that they were capable of designing training programs as they engaged in each stage of the training design process, and, furthermore, this was related to whether they had higher ability to work with SMEs through the consultation process. 


\section{Influences of Demographic Characteristics}

Education level. Among the HRD professionals who had worked with SMEs, the perceived ability to work with SMEs was influenced by education level. Among HRD professionals who had not worked with SMEs, the perceived current ability in the training design process was influenced by education level as well. A stronger education background was perceived to have helped the HRD professionals who had worked with SMEs to have a higher ability to work with SMEs and to have helped HRD professionals who had not worked with SMEs to have a higher current ability in the training design process. A higher percentage of HRD professionals who had worked with SMEs had obtained master's degrees (49.2\%). A higher percentage of HRD professionals who had not worked with SMEs had obtained bachelor's degrees $(50.8 \%)$. This result was not surprising to the researcher. It was interpreted as an indication that HRD professionals viewed the education system in universities or colleges as the main source of their professional development and that it informed what they knew or did not know about themselves.

Experience in designing training programs. Among HRD professionals who had not worked with SMEs, perceived current ability in the training design process was influenced by their experience in designing training programs. Forty-nine of the HRD professionals not only had experience in working with SMEs but also had experience in designing training programs $(80.3 \%)$. HRD professionals who had not worked with SMEs had experience in designing training programs (53.8\%). In other words, a higher percentage of HRD professionals who had worked with SMEs had experience in designing training programs compared to HRD professionals who had 
not worked with SMEs. In fact, this was interpreted as an indication that experience in designing training programs was viewed as the first step in approaching training design programs. Without experience in designing training programs, it must be very difficult for HRD professionals in Taiwan to understand what their current ability in the training design process is and to start a dialogue with SMEs regarding the design of training programs.

Years of work experience in HR related jobs. Among HRD professionals who had not worked with SMEs, perceived current ability in the training design process was influenced by the years of work experience in HR related jobs. Of HRD professionals who had not worked with SMEs, 47.7 percent had one to five years of professional experience in HR related jobs. This indicates that the adaptive time of learning the HR area in the actual work environment is still an important component in the preparation of HRD professionals that helps them realize what they are able to perform in their jobs and develop such abilities as training program design.

Sources of professional development. The results demonstrated that the majority of HRD professionals in Taiwan at the time of this study usually learned about designing training programs through self-directed informal learning and formal professional development programs outside their organizations. They indicated that although most HRD professionals had obtained at least bachelor's degrees, the academic education system in universities and colleges did not provide all that they needed to develop their ability so that self-learning and learning outside the organization were the major methods of obtaining the knowledge and skills needed to approach the design of training programs. 


\section{Implications}

The first part of this section presents implications for future research, including a revised conceptual framework to improve the design of research examining the relationships among all variables. The second part provides several implications for HRD practitioners, business organizations, and higher education.

Implications for Future Research

This study only partially demonstrated that HRD professionals in Taiwan perceived the value of working with SMEs during the training design process. However, this study did not address the actual way in which HRD professionals can utilize a logical approach to extracting the necessary information from SMEs for use in the training content, how HRD professionals and SMEs interact with each other, and what kinds of questions regarding the design of training should be proposed. Further research should be conducted in these areas.

To follow this study, additional interesting research studies can be conducted. First, the data examined in this study was based on HRD professionals' perceptions. Their actual ability was not examined in this study. The results might be different for data based on their perceptions and data based on their actual ability. Thus, additional research can examine whether the actual ability of Taiwan HRD professionals in the training design process is congruent with their perceptions of their ability.

Second, the education level had an influence on the perceived ability to work with SMEs among HRD professionals who had worked with SMEs and the perceived current ability in the training design process among HRD professionals who had not 
worked with SMEs as well. Thus, education level was logically related to the development of their ability. Further research can examine whether HRD professionals' major fields are in any way related to their ability to design training programs and to work with SMEs.

Third, this study demonstrated that the role of SMEs to assist HRD professionals through conceptualizing their theoretical knowledge and contributing their practical experience to the training content may in part influence the ability of HRD professionals to design training programs. However, the perceived ability of SMEs was not part of the study. A proposed approach for future study is to determine what competencies SMEs perceive can assist HRD professionals in designing training programs.

Fourth, this research may be replicated in other Asian countries, such as Mainland China, Japan or Singapore, since Taiwan and these countries have similar cultural backgrounds and no research of this kind has been conducted in these countries.

Fifth, additional research can be conducted in which the criteria for training design competencies and the ability to work with SMEs can become the competencies of HRD professionals needed to meet the requirements of ISO 10015, the standardization of quality of training. Such research would be useful as most HRD professionals in the organizations are responsible for the training programs. Helping an organization acquire ISO10015 certification has become one of the main tasks of HRD professionals. Thus, there is a need to ensure that HRD professionals have 
sufficient ability to design training programs in order to fulfill the second step of ISO 10015--design and plan training.

Finally, this study was based on the conceptual framework presented in Figure 2.2. Based on the results, it can be concluded that most of the original conceptual framework was supported. However, two parts of the original conceptual framework were not supported. The first unexpected result was that, among HRD professionals who had and who had not worked with SMEs, the perceived current ability and the desired ability in the training design process were not significantly different. Therefore, follow-up research studies that utilize qualitative data, such as in-depth interviews to acquire more substantial data, are encouraged to confirm what tasks the HRD professionals are responsible for in training design programs, especially in technical skills training programs. Also, it is necessary to confirm how much HRD professionals know about the systematic training design process at present because this result revealed that an instrument defining training design competencies as categorized by a systems approach, ADDIE, seemed difficult, confusing, and too complicated for them to understand. The second unexpected result was that the organization size and years of work experience were not related to the HRD professionals' current ability, desired ability, or ability to work with SMEs. The revised framework as presented in Figure 5.2 will serve as a guide for the future research. 


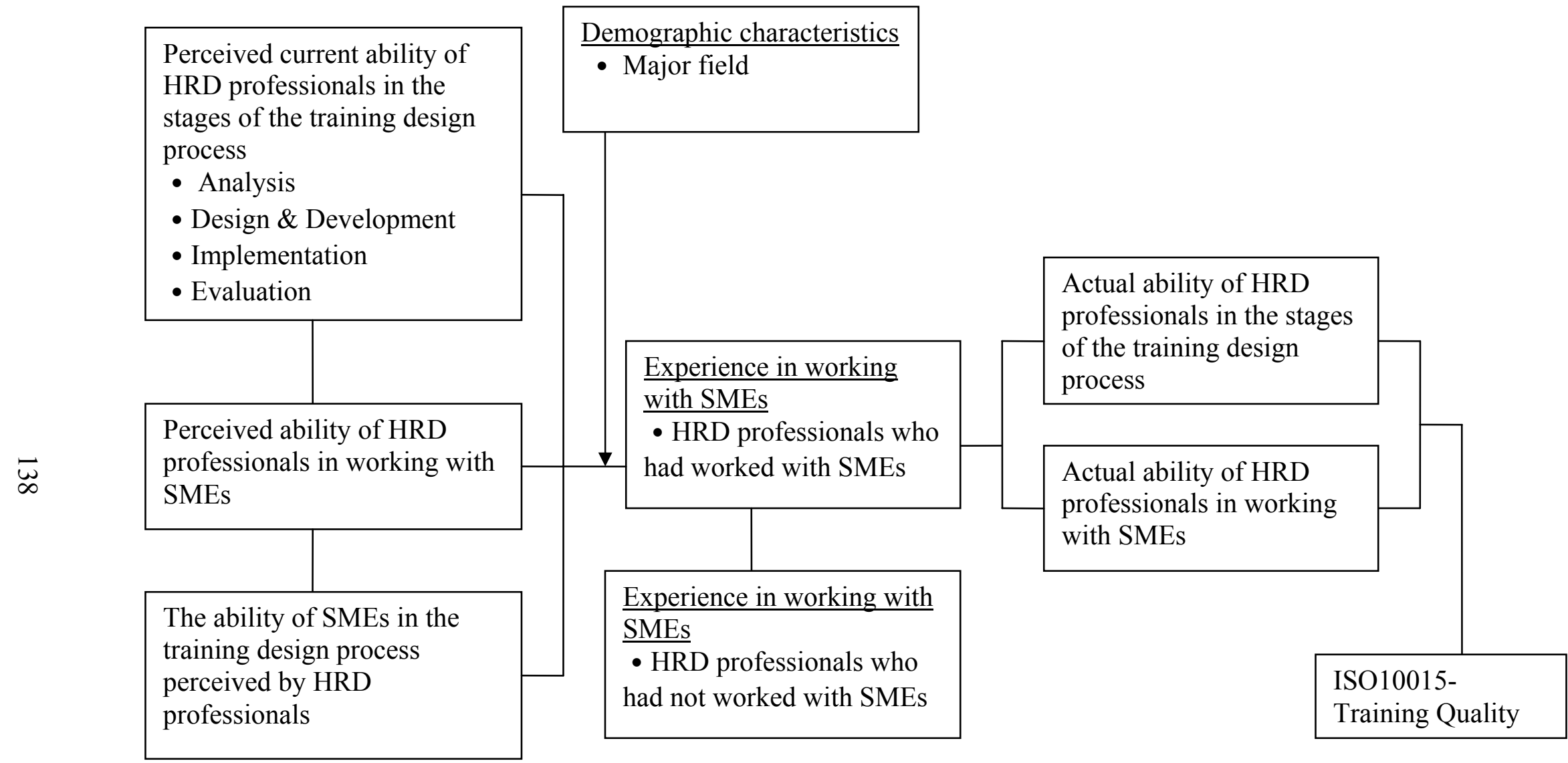

Figure 5.2: Revised conceptual framework 
Implications for HRD Practitioners

The results of this study showed that a lower percentage of HRD professionals who had worked with SMEs had no experience in designing training programs $(9.5 \%)$. Or, in other words, a higher percentage of HRD professionals who had worked with SMEs had experience in designing training programs than HRD professionals who had not worked with SMEs. This result demonstrated that HRD professionals perceived that their ability to design training programs had become the basis for their work with SMEs. Thus, it is critical for HRD professionals to take notice of available opportunities to develop HRD professionals' ability in training design. There are two approaches in the methods suggested: an approach based on instructional design principles and a training content approach. The instructional design principles are an elaboration of the basic concepts regarding training design programs. The training content approach is a logical approach to extracting the necessary information from SMEs through consultation with them for development of the training content.

\section{Implications for Business Organizations}

The significant relationship between the ability to design training programs and the ability to work with SMEs found in this study was that the higher the current ability of HRD professionals in the training design process, the higher their ability to work with SMEs. However, the results showed that HRD professionals utilized selfdirected learning and sources outside of the organizations as their main methods for learning how to design training programs. If the organizations can provide training programs focused more on training design competencies and provide opportunities for 
practice to HRD professionals, the HRD professionals will improve their ability and the organizations can save more modest expenditures for designing training programs. That is, the organizations can purchase fewer training programs packages from consultants and reduce the number of outside or inside SMEs hired to design training programs. In addition, the results of the study should be used as a framework for the qualifications of the HRD professionals in the organization so that appropriate high quality training can be provided for HRD professionals working with SMEs on different subject matters. Also, the training of HRD professionals must be systematic and comprehensive in order to include the competencies that HRD professionals need to possess and which may become the basic criteria to qualify a solid professional in the HRD field.

Implications for Higher Education

Education level had an influence on the perceptions of HRD professionals regarding their ability to work with SMEs and their current ability in the training design process. This means that the demand for education among HRD professionals is likely to increase. Academic training programs must begin to provide more opportunities for HRD major students to learn the instructional design process through experience related to their eventual career path as well as to learn consultation skills. In general, professional educators acknowledge that knowledge of the complexities of instructional design is not enough to ensure the designer's success. The more important and essential elements are consultation, interviewing, and human relations with SMEs (Bratton, 1983). 
Therefore, the bachelor's program can provide some basic courses regarding the principles of instructional design, the systems thinking approach in the HRD area, and the foundation of training and development; master's or doctoral programs can develop appropriate curricula with courses regarding the skills of systematic training design and consultation skills such as job needs analysis, structured training program design, structured on-the-job training, internal consulting for HRD professionals, and training evaluation for advanced students. This will help HRD professionals prepare for their roles with a general set of training design competencies and training content approach skills by sampling the best of both the education and training worlds. 


\section{REFERENCES}

AECT Task Force on ID Certification (1981). Competencies for the instructional development professionals. Journal of Instructional Development, 5(1), 14-15.

Afifi, A, Clark, V.A., \& May, S. (2004). Computer-aided multivariate analysis (4 ${ }^{\text {th }}$ ed.). Boca Raton, Fla.: Chapman \& Hall/CRC.

Alreck, P. L., \& Settle, R. B. (1995). The Survey Research Handbook. Chicago: Irwin.

Anderson, C. L., O’Neil, H. F., \& Baker, E. L. (1991). Implementation of instructional systems development in the U.S. army: lessons learned from research utilization. In R. Dillon \& J. Pellegrino (Eds.). Instruction. New York: Praeger.

Argyris, C. (1970). Intervention Theory and Method: A Behavioral Science View. Reading, Mass.: Addison-Wesley.

Armstrong, J. B., \& Sherman, T. M. (1988). Caveat emptor: How SME's can ensure good ID. Performance and Instruction, 27(4), 13-18.

Ary, D., Jacobs, L. C., \& Razavieh, A. (2001). Introduction for Research in Education. Belmont, CA: Wadsworth.

Bartz, A. E. (1999). Basic Statistic Concepts. Upper Saddle River, NJ: Prentice-Hall.

Blake, R. R., \& Mouton, J. S. (1978). The New Managerial Grid. Houston, Tex.: Gulf.

Block, P. (1981). Flawless Consulting. San Diego, CA: University Associates.

Branson, R. K. (1977). Military and Industrial Training. In L. J. Briggs (Ed.), Instructional Design: Principles and Applications. Englewood Cliffs, NJ: Educational Technology Publications.

Bratton, B. (1979-80). The instructional development specialist as consultant. Journal of Instructional Development, 3(2), 2-8.

Bratton, B. (1981). Training the instructional development specialist to work in unfamiliar content areas. Journal of Instructional Development, 4(3), 21-23. 
Bratton, B. (1983). The instructional design specialist-subject matter relationship. Educational Technology, 23(6), 13-16.

Briggs, L. J. (1977). Instructional Design: Principles and Applications. Englewood Cliffs, NJ: Educational Technology Publications.

Brokes, A. (1975). A process model of consultation. In C. A. Parker (Ed.), Psychological Consultation: Helping Teachers Meet Special Needs. Minneapolis: Leadership training institute.

Caplan, G. (1970). Theory and Practice of Mental Health Consultation. New York: Basic books.

Lee, C. (2004). Perceived job change toward dimensions of knowledge work among three levels of employees in a Korean bank. Unpublished doctoral dissertation, Ohio State University, Columbus.

Chang, K. L. (2000). 人力資源發展人員所需能力與角色之研究 [The Competencies and Roles of HRD]. Unpublished master's thesis, National Dong Hwa University, Hualian, Taiwan.

Chang, Y. F. (2001). 人力資源發展人員的角色及專業能力之分析 [Job Roles and Professional Competence of Human Resource Development Specialist]. Unpublished master's thesis, National Chung Cheng University, Chia-Yi, Taiwan.

Chang, W. L. (1999). Human Resource Management, Taipei: Hw-Tei (Chinese).

Chen, H. C. (2005), Cross cultural constructor validation of the learning transfer system inventory in Taiwan, Human Resource Development Quarterly, 16(1), 55-84.

Chen S. Y. (2003). Perceptions of Taiwan practitioners on expertise level and importance workplace learning and performance (WLP) competencies. Unpublished doctoral dissertation, Pennsylvania State University, University Park.

Chen, S. Y., Bian, M. D., \& Hom, Y-M. (2005). Taiwan HRD practitioner competencies: an application of the ASTD WLP competency model. International Journal of Training and Development, 9(1), 21-32.

Chen, W. W. (1998). 高科技産業HRD 經理專業能力之研究 [A Study of Professional Competencies of the HRD Manager in High-tech Industries]. Unpublished master's thesis, National Taiwan Normal University, Taipei, Taiwan. 
Cheng, H. (1988). 人力資源發展專業人員的能力及角色調查報告 [The competencies and roles of HRD]. Labor Administration, 19.

Cheng, H. (1991). 人力資源發展專業人員的能力調查報告 [Research report of competence of HRD professionals in Taiwan]. Labor Administration, 44, 49-54.

Chi, M. T. H., Glaser, R., \& Farr, M. J. (1988). The Nature of Expertise. Hillsdale, NJ: Lawrence Erlbaum Associates.

Chien, H. J. (2003). 企業網路化訓練課程設計影響因素之研究 [A Study of Factors the Curriculum Design for Corporate Web-based Training]. Unpublished master's thesis, National Taiwan Normal University, Taipei, Taiwan.

Chiu, Y. F. (2003). 網路化訓練教學設計人員能力之研究 [A Study of Competencies for Instructional Designers in Web-based Training]. Unpublished master's thesis, National Taiwan Normal University, Taipei, Taiwan.

Colton, F. (1974). A basic approach to the design specialist-teacher relationship. Audiovisual Instruction, 17, 24-25.

Cram, D. D. (May, 1981). Designing instructional: meeting with the SME. NSPI Journal, 20(4), 5-8.

Davidove, E. A. (1993). Using content experts to help produce training. Performance \& Instruction, 36, 18-23.

Davies, I. (1975). Some aspects of a theory of advice: the management of an Instructional developer-client, evaluator-client relationship, Instructional Science, 3, 351-373.

Davis, P., Naughton, J., \& Rothwell, W. (2004). New Roles and New Competencies for the Profession, $T \& D$, 58(4): 26-36.

Deal, C. D. (2004). Training across cultures: Designing training for participants from China, India, and Mexico. Unpublished doctoral dissertation, The University of New Mexico, New Mexico.

Deden-Parker, A. (February, 1981). Instructional technology skills sought by industry, NSPI Journal, 20(1), 24-25, 30.

DeSimone, R. L., \& Harris, D. M. (1998). Human Resource Development, Fort Worth, TX: The Dryden Press.

Dick, W. (1988). Working with subject specialists: A commentary on Morrison and Tessmer. Journal of Instruction Development, 11(2), 37-39. 
Dick, W. \& Carey, L. (1996). The systematic design of instruction (4 ${ }^{\text {th }}$ ed.). Dallas Texas: Harper Collins.

Dick, W., Carey, L., \& Carey, J. O. (2005). Systematic Design of Instruction (6 ${ }^{\text {th }}$ ed.). Boston: Pearson/Allyn and Bacon.

Dormant, D. (1986). Clients are people, too. Performance and Instruction, 25(4), 3-5.

Dubois, D., \& Rothwell, W. (2004). Competency-Based or a Traditional Approach to Training? $T+D, 58(4), 46-57$.

Elkin, G. (1990). Competency-based human resource development, Industrial and Commercial Training, 22(4), 20-25.

Elson, John, L. II (2003). Expert and Novice Performance in an Industrial Engineering Scaled World Simulation. Unpublished doctoral dissertation, Ohio State University, Columbus.

Fraenkel, J. R. and Wallen, N. E. (2000). Validity and reliability. How to design and evaluate research in education. Boston : McGraw-Hill.

Fu, C. J., Ye, J. L., \& Chu, H. C. (2003). The HR practices in high-tech business in Taiwan- from the employers perspectives. In K. P. Kuchinke (ed.), Proceeding of the 2003 Annual Conference of the Academy of Human Resource Development, Minneapolis, MN: Academy of Human Resource Development, $752-759$.

Gagné, R. M., Briggs, L. J., \& Wager, W. W. (1992). Principles of Instructional Design $\left(4^{\text {th }}\right.$ ed.). Fort Worth, TX: Harcourt Brace Jovanovich College Publishers.

Gagné, R. M., Wager, W. W., \& Golas, K. C. (2005). Principles of Instructional Design. John M. Keller Publish info Belmont, CA: Wadsworth/Thomson Learning.

Gall, M. D., Borg, W. R., \& Gall, J. P. (1996). Educational research: An introduction $\left(6^{\text {th }}\right.$ ed.). White Plains, NY: Longman.

Gay, L. R., \& Airasian, P. (2003). Educational Research: Competencies for Analysis and Application. Upper Saddle River, N.J.: Merrill/Prentice Hall.

Gayeski, D. W, Wood, L. E., \& Ford, J. M. (1992). Getting inside an expert's brain. Training and Development, 8(3), 7-14.

Gilbert, T. F. (1978). Human Competence: Engineering Worthy Performance. NY: McGraw-Hill. 
Gilbert, T. F. (1996). Human Competence: Engineering Worthy Performance (Tribute ed.). Amherst, MA: HRD Press.

Gilley, J. W., Eggland, S. A., \& Gilley, A. M. (2002). Principles of Human Resource Development ( $2^{\text {th }}$ ed.). NY: Addison-Wesley publishing company.

Glaser, R. (1985). The nature of expertise (Occasional Paper No. 107. National Center For Research in Vocational education). Columbus, OH: Ohio State University.

Gustafson, K. L. (1996). Instructional design: Models. In A. C. Tuijnman (Ed.), International Encyclopedia of Adult Education and Training (2 ${ }^{\text {nd }}$ ed., pp. 503509). Oxford, U. K.: Pergamon.

Gustafson, K. L., \& Branch, R. M. (2002). Survey of Instructional Development Models with an Annotated ERIC bibliography ( $4^{\text {th }}$ edition). (ERIC Document Reproduction Service No: ED477517).

Hartle, F. (1995). How to Re-engineer Your Performance Management Process. London: Kogan Page.

Havelock, R. (1973). The Change Agent's Guide to Innovation in Education. Englewood Cliffs, N.J., Educational Technology Publications.

Herling, R. W. (2000). Operational definitions of expertise and competence. In R.W. Herling \& J. Provo (Eds.). Advances in developing human resources: Strategic perspectives on knowledge, competence, and expertise. San Francisco: BerrettKoehler.

Hoffman, R., Shadbolt, N. R., et al. (1995). Eliciting knowledge from experts: a methodological analysis. Organizational Behavior and Human Decision Processes, 62(2), 1259-158.

HSBIP (2005). Hsinchu Science-Based Industrial Park. <http://www.sipa.gov.tw $>$ (July 6, 2005).

Huang, W. R. \& Jacobs, R. L. (2004). Impact of ISO Certification on Training and Development Activities in the Electronics Industry in Taiwan. In Y. Moon, A. M. Osaman-Gani, S. Kim, G. L. Roth, \& H. Oh (eds.), Proceedings of the $3^{\text {rd }}$ Asian Conference of the Academy of Human Resource Development, Seoul, South Korea: Academy of Human Resource Development, 644-648.

Indermill, K. L. (March, 1986). What to do if you've got SME sclerosis. Performance and Instructions, 25(2), 14-15, 19. 
Ingram, A. L., Heitz, K., Reid, C., Walsh, M. B., \& Wells, C. (1994). Working with subject matter experts. Performance and Instructional, 33(8), 17-22.

International Board of Standards for Training, Performance, and Instruction (IBSTPI) (1988). Instructor competencies: The standards. Vol.1. Evergreen, CO: Author.

Jacobs, R. L. (1990). Human resource development as an interdisciplinary body of knowledge. Human Resource Development Quarterly, 1(1), 65-71.

Jacobs, R. L. (1997). A taxonomy of employee development: Toward an organizational culture of expertise. In R. Torraco (ed.), Proceedings of the 1997 Annual Conference of the Academy of Human Resource Development, Baton Rouge, LA: Academy of Human Resource Development, 278-283.

Jacobs, R. L. (2001). Managing employee competence in global organizations. In Kidd, J. Li, X, \& Richter, F., (eds.). Maximizing Human Intelligence Development in Asian Business. New York: Palgrave.

Jacobs, R. L. (2003). Structured on-the-job training: Unleashing employee expertise in the workplace ( $2^{\text {nd }}$ edition). San Francisco, Berrett-Koehler Publications, Inc.

Jacobs, R. L \& Washington, C. (2003). Employee development and organizational performance: a review of literature and directions for future research. Human Resource Development International, 6(2).

Jheng, J. H. (1994). 企業界教育訓練人員基本專業能力之咑究 [The Study of the Essential Competencies for Training Personnel in Business]. Unpublished master's thesis, Tamkang University, Taipei, Taiwan.

Johnson, B., \& Christensen L. (2000). Educational Research: Qualitative and quantitative approaches. Needham Heights, MA: Allyn \& Bacon.

Jones, J. E. (2002). Self-determination theory as a model for motivation in a training context. Unpublished doctoral dissertation, University of Oklahoma, Norman.

Keppell, M. J. (1997). Development and Pilot-testing of a Method to Assist Instructional Designers Elicit Unfamiliar Content from Subject Matter Experts. Unpublished doctoral dissertation, University of Calgary, Calgary, Alberta.

Klemp, George O., Jr. (1980). The Assessment of Occupational Competence. Report to National Institute of Education. Washington, DC: National Institute of Education.

Krejcie, R. V. and Morgan, D. W. (1970). Determining sample size for research activities. Educational and Psychological measurement, 30, 608. 
Kuchinke, K. P. (1996). Experts and Expertise: the status of the research literature on superior performance. In K. P. Kuchinke (ed.) Academy of Human Resource Development 1996 Conference Proceeding. Minneapolis, MN: Academy of Human Resource Development.

Kuchinke, K. P. (1997). Employee expertise: The status of the theory and the literature. Performance Improvement Quarterly, 10, 72-77.

Kurpius, D. J. \& Brubaker, J. C. (1976). Psycho-education Consultation: Definitionsfunctions-preparation. Bloomington, Indiana: Indiana University.

Lee, L. S. (2000). 訓練與學科專家合作之道 [The collaboration between training experts and subject matter experts]. 人力培訓專刊, 16(2), 60-66.

Lee, S. H., \& Rothwell, W. J. (1995). Exploring HRD competencies in Taiwan: The results of a cross-cultural study, International Journal of Vocational Education and Training, 3(2), 5-20.

Lee, S. H. (1998). 人力資源發展專業能力與角色之㸴究 [The competencies for Human Resource Development Professionals]. Bulletin of National Pingtung University of Science and Technology, 7(4), 319-326.

Lee, W. W. (1994). Subject matter experts and instructional designers: making distinctions, Performance and Instruction, 33(8), 23-25.

Leitzman, D., Walter, S., Earle, S., \& Myers, C. (1979). Contracting for instructional development. Unpublished manuscript, Indiana University.

Lien, B. Y. H. \& McLean, G. N. (2004). Portraits of Taiwanese HR practitioners performing HRD tasks. Human Resource Development International, 7(1), 73-83.

Lin, Y. C. \& Jacobs, R. L. (2004). A Theoretical Framework of Collaboration between Training Designers and Subject Matter Experts (SMEs): A Review of Literature. In Y. Moon, A. M. Osaman-Gani, S. Kim, G. L. Roth, \& H. Oh (eds.), Proceedings of the $3^{\text {rd }}$ Asian conference of the Academy of Human Resource Development, Seoul, Korea: Academy of Human Resource Development, 134-144.

McLagan, P. A. (1983). Models for excellence: the conclusions and recommendations of the ASTD training and development competency study. Washington, D.C.: American Society for Training and Development.

McLagan, P. A. (1989). Models for HRD Practice. Alexandria, VA: American Society for Training and Development. 
McMillan, J. H. and Schumacher, S. (1997). Research in education: A conceptual introduction $\left(4^{\text {th }}\right.$ ed.). New York: Longman.

Mansfield, B. (2004). Competence in transition, Journal of European Industrial Training, 28(2/3/4), 296-309.

Maple, R. J. (1994). "Well, you're the CE... I'm the ID..." describing your role-and selling your worth- to content experts. Performance and Instruction, 33(8), $36-40$.

Moller, L. (1995). Working with subject matter experts, TechTrends, 40(6), 26-27.

Morrison, G. R. (1988a). The instructional designer-subject specialist relationship: implications for professional training. Journal of Instructional Development, 1(2), 24-27.

Nadler, L. (1984). Human Resource Development: Handbook of Human Resource Development. New York: Wiley.

Nelson, W. A., Magliano, S., \& Sherman, T. M. (1988). The intellectual content of instructional design. Journal of Instructional Development, 11(2), 29-35.

Ontario Society for Training \& Development, Professional Development Committee (1979). Competency Analysis for Trainers: A Personal Planning Guide:_A Self Appraisal Development Process for the Training and Development Person. Publish info Toronto, Ont.: the Society.

Parhar, M., \& Mishra, S. (2000).Competencies for Web-based instructional designers. Indian Journal of Open Learning, 9(3), 415-422.

Parry, S. B. (June, 1998). Just what is a competency? And why should you care? Training, 35(6), 58-94.

Peeraponvitoon, M. (1999). A Survey of Workplace Learning and Performance: Competencies and Roles for Practitioners in Thailand. Unpublished doctoral dissertation, Pennsylvania State University, University Park.

Pinto P. R. \& Walker, J. W. (1978). A Study of Professional Training and Development Roles and Competencies. Madison, WI: American Society for Training and Development.

Price, R. (1976). A Description of the Verbal Behavior of Selected Instructional Developers in their Initial Conference with New Clients: An Exploratory Study. Unpublished doctoral dissertation, Michigan state university, East Lasing. 
Reigeluth, C. M. (1983). Instructional design: What is it and why is it? In C. M. Reigeluth (Ed.). Instructional Design Theories and Models: An Overview of their Current Status (pp.3-36). Hillsdale, NJ: Lawrence Erlbaum.

Reigeluth, C. M. (1996). Instructional design: Guidelines and theories. In A. C. Tuijnman (Ed.), International encyclopedia of adult education and training ( $2^{\text {nd }}$ ed., pp. 497-503). Tarrytown, N.Y.: Pergamon.

Richey, R., Fields, D., Foxon, M. (with Roberts, R. C.; Spannaus, T. \& Spector, J. M.) (2001) Instructional Design Competencies: The Standards ( $\left.3^{\mathrm{rd}} \mathrm{Ed}\right)$ Eric Clearinghouse on Information and Technology, Syracuse, NY.

Richy, R. (1986). The Theoretical and Conceptual Bases of Instructional Design. London: Kogan Page; New York : Nichols Pub. Co.

Rodriguez, S., Stephens, R., \& Arena, S. (1991). Interviewing subject matter experts" strategies for instructional design success. Educational Technology, 31(12), $27-32$.

Rose, J., \& Riegert, E. (1976). Looking at the instructional developer from the client's point of view. Papered presented at the Annual Convention of the Association for Educational Communication and Technology, Anaheim.

Rossett, A. (1987). Training Needs Assessment. Englewood Cliffs, NJ: Educational Technology Publications.

Rothwell, W. J., \& Kazanas, H. C. (1992). Mastering the Instructional Design Process: A Systematic Approach. San Francisco: Jossey-Bass Publishers.

Rothwell, W. J. (1996). ASTD Models for Human Performance Improvement Roles, Competencies, and Outputs. Alexandria, VA: American Society for Training and Development.

Rothwell, W. J., Sanders, E. D., \& Soper, J. G. (1999). ASTD Models for Workplace Learning and Performance. Alexandria, VA: American Society for Training and Development.

Rowland, G. (1992). What do instructional designers actually do? An initial investigation of expert practice. Performance Improvement Quarterly, 5(2), 65-86.

Rowland, G. (1994). Designing for human performance. Performance Improvement Quarterly, 7(3), 1-128. 
Rummler, A.G., \& Braches, A.P. (1995). Improving performance: how to manage the white space $\mathrm{pm}$ the organizational chart ( $2^{\text {nd }}$ edition $)$. San Francisco, CA: Jossey-Bass.

Rutt, D. P. (1980). A framework for investigating consultation in instructional development. Journal of Instructional Development, 3(2), 9-15.

Rutt, D. P. (1985). Consultation in instructional development: a first look. In R. K. Bass and C. R. Dills (Eds.). Instructional development: the state of the art. II (pp. 294-309). Iowa: Kendall/Hunt publishing company

Ryan, T. A. (1975). Analysis of the systems approach. In S. D. Zalatimo and P. J. Sleeman (Eds.) A systems approach to learning environments (pp. 118-129). Pleasantville, NY: Docent Corporation.

Ruona, W. (2000). Should we define the profession of HRD? View of leading scholars. In P. Kuchinke (ed.), Proceedings of 2000 Annual Academy of Human Resource Development, Vol.1, Baton Rouge, LA: Academy of Human Resource Development, 196-204.

Salas, E. \& Cannon-Bower, J. A. (2000). Designing training system. In E. A. Locke (Eds.). Handbook of Principles of Organizational Behavior. Malden, MA: Blackwell Business.

Schein, E. H. (1969). Process Consultation. Reading, Massachusetts; Addison-Wesley Publishing Co., Inc.

Schein, E. H. (1978). The role of the consultant: content expert or process facilitator. The Personnel and Guidance Journal, 56, 339-343.

Sedlack, R. G., \& Stanley, J. (1992). Social Research Theory and Methods. Boston: Allyn and Bacon.

Shrock, S. A. (1995). A brief history of instructional development. In G. J. Anglin (Eds.). Instructional Technology: Past, Present, and Future. Englewood, Colo.: Libraries Unlimited.

Siber, K. (1975). Organizational and Personnel Management Structures Needed for the Successful Implementation of Instructional Development in Educational Institutions. Unpublished manuscript, Governors state university, Park forest south, Illinois.

Spencer, L. M., \& Spencer, S. M. (1993). Competence at Work: Model for Superior Performance. New York: John Wiley \& Sons, Inc. 
Spradley, J. P. (1979). The Ethnographic Interview. New York: Holt, Rinehart, and Winston.

Steele, F. (1975). Consulting for Organizational Change. Cambridge, Massachusetts: University of Massachusetts Press.

Streumer, J. N., \& Tuijnman, A. C. (1996). Curriculum in adult education. In A. C. Tuijnman (Ed.), International Encyclopedia of Adult Education and Training ( $2^{\text {nd }}$ ed., pp.472-480). Oxford, U.K.: Pergamon.

Su, P. M. (2004). 人力資源課程設計與專業人員核心職能關聯性之研究一以國內 人力資源相關系所爲例 [The Relationship between Human Resources Curricula Designing and Professional Core Competence]. Unpublished master's thesis, National Chung Cheng University, Chia-Yi, Taiwan.

Swanson, R. A. (1990). HRD performance interventions. Human Resource Development Quarterly, 1(3), 207-208.

Swanson, R. A. (1994). Analysis for Improving Performance: Tools for Diagnosing Organizations and Documenting Workplace Expertise. San Francisco: BerrettKoehler.

Swanson, R. A. (1996). Analysis for Improving Performance: Tools for Diagnosing Organizations and Documenting Workplace Expertise. San Francisco: BerrettKoehler.

Swanson, R. A. (2003). A disservice to the ideas of theory, research, and expertise. Human Resource Development Review, 2(2), 206-210.

Swanson, R. A. \& Holton III, E. F. (2001). Foundations of Human Resource Development. San Francisco: Berrett-Koehler.

Swanson, R. A. \& Torraco, R. J. (1995). Twentieth-century influences. In L. Kelly's (Ed.). The ASTD Technical and Skills Training Handbook. New York: McGraw Hill, Inc.

Tessmer, M. (1988). Subject specialist consultation in instructional design: higher education. Journal of Instructional Development, 11(2), 29-35.

Tessmer, M. (1998). Meeting with the SME to design multimedia exploration systems. Educational Technology Research and Development, 46(2), 79-95.

Tilles, S. (1961). Understanding the consultant's role. Harvard Business Review, 39, 87-89. 
Trautman, S., \& Klien, K. (1993). Ask an expert. T\&D, 47(7), 45-48.

Tuijnman, A. C. (1996a). Educational technology: Introduction. In A. C. Tuijnman (Ed.), International encyclopedia of adult education and training ( $2^{\text {nd }}$ ed., pp.453-455). Oxford, U.K.: Pergamon.

Wallington, C. J. (1981). Generic skills of an instructional developer. Journal of Instructional Development, 4(3), 28-32.

Washington, C. L. (2002). The Relationships among Learning Transfer Climate, Transfer Self-efficacy, Goal Commitment, and Sales Performance in an Organization Undergoing Planned Change. Unpublished doctoral dissertation, Ohio State University, Columbus.

Wedman, J. F. (1987). Conceptualizing unfamiliar content. Journal of Instructional Development, 10(3), 16-21.

White, R. W. (1959). Motivation reconsidered: the concept of competence, Psychological Review, 66 (5), 279-333.

Williams, S. W. (1999). Improving technical training: the effectiveness of technical subject matter experts as trainers. In K. P. Kuchinke (ed.), Proceedings of the 1999 Annual Conference of the Academy of Human Resource Development, Baton Rouge, LA: Academy of Human Resource Development, 588-595.

Williams, S. W. (2001). The effectiveness of subject matter expert as technical trainers. Human Resource Development Quarterly, 12(1), 91-97.

Yancey, C. (1995). The ABCs of working with SMEs. Performance \& Instruction, 35(1), 6-9.

Yang, B. (2005). Factor analysis methods. In R. A. Swanson \& F. H. III Holton (Ed.), Research in organizations: Foundations and Methods of Inquiry (pp.181-199). San Francisco, CA: Berrett-Koehler.

Yang, J. C. (1994). Perceived competencies needed by HRD managers in Korea. Unpublished doctoral dissertation, University of Minnesota, Twin Cities.

Yoo, P. J. (1999). Korean human resource development (HRD) practitioners' perceptions of expertise level and importance of workplace learning and performance (WLP) competencies. Unpublished doctoral dissertation, Pennsylvania State University, University Park. 
Appendix A

SURVEY 
The Perceptions of Human Resource Development (HRD) Professionals

in Taiwan Regarding their Working Relationships

with Subject Matter Experts (SMEs)

During the Training Design Process

\section{CONSENT FOR PARTICIPATION}

Protocol Number: 2005B0214

Principal Investigator: Ronald L. Jacobs

I consent to my participation in research being conducted by Ronald L. Jacobs of The Ohio State University and his advisee, Miss Yi-chun Lin.

I understand the purpose of the study and the amount of time it will take to finish this survey which was described in the invitation letter.

I know that I can choose to participate or not to participate in this survey without any stress or enforcement from someone. If the questions in this survey make me feel uncomfortable or the timing is not appropriate to answer this survey, I can withdraw from the study anytime.

I am aware that, although every effort to protect confidentiality will be made, no guarantee of internet survey security can be given; transmissions can be intercepted and IP address can be identified.

I can contact the investigator at Jacobs.3@osu.edu or Yi-chun Lin at lin.565@osu.edu if I have any questions. Also, I can reach the Office of Responsible Research Practice at 002-1-800-678-6251 if I have questions about my rights as a research participant. 
Part 1: Please check your response to each item

1. How many employees does your organization have?

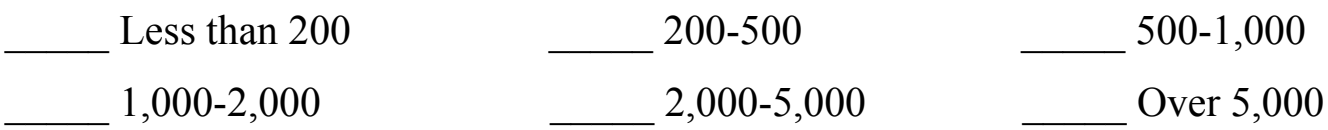

2. What is your highest level of formal education?

Doctoral Degree

Bachelor's Degree

High School Diploma
Master's Degree

Associate's Degree

Other Degree

Designing training programs refers to the process of synthesizing and operationalizing the inputs from Subject Matter Experts (SMEs) to create the formal training programs which are typically used to enable employees to develop the knowledge and skills required to perform their jobs.

3. How did you learn about designing training programs? (Check all that apply)

Self-directed informal learning Formal professional development programs outside your organization Formal professional development programs inside your organization Learned as part of an academic degree program Other (Please specify) None of the above

4. a). How many years of work experience do you have?

Years

b). How many years of work experience do you have in human resources related jobs?

Years

c). Do you have any experience in designing training programs?

Yes (Please continue to answer the question "d" and Part 2)

No (Please jump to answer Part 2)

d). What percentage of your job consists of designing training programs?

$-25 \% \quad 26 \%-50 \%$

$51 \%-75 \%$ $76 \%+$ 
Part 2: Please rate your current and desired ability to perform the following training design competencies.

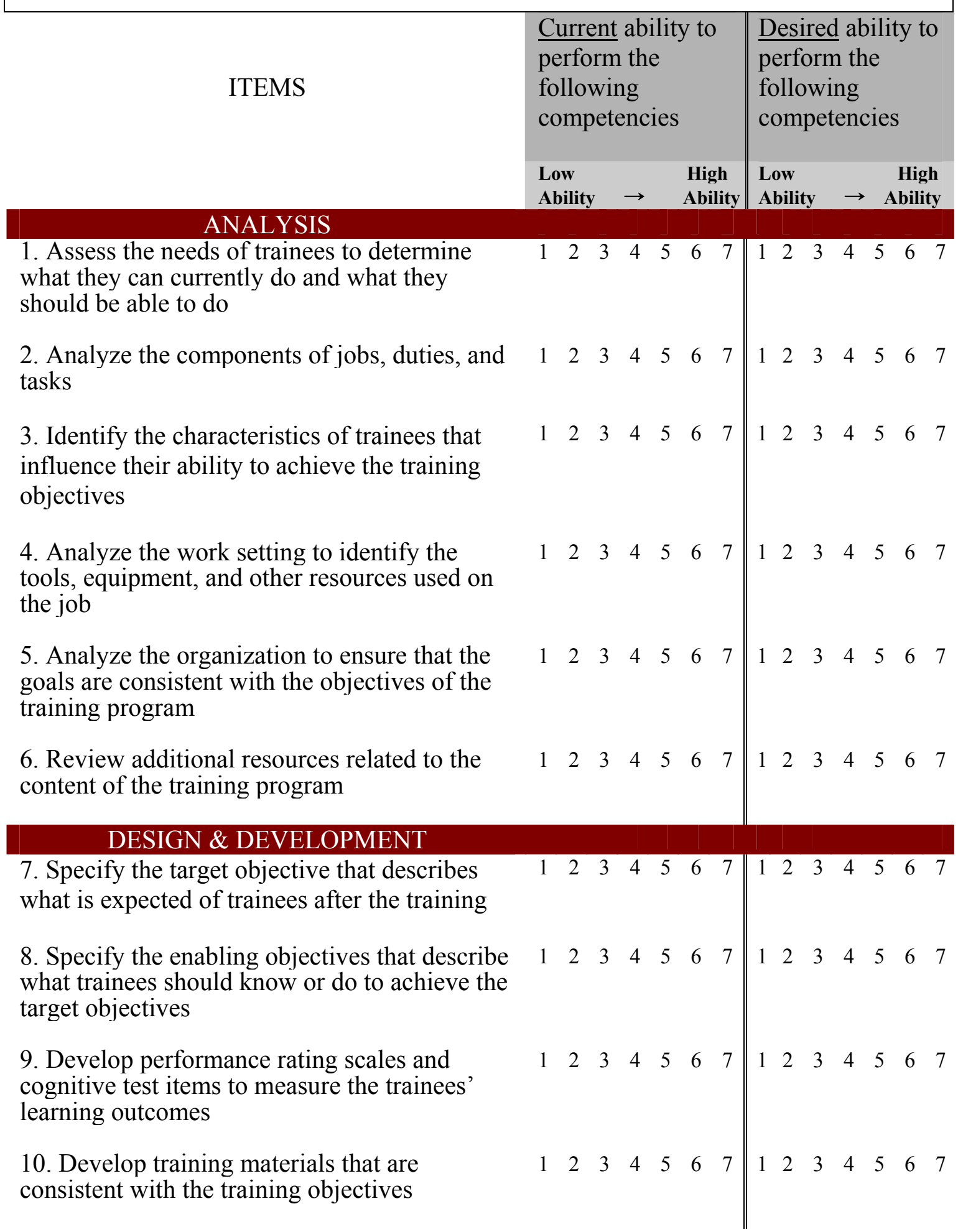


11. Identify training strategies, methods, and approaches to present the training content

12. Design lessons based on a logical learning sequence

13. Use a structured writing format to prepare trainer and trainee guides

\begin{tabular}{lllllll||lllllll}
1 & 2 & 3 & 4 & 5 & 6 & 7 & 1 & 2 & 3 & 4 & 5 & 6 & 7
\end{tabular}

\begin{tabular}{lllllll|lllllll}
1 & 2 & 3 & 4 & 5 & 6 & 7 & 1 & 2 & 3 & 4 & 5 & 6 & 7
\end{tabular}

14. Select appropriate technology as a means to $\begin{array}{llllllll}1 & 2 & 3 & 4 & 5 & 6 & 7\end{array}$

$\begin{array}{lllllll}1 & 2 & 3 & 4 & 5 & 6 & 7\end{array}$ deliver training

\section{IMPLEMENTATION}

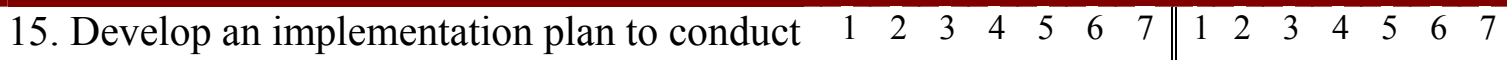
the training program

16. Ensure the organization to support the training program

17. Record the progress of trainees during the training

\section{EVALUATION}

18. Evaluate the trainees' overall satisfaction with the training program

19. Determine what trainees have learned from the training program

20. Report the results of the training program to management

21. Determine the financial benefits of the training program

\begin{tabular}{lllllll||lllllll}
1 & 2 & 3 & 4 & 5 & 6 & 7 & 1 & 2 & 3 & 4 & 5 & 6 & 7 \\
1 & 2 & 3 & 4 & 5 & 6 & 7 & 1 & 2 & 3 & 4 & 5 & 6 & 7 \\
1 & 2 & 3 & 4 & 5 & 6 & 7 & 1 & 2 & 3 & 4 & 5 & 6 & 7 \\
1 & 2 & 3 & 4 & 5 & 6 & 7 & 1 & 2 & 3 & 4 & 5 & 6 & 7
\end{tabular}

NEXT 
Subject Matter Experts (SMEs) are individuals who have in-depth knowledge and skills in a specific topic or aspect of their jobs, and who work with HRD professionals to assist in the design of training programs related to their knowledge and skills.

1. a). Do you have any experience in collaborating with an SME?

Yes (Please continue to answer the question " $b$ " and Part 3)

No (The end! Thanks for your participation in this survey)

b). When you are designing a training program, what percentage of time do you typically spend collaborating with an SME?

$-25 \%$

$26 \%-50 \%$

$51 \%-75 \%$ $76 \%+$

NEXT 
(-) (-) (-) You are almost done. Next section is the last one. $\bullet \bullet \bullet$

Part 3: Please reflect on an SME that you have worked with as part of designing a training program in the past six months. Please rate your ability to work with that person to perform the following competencies.

Subject Matter Experts (SMEs) are individuals who have in-depth knowledge and skills in a specific topic or aspect of their jobs, and who work with HRD professionals to assist in the design of training programs related to their knowledge and skills.

\section{ITEMS}

Ability to perform the following competencies

Low Ability $\rightarrow$ High Ability

1. Clarify the role and tasks expected of the SME during the training project

2. Obtain a commitment from the SME to be involved in the training project

3. Prepare an agenda for each meeting with the SME

4. Provide examples to ensure the SME understands how the training will be carried out

5. Ensure that the SME understands the target objective of the training program

6. Use open-ended questions to prompt the SME to provide more detailed information

7. Ask the SME to review the training program to identify weaknesses or missing components

8. Renegotiate with the SME regarding the design of the training program

\begin{tabular}{|ccccccc}
1 & 2 & 3 & 4 & 5 & 6 & 7 \\
1 & 2 & 3 & 4 & 5 & 6 & 7 \\
1 & 2 & 3 & 4 & 5 & 6 & 7 \\
1 & 2 & 3 & 4 & 5 & 6 & 7 \\
1 & 2 & 3 & 4 & 5 & 6 & 7 \\
1 & 2 & 3 & 4 & 5 & 6 & 7 \\
1 & 2 & 3 & 4 & 5 & 6 & 7 \\
1 & 2 & 3 & 4 & 5 & 6 & 7
\end{tabular}

Done

The end! Thanks for Your Feedback!!!

Remember to fully close your browser to logout of whatever web sites you've been using before leaving your machine unattended! 
Appendix B

SURVEY IN CHINESE 


\section{問卷調查}

台灣人力資源發展人員與内容専家間 對於課程設計過程中之工作關係認知

A Survey of

The Perceptions of Human Resource Development (HRD) Professionals in Taiwan Regarding Their Working Relationships with the Subject Matter Experts (SMEs) During the Training Design Process

\section{參 與 填 答 同 意 書}

研究計畫編碼：2005B0214

研究計畫主持人: Ronald L. Jacobs

受訪者同意參與由美國俄亥俄州立大學 Ronald L. Jacobs 教授和博士班研究生 林怡君同學共同主持的研究計畫之問卷。

受訪者充分瞭解邀請函中所簡述之研究目的及填答問卷時所需時間。

受訪者有權決定是否參與填答此問卷, 回答本問卷係基於個人意願而非任何壓力 迫使。如果問卷内容讓受訪者覺得窒礙難以回答, 受訪者可以隨時退出此問卷。

受訪者瞭解研究計畫者會盡全力保護受訪者網路問卷回覆之安全, 以防被駭客艅 取, 但不能完全保證滴水不露, 有可能傳輸過程被攔截或 IP 位置被定位。

如果受訪者有任何疑問, 受訪者可以直接聯絡研究計畫主持人(電子信箱: jacobs.3@osu.edu); 或者，林怡君同學（電子信箱：1in.565@osu.edu）。 倘若受訪者有任何關於參與者權益之疑問, 可以直接聯絡本校之研究計畫督導處 (002-1-800-678-6251)。

我同意答與此問卷缹—不同意 
第一部分：個人資料 請點選符合 您狀況之選項。

1. 您服務公司的總員工人數有多少?

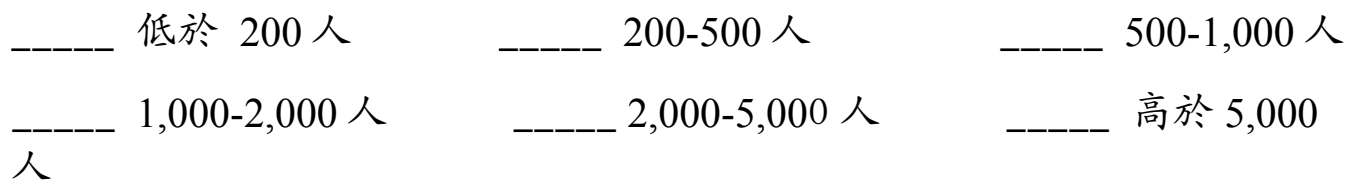

2. 您的最高教育程度爲何? (依據已拿到正式文憑爲主)

_-_-_ 博士_ _-_-_ 碩士_ _

_ _

「設計訓練課程」(Designing training programs) 是指「企業爲培 養員工専業知識及技術之能力, 所規劃出的課程内容及訓練程 序」。

3. 您是否曾参與或接受過下列關於設計訓練課程的專業訓練?（可複選） 蒐集教材, 自行研讀 企業外的専業訓練課程 企業内的專業訓練課程 攻讀專業學位 其他, 請説明 未曾自學或接受過任何専業訓練

4. a). 您總共有幾年的工作經驗? 年

b). 您從事「人力資源」相關工作有幾年的經驗? 年

c). 您是否曾經参與過「設計訓練課程」的經驗？

是 (請繼續回答“d”小題及第二部分)

否 (請跳至第二部分)

d.) 您的業務範圍中, 約有多少比例是與「設計訓練課程」相關之工作?

小於 $25 \%$ $26 \%-50 \%$ $51 \%-75 \%$ 大於 $76 \%$ 請至下一部分 
第二部分：請自我評估點選下列選項符合 您『已具備』及『期望具備』的訓 練課程設計之能力。

選項

\section{已具備之訓練課 期望具備的訓練 程設計能力 \\ 課程設計能力}

低 $\rightarrow$ 高 低 $\rightarrow$ 高

\section{分 析}

1. 評估受訓者的需求, 確認他們目前所能達 成及應能達成任務之間的差異

2. 確認工作、職責範瞦、及任務内容之組成 要素

4. 分析工作環境以辨認工作所需要之工具、 器材及其他資源

5. 分析公司組織, 以確保訓練目標與組織目 標一致

6. 複閲關於訓練課程内容的其他有用資源

\begin{tabular}{lllllll||lllllll}
1 & 2 & 3 & 4 & 5 & 6 & 7 & 1 & 2 & 3 & 4 & 5 & 6 & 7
\end{tabular}

\begin{tabular}{llllll|lllllll}
2 & 3 & 4 & 5 & 6 & 7 & 1 & 2 & 3 & 4 & 5 & 6 & 7
\end{tabular}

\begin{tabular}{lllllll|lllllll}
1 & 2 & 3 & 4 & 5 & 6 & 7 & 1 & 2 & 3 & 4 & 5 & 6 & 7
\end{tabular}

\section{設計舅 發展}

7. 明確説明受訓者在訓練後應達成之最終目

標 (Target Objective)

8. 明確説明訓練之行動目標(Enabling Objective), 使受訓者瞭解哪些事情及應從 事哪些活動以便達成行動目標

9. 訂定績效評比尺度及認知測試項目評量受 訓之結果

10. 發展出符合學習目標之訓練教材

11. 辨認呈現訓練内容的訓練策略、方法及途 徑

12. 按部就班地設計課程内容之章節 
14. 選定適合呈現教學内容之科技工具

\begin{tabular}{lllllll||lllllll}
1 & 2 & 3 & 4 & 5 & 6 & 7 & 1 & 2 & 3 & 4 & 5 & 6 & 7
\end{tabular} 倝 行

15. 爲訓練課程訂定推行計畫書 \begin{tabular}{lllllll|lllllll}
1 & 2 & 3 & 4 & 5 & 6 & 7 & 1 & 2 & 3 & 4 & 5 & 6 & 7
\end{tabular}

16. 確立管理高層對訓練課程之支持

\begin{tabular}{lllllll|lllllll}
1 & 2 & 3 & 4 & 5 & 6 & 7 & 1 & 2 & 3 & 4 & 5 & 6 & 7
\end{tabular}

17. 在訓練過程中, 記錄受訓者之學習進度 評 估

18. 評估受訓者對訓練課程之整體滿意度

19. 確定受訓者已從訓練中習得應有知識

20. 將訓練成果呈報給管理高層

21. 評估訓練課程所獲致之財務利益 \begin{tabular}{lllllll|lllllll}
1 & 2 & 3 & 4 & 5 & 6 & 7 & 1 & 2 & 3 & 4 & 5 & 6 & 7
\end{tabular} \begin{tabular}{lllllll|lllllll}
1 & 2 & 3 & 4 & 5 & 6 & 7 & 1 & 2 & 3 & 4 & 5 & 6 & 7
\end{tabular} \begin{tabular}{lllllll|lllllll}
1 & 2 & 3 & 4 & 5 & 6 & 7 & 1 & 2 & 3 & 4 & 5 & 6 & 7
\end{tabular} \begin{tabular}{lllllll|lllllll}
1 & 2 & 3 & 4 & 5 & 6 & 7 & 1 & 2 & 3 & 4 & 5 & 6 & 7
\end{tabular} \begin{tabular}{lllllll|lllllll}
1 & 2 & 3 & 4 & 5 & 6 & 7 & 1 & 2 & 3 & 4 & 5 & 6 & 7
\end{tabular}

請至下一部分 
一「内容専家」(Subject Matter Experts) 是指「對特定領域或工作 笧瞦有高度知諳與技能的專業人士, 提供其所學之知識, 藉以補足 人力資源發展人員在設計訓練課程内容上之不足」。

1. a.) 您是否曾經與「内容專家」有合作過的經驗?

是(請繼續回答 “b”小題及第二部分) 否 (請結束作答; 跳至 Thank you 視窗)

b.) 當您在設計訓練課程時, 大約有多少比例需與内容専家合作?

-


$\odot \odot \odot$ 您即將完成此份問卷。第三部分是最後一個部分 $\odot \odot \odot$

第三部分：内容專家是 您在設計訓練課程時的合作伙伴。請回想 您過去六 個月内與他(她)合作的經驗, 自我評估『您已具借與内容尃家合作的能力』。

「内容専家／（Subiect Matter Exnerts）是指厂對特定領域或工作範瞦有高度 知識與技能的専業人士, 提供其所學之知識, 藉以補足人力資源發展人員在設 計訓練課程内容上之不足」。

選項

您已具備之能力

低 $\rightarrow$ 高

1. 嶅清訓練専案之中「内容専家」預期應有的角色及任務

2 獲得「内容專家」對於訓練專案參與之承諾

3. 準備與「内容専家」開會的議程

4. 提供先前進行過的案例當作參考, 幫助「内容専家」了 解訓練如何實行

5. 確定「内容専家」瞭解訓練之最終目標

6. 運用開放式之提問法, 引導「内容専家」提供更詳盡之 資訊

7. 要求「内容專家」複閲整體訓練專案, 並指出其缺點或 待補強之處

8. 與「内容専家」針對訓練課程的設計, 再度協商討論

2

34

$\begin{array}{lll}5 & 6 & 7\end{array}$


Appendix C

RECRUITMENT LETTER 
Dear participant,

Greetings! My name is Yi-chun Lin. I am a doctoral candidate majoring in Human Resource Development (HRD) in the Department of Workforce Development \& Education at The Ohio State University, Columbus, Ohio, U.S.A.

I am looking for HRD professionals to participate an anonymous web-based survey. It is regarding the working relationships between HRD professionals and Subject Matter Experts (SMEs) during the training design process. The purpose of this research is to help HRD professionals understand their individual ability to design training programs and understand their ability to work with SMEs in order to accomplish an effective training program. I hope you find this concept interesting.

The following question is to determine if you are eligible. Please check " $\sqrt{ }$ " your response to each question:

1. Are you a Human Resource Development (HRD) professional in your company?

Yes No

If you answer "yes", please leave your contact information and return your response to me by email at lin.565@osu.edu. I will send the web-based questionnaire to you within one month.

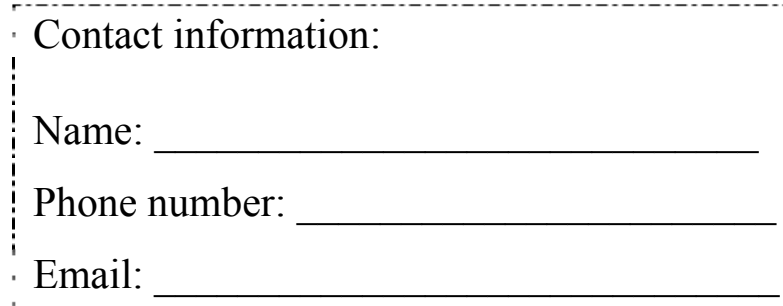

$\Delta$ If you do not qualify, please still return your response to me by email. It helps me confirm the participant list.

Thanks for your help. I appreciate very much!!! 
Appendix D

RECRUITMENT LETTER

IN CHINESE 
各位業界先進您好：

我是林怡君，現爲美國俄亥俄州州立大學 (Ohio State University；OSU) 博士班 四年級學生, 主修人力資源發展 (Human Resource Development)。目前需要您幫 忙完成博士論文的問卷部分!!!!

我正在找寻人力資源發展人員參與匿名之網路問卷。此問卷是探討關於『人力 資源發展人員與内容專家 (Subject Matter Experts；SMEs) 間對於課程設計過程 中之工作關係認知』的議題。本研究祈能幫助人力資源發展人員更瞭解其在設 計訓練課程方面所需具備的専業能力, 以及與内容専家合作時所必需之能力, 以便能夠完成有效的訓練專案。希望這樣的研究議題能引起您的共鳴與認同。

首先, 想請您回答下列問題, 請勾選 “ $\sqrt{ }$ ” 做答:

1. 請問您是公司的人力資源發展人員嗎?

是—不是

A如果上述之問題, 您回答 “是”。可否麻煩您留下您的聯絡方式, 並回覆此 問卷邀請函到我的電子信箱：lin.565@osu.edu, 以便在一個月内寄送網路問卷 給您填答。

您的聯絡方式:

Email 信箱:

A如果這 “非”，也請回覆此問卷邀請函到我的電子信箱, 以便我確認邀請函之 回覆名單。謝謝您的幫忙, 十分感激!!! 
Appendix E

PHONE RECRUITMENT SCRIPT 
Subject: HRD professionals

Conversation Dialog:

To the operator:

Hello! Could you transfer me to HR department?

To HR department:

Hello! This is Yi-chun Lin. I am a Ph.D. student majoring human resource development at Ohio State University. I am doing a study regarding the training program design. I need your help to fill up the survey. May I ask you if you are a human resource development professional?

****** Answer "Yes"******

Thanks! May I have your name, phone, and email address?

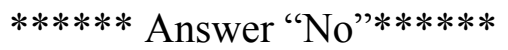

Oh. Thanks. I appreciate your help. Have a nice day!

**************** Get the name, phone, and email address $* * * * * * * * * * * * * * * * * * * *$

To human resource development professionals:

Thanks. You will get the hyperlink of the web-based survey via email around one month from now. I appreciate your help very much. Bye-bye. 
Appendix F

PHONE RECRUITMENT SCRIPT

IN CHINESE 
對象：人力資源發展人員

對話内容如下:

To 接線生：您好！可以麻煩您幫我轉接到人資部嗎?

To 人資部：

您好！我是林怡君，現就讀於美國俄亥俄州立大學，主修人力資源 發展的博士班生。現在在做關於課程設計方面的研究, 希望請你回 答問卷, 請問您是否是人力資源發展人員嗎?

****** 回答 “是”

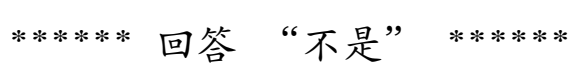

我可否留下您的聯絡方式(您的大名、喔! 謝謝您的短忙, 祝您有美好的一 電話、及電子信箱) ? 天!

紀錄對方的大名、電話、及電子信箱

To 人力資源發展人員:

謝謝您! 我會在一個月内寄送網路問卷到您的電子信箱。謝謝您的 幫忙！再見。 
Appendix G

PILOT TEST INVITATION LETTER 
Dear graduate students,

I would like to invite you to participate in a PILOT TEST by using a web-based survey. The topic is the perceptions of human resource development (HRD) professionals regarding their working relationships with Subject Matter Experts (SMEs) during the training design process.

I would like you to provide help clarifying any confusing items and suggestions for improving the format and wording as well as to evaluate the overall appearance of the instrument. Your answer will not be included in the data.

To participate, click on the following:

http://www.surveymonkey.com/s.asp?u=778191449228

Please complete the survey and submit it by Nov 25, 2005.

If you have questions or comments, please do not hesitate to contact me by email at $\underline{\text { lin.565@,osu.edu }}$

Thank you so much in advance for sharing your time and expertise. 
Appendix H

PILOT TEST INVITATION LETTER

IN CHINESE 
各位同學 您好：

我想請您幫我測試這份網路問卷。此問卷是探討關於『人力資源發展人員與内 容專家 (Subject Matter Experts；SMEs）間對於課程設計過程中之工作關係認 知』的議題。

我想請您幫我检查是否有哪些字或句子的意思是模糊不清或不易懂, 並評估此 份問卷的格式及整體外觀是否清楚。您回答的答案並不會列入正式的資料。

請連結此網站參與測試： http://www.surveymonkey.com/s.asp?u=778191449228

煩請撥冗於 2005 年 11 月 25 日之前回覆您的意見給我。您的意見將可以幫助我 的問卷更爲完善, 請直接與我聯繫（電子郵件：

感謝你(妳)撥空参與。 


\section{Appendix I}

INVITATION LETTER 
Dear participant,

Greetings! My name is Yi-chun Lin. I am a doctoral candidate majoring in Human Resource Development (HRD) in the Department of Workforce Development \& Education at The Ohio State University, Columbus, Ohio, U.S.A.

I would like to invite you to participate in a web-based survey. The topic is the perceptions of Human Resource Development (HRD) professionals regarding their working relationships with Subject Matter Experts (SMEs) during the training design process.

Please understand that only aggregate data will be reported in this study results and we will protect your privacy. You will see the survey is conducted in an anonymous manner.

Please answer it where/when you feel comfortable and are able to connect the Internet. The survey will take 20 minutes to complete.

To participate, click on the following:

http://www.surveymonkey.com/s.asp?u=388141489128

Please complete the survey and submit it by Dec 15, 2005.

If you have questions or comments, please do not hesitate to contact me by email at lin.565@osu.edu. You may also contact my advisor, Dr. Ronald L. Jacobs, The Ohio State University, by email at jacobs.3@,osu.edu.

Thank you so much in advance for sharing your time and expertise. 
Appendix $\mathbf{J}$

\section{INVITATION LETTER}

IN CHINESE 
各位業界先進您好：

我是林怡君, 現就讀於美國俄亥俄州立大學（Ohio State University）人力發展與 教育學系博士班, 我的主修是人力資源發展 (HRD)。

想在此邀請您撥冗填䳆一份關於『人力資源發展人員與内容専家 (Subject Matter Experts；SMEs) 間對於課程設計過程中之工作關係認知』的問卷。

此問卷採匿名填答。我們會盡所能保護填答者的隱私權, 我們不會進一步追 蹤問卷填答者的個人資料, 在研究報告中亦僅呈現櫓總資料。請您在適當的 時間及有網路連結的地方回答問卷, 本問卷填答估計將耗時 20 分鐘。

請連結此網站參與填答: http://www.surveymonkey.com/s.asp?u=388141489128

煩請撥冗於 2005 年 12 月 15 日之前回覆。

我很樂意答覆您的所有問題。您可以直接與我聯繫 (電子郵件 :

lin.565@osu.edu) 。或者, 您也可以聯絡我的指導教授 Dr. Ronald L. Jacobs (電子郵件 : jacobs.3@osu.edu)。 
Appendix K

REMINDER LETTER 


\section{Dear Participant,}

Sorry to bother you again!

Two weeks ago, you should have received a request to participate in the web-based survey asking about "the perceptions of Taiwan HRD professionals regarding their working relationships with SMEs during the training design process". Your assistance in helping us improve the ability of HRD professionals to design the training programs and to work with SMEs.

If you have already submitted your survey, please accept our sincere "THANKS". There is no need to provide your answers again. If you have not responded, please "RESPOND" as soon as possible. Please go to http://www.surveymonkey.com/s.asp?u=388141489128 to complete your survey on-line.

Thanks for your time and efforts in this project.

Sincerely,

Yi-chun Lin

Ph.D. Candidate

Workforce Development \& Education

The Ohio State University

lin.565@osu.edu 
Appendix L

REMINDER LETTER

IN CHINESE 
各位業界先進您好：

再次打擾您，不好意思!!

雨個星期前, 您應該有收到邀請您填宾一份關於『人力資源發展人員與内容專 家 (Subject Matter Experts)間對於課程設計過程中之工作關係認知』的網路問 卷。您的問卷回覆, 更瞭解其在設計訓練課程方面所需具備的專業能力, 以及 與内容専家合作時所需之甫業能力。

如果您已經回覆問卷, 請接受我由哀的“感謝”, 您不用再回覆問卷。

如果您尚未回覆問卷, 請連結此網站參與填答:

http://www.surveymonkey.com/s.asp?u=388141489128

謝謝您熱情參與!!

林怡君

博士候選人

人力發展與教育學系 美國俄亥俄州州立大學

lin.565@osu.edu 